INTERNATIONAL FOOD POLICY

RESEARCH INSTITUTE

sustainable solutions for ending hunger and poverty

IFPR ${ }^{\circledR}$ A member of the CGIAR consortium

IFPRI Discussion Paper 01240

December 2012

\title{
The Women's Empowerment in Agriculture Index
}

\author{
Sabina Alkire \\ Ruth Meinzen-Dick \\ Amber Peterman \\ Agnes R. Quisumbing \\ Greg Seymour \\ Ana Vaz
}

Poverty, Health, and Nutrition Division 


\section{INTERNATIONAL FOOD POLICY RESEARCH INSTITUTE}

The International Food Policy Research Institute (IFPRI) was established in 1975 to identify and analyze national and international strategies and policies for meeting the food needs of the developing world on a sustainable basis, with particular emphasis on low-income countries and on the poorer groups in those countries. IFPRI is a member of the CGIAR Consortium.

\section{PARTNERS AND CONTRIBUTORS}

IFPRI gratefully acknowledges the generous unrestricted funding from Australia, Canada, China, Denmark, Finland, France, Germany, India, Ireland, Italy, Japan, the Netherlands, Norway, the Philippines, South Africa, Sweden, Switzerland, the United Kingdom, the United States, and the World Bank.

\section{AUTHORS}

Sabina Alkire, Department of International Development, University of Oxford

Director, Oxford Poverty and Human Development Initiative

Ruth Meinzen-Dick, International Food Policy Research Institute

Senior Research Fellow, Environment and Production Technology Division

Amber Peterman, International Food Policy Research Institute

Research Fellow, Poverty, Health, and Nutrition Division

Agnes R. Quisumbing, International Food Policy Research Institute

Senior Research Fellow, Poverty, Health, and Nutrition Division

A.Quisumbing@cgiar.org

\section{Greg Seymour, American University}

$\mathrm{PhD}$ candidate

Ana Vaz, University of Oxford

D.Phil candidate in Economics, Oxford Poverty and Human Development Initiative

\footnotetext{
Notices

${ }^{1}$ IFPRI Discussion Papers contain preliminary material and research results. They have been peer reviewed, but have not been subject to a formal external review via IFPRI's Publications Review Committee. They are circulated in order to stimulate discussion and critical comment; any opinions expressed are those of the author(s) and do not necessarily reflect the policies or opinions of IFPRI.

2. The boundaries and names shown and the designations used on the map(s) herein do not imply official endorsement or acceptance by the International Food Policy Research Institute (IFPRI) or its partners and contributors.

Copyright 2012 International Food Policy Research Institute. All rights reserved. Sections of this material ma Copyright 2012 International Food Policy Research Institute. All rights reserved. Sections of this material may be reproduced for personal and notfor-profit use without the express written permission of but with acknowledgment to IFPRI. To reproduce the material contained herein for profit or commercial use requires express written permission. To obtain permission, contact the Communications Division at ifpri-copyright@cgiar.org.
} 


\section{Contents}

Abstract

Acknowledgments

1. Introduction 1

2. Measuring Women's Empowerment in Agriculture 4

3. The Concept of Multidimensional Indexes 13

4. Questionnaire Development and Case Studies 15

5. Field Implementation Considerations 18

6. Statistical Analysis of the Raw Data 22

7. Index Options 25

8. Computing the Women's Empowerment in Agriculture Index 33

9. Pilot Findings 37

10. Correlation with Other Measures 46

11. Intrahousehold Patterns of Empowerment 58

12. Next Steps 59

Appendix: Supplementary Table 61

References 63 


\section{Tables}

2.1-The domains, indicators, and weights in the Women's Empowerment in Agriculture Index 8

9.1-Bangladesh pilot WEAI

9.2-Bangladesh 5DE, decomposed by dimension and indicator 38

9.3-Guatemala pilot WEAI 40

9.4-Guatemala 5DE, decomposed by dimension and indicator 41

9.5-Uganda pilot WEAI

9.6-Uganda 5DE, decomposed by dimension and indicator 44

10.1 - Tabulations between empowerment and individual and household's characteristics$\begin{array}{ll}\text { Bangladesh pilot } & 47\end{array}$

10.2 - Tabulations between empowerment and answers to decisionmaking and autonomy questionsBangladesh pilot

10.3 - Tabulations between empowerment and individual and household's characteristicsGuatemala pilot

10.4-Tabulations between empowerment and answers to decisionmaking and autonomy questionsGuatemala pilot

10.5-Tabulations between empowerment and individual and household characteristics - Uganda pilot

10.6-Tabulations between empowerment and answers to decisionmaking questions - Uganda pilot 56

11.1-Empowerment patterns, by household 58

A.1-Five domains of empowerment indicator definitions 61

\section{Figures}

5.1-Maps of WEAI pilot survey areas $\quad 19$

9.1-Contribution of each indicator to disempowerment in Bangladesh sample 39

9.2 - Contribution of each indicator to disempowerment in Guatemala sample 42

9.3 - Contribution of each indicator to disempowerment in Uganda sample 45 


\begin{abstract}
The Women's Empowerment in Agriculture Index (WEAI) is a new survey-based index designed to measure the empowerment, agency, and inclusion of women in the agricultural sector. The WEAI was initially developed as a tool to reflect women's empowerment that may result from the United States government's Feed the Future Initiative, which commissioned the development of the WEAI. The WEAI can also be used more generally to assess the state of empowerment and gender parity in agriculture, to identify key areas in which empowerment needs to be strengthened, and to track progress over time. The WEAI is an aggregate index, reported at the country or regional level, based on individual-level data collected by interviewing men and women within the same households. The WEAI comprises two subindexes. The first assesses the degree to which women are empowered in five domains of empowerment (5DE) in agriculture. It reflects the percentage of women who are empowered and, among those who are not, the percentage of domains in which women enjoy adequate achievements. These domains are (1) decisions about agricultural production, (2) access to and decisionmaking power about productive resources, (3) control of use of income, (4) leadership in the community, and (5) time allocation. The second subindex (the Gender Parity Index [GPI]) measures gender parity. The GPI reflects the percentage of women who are empowered or whose achievements are at least as high as the men in their households. For those households that have not achieved gender parity, the GPI shows the empowerment gap that needs to be closed for women to reach the same level of empowerment as men. This technical paper documents the development of the WEAI and presents pilot data from Bangladesh, Guatemala, and Uganda, so that researchers and practitioners seeking to use the index in their own work would understand how the survey questionnaires were developed and piloted, how the qualitative case studies were undertaken, how the index was constructed, how various indicators were validated, and how it can be used in other settings.
\end{abstract}

Keywords: agricultural development, multidimensional measurement, gender equality, women's empowerment 


\section{ACKNOWLEDGMENTS}

The results presented in this paper are the work of many individuals across numerous organizations. Funding for the Women's Empowerment in Agriculture Index was provided by the US government's Feed the Future Initiative. We thank Caren Grown, and Emily Hogue for their guidance and dedication in conceptualizing and realizing this instrument for Feed the Future's use and for their support and emphasis on furthering knowledge surrounding gender and agricultural programming.

We thank Joanne Tomkinson of the Oxford Poverty and Human Development Initiative; Amy Margolies, Chiara Kovarik, Betsy Pereira, David Popham, and Ashley St. Thomas of the International Food Policy Research Institute; Elisabeth Becker of Yale; and John Hammock of the Oxford Poverty and Human Development Initiative for their valuable input to design, fieldwork, and administrative and communication components of the Women's Empowerment in Agriculture Index. In addition, we would like to thank the participants of the initial and final methods workshops as well as others who have provided helpful feedback and guidance in developing and refining results, including Michelle Adato, Julia Behrman, Mayra Buvinic, Violet Danshik, Cheryl Doss, Maria Floro, James Foster, Amelia Goh, Nandini Gunewardena, Eric Haglund, Marya Hillesland, Krista Jacobs, Kiersten Johnson, Talip Kilic, Neha Kumar, Paul Melgar, Vanessa Moreira, Pierella Paci, Rajul Pandya-Lorch, Prabhu Pingali, Susan Richter, Gwendolyn Stansbury, Anne Swindale, Monica Tejada, and Anna Toness. Finally, we thank our collaborators, Data Analysis and Technical Assistance, Ltd., in Bangladesh, Vox Latina in Guatemala, and Associates Research Uganda Limited in Uganda, including all the individuals who worked as enumerators and data entry and logistics specialists on the pilot survey and case studies. Special thanks go to photographers Shafique Alam Kiron, Alfonso Porres, and Leah Natongi for their beautiful photographs accompanying case studies. Last, we thank Md. Zahidul Hassan, Monica Dardon, and Herbert Kamusiime, who led the fieldwork in Bangladesh, Guatemala, and Uganda, respectively, and who made this work possible. 


\section{INTRODUCTION}

Empowering women and reducing gender inequalities are two key objectives of development policy. The third Millennium Development Goal (MDG3), adopted as part of the United Nations Millennium Declaration in 2000, explicitly aims to promote gender equality and empower women. These not only are goals in themselves but have been shown to contribute to improving productivity and increasing efficiency. For example, the Food and Agriculture Organization's (2011) The State of Food and Agriculture: Women in Agriculture: Closing the Gender Gap for Development states that closing the gender gap in agriculture is essential to increasing agricultural productivity, achieving food security, and reducing hunger. The World Bank's (2011) World Development Report 2012: Gender Equality and Development reinforces this message and identifies the significant effects of women's empowerment on the efficiency and welfare outcomes of project or policy interventions.

While the concept of "equality" is intuitively easy to understand, "empowerment" is a broad concept that is used differently by various writers, depending on the context or circumstance. In an attempt to come to a common understanding applicable across multiple domains and disciplines, Kabeer (2001) defines empowerment as expansion of people's ability to make strategic life choices, particularly in contexts where this ability had been denied to them. ${ }^{1}$

The motivations for empowering women are not mutually exclusive: rather, they reinforce each other. Closing the gender gap in assets - allowing women to own and control productive assetsincreases both their productivity and their self-esteem. A woman who is empowered to make decisions regarding what to plant and what (and how many) inputs to apply on her plot will be more productive in agriculture. An empowered woman will also be better able to ensure her children's health and nutrition, in no small part because she is able to take care of her own physical and mental well-being (see Smith et al. 2003 and the studies reviewed therein).

Which measures can be used to track progress on these goals? Women's empowerment and gender inequality are typically measured at the aggregate country level, which does not allow for heterogeneities between regions, socioeconomic status, marital status, age, or ethnicities. The indicators proposed for tracking MDG3 (ratios of girls to boys in primary, secondary, and tertiary education; the share of women in wage employment in the nonagricultural sector; and the proportion of seats held by women in national parliament), although useful for characterizing progress toward gender equality, are proxy or indirect indicators and thus do not provide direct measures of empowerment as experienced by individuals. The Gender Gap Index (Hausmann, Tyson, and Zahidi 2011 and previous years), although covering gender inequalities in a broader set of domains (education, health, economic opportunity, and political opportunity), is based on aggregate indicators that, similar to the MDG3 indicators, do not provide a direct measure of empowerment. ${ }^{2}$ Nationally representative surveys such as some demographic and health surveys (DHS) include a range of questions about decisionmaking, such as who decides about the use of woman-earned income and who within the family has the final say about a range of decisions (for example, decisions about the woman's own healthcare, large and daily household purchases, visits to family or relatives, and what food should be cooked each day). Although DHS provide a direct measure of decisionmaking within the household, the domains in which decisionmaking is measured are typically confined to the household and domestic sphere. Therefore, these questions do not adequately cover other dimensions of a woman's life, particularly decisions in the productive and economic spheres. Nor do they consider measures of empowerment other than intrahousehold allocation of decisionmaking powers. However, such measures of empowerment are limited in several ways (Alkire 2005; Narayan-Parker 2005; Alsop, Bertelsen, and Holland 2006; Kishor and Subaiya 2008).

\footnotetext{
${ }^{1}$ There is a growing literature on the measurement of empowerment (see Kabeer 1999; Narayan 2005; Alsop and Heinsohn 2005); the most recent studies attempt to develop multiple indicators because empowerment is a multidimensional concept. See, for example, Ibrahim and Alkire (2007).

${ }^{2}$ See http://mdgs.un.org/unsd/mdg/host.aspx?Content=indicators/officiallist.htm for a list of official MDG indicators.
} 
There is renewed interest in the agricultural sector as an engine of growth and development and greater recognition of the importance of women in agriculture. However, without tools for measuring the impact of agricultural interventions on women's empowerment, the impacts of programs on empowerment (or disempowerment) are likely to receive much less attention than income or other more measurable outcomes. Therefore, there is a need for measures of empowerment that are robust, inclusive, and comparable over time and space. Indexes that capture many different dimensions provide a summary measure that allows for comparability. Because most indexes and indicators used in monitoring development progress on gender equity have little coverage of the agricultural sector, whereas many agriculture-related indicators are gender-blind, there is a clear need for a tool to measure and monitor the impact of agricultural interventions on empowerment of women within the agricultural sector (Kishor and Subaiya 2008; Malhotra and Schuler 2005). As noted by Secretary of State Hillary Clinton (2012), "Data not only measures progress, it inspires it. ... What gets measured gets done. Once you start measuring problems, people are more inclined to take action to fix them because nobody wants to end up at the bottom of a list of rankings."

The Women's Empowerment in Agriculture Index (WEAI) is a new survey-based index designed to measure the empowerment, agency, and inclusion of women in the agricultural sector. The WEAI was initially developed as a tool to reflect women's empowerment that may result from the US government's Feed the Future Initiative, which commissioned the development of the WEAI. However, the WEAI or adaptations of it can also be used more generally to assess the state of empowerment and gender parity in agriculture, to identify key areas in which empowerment needs to be strengthened, and to track progress over time.

The WEAI builds on recent research to develop indicators of agency and empowerment (for example, Narayan 2005; Narayan and Petesch 2007; Alsop, Bertelsen, and Holland 2006; Ibrahim and Alkire 2007) that propose domain-specific measures of empowerment obtained using questions that can be fielded in individual or household surveys. Based on the Alkire-Foster (Alkire and Foster 2011) methodology, the WEAI is an aggregate index, reported at the country or regional level, based on individual-level data collected by interviewing men and women within the same households. The WEAI comprises two subindexes. The first reflects the percentage of women who are empowered in five domains of empowerment (5DE) in agriculture. Among women who are not fully empowered, the index also reflects the percentage of indicators in which women enjoy adequate achievements. ${ }^{3}$ These five domains of the WEAI are (1) decisions about agricultural production, (2) access to and decisionmaking power about productive resources, (3) control of use of income, (4) leadership in the community, and (5) time allocation. The second subindex (the Gender Parity Index [GPI]) measures gender parity. The GPI reflects the percentage of women who are empowered or whose empowerment score meets or exceeds that of the men in their households. For those households that have not achieved gender parity, the GPI shows the empowerment gap that needs to be closed for women to reach the same level of empowerment as men.

This technical paper was written by researchers from the International Food Policy Research Institute (IFPRI) and the Oxford Poverty and Human Development Initiative (OPHI) to document the piloting and development of the WEAI so that researchers and practitioners seeking to use the index in their own work would understand how the survey questionnaires were developed and piloted, how the qualitative case studies were undertaken, how the index was constructed, how various indicators were validated, and how it can be used in other settings. The index evolved in late 2010 and early 2011 out of discussions among US government agencies involved in the Feed the Future Initiative regarding the need for an indicator to monitor women's empowerment. The discussions initially revolved around using a gender perceptions index but eventually focused on an index similar to the multidimensional poverty indexes being developed by OPHI. Following the definition of 5DE in agriculture by the United States Agency for International Development (USAID), work began at IFPRI in June-July 2011 to develop

\footnotetext{
${ }^{3}$ Empowerment within a domain means that the person has adequate achievements or has achieved adequacy (that is, surpasses a threshold) for that domain.
} 
questionnaire modules that could be used to elicit responses on each of these domains. The full surveywith household and individual questionnaires, administered to a primary male and a primary female respondent in each household ${ }^{4}$ - was piloted from September to November 2011 in Feed the Future zones of influence in Bangladesh, Guatemala, and Uganda. Index development took place from November 2011 to January 2012. Qualitative interviews and case studies with individuals, as well as a technical consultation with outside experts in January 2012, provided further input into the choice of indicators that comprise the index. The WEAI itself was launched on February 28, 2012, at the 56th session of the Committee on the Status of Women at the United Nations, New York, and subsequently in three separate presentations in March in London, New Delhi, and Washington, DC.

This paper is organized as follows. Section 2 reviews the literature on measuring women's empowerment in agriculture, the definition of 5DE in agriculture, and the rationale for measuring intrahousehold gender equality. Section 3 introduces the Alkire-Foster method. Sections 4 and 5 present the survey questionnaire, the case studies, and field implementation. Section 6 presents statistical analysis (correlation analysis and validity tests) of the raw data. Section 7 defines the indicators used; how they are constructed, and the cut-offs that are set. Section 8 specifies the properties of the index, its computation, and its interpretation, using these specific indicators. Section 9 presents the results of the pilot studies. Section 10 examines the relationship between the index and other correlates of empowerment (wealth, education, household structure, household food security, and other measures of empowerment). Section 11 discusses outstanding issues and the way forward.

\footnotetext{
${ }^{4}$ This index purposely does not use the concepts of male-headed and female-headed households, which are fraught with difficulties and assumptions about "headship" (see Buvinić and Rao Gupta 1997; Budlender 2003; Deere, Alvarado, and Twyman 2012). Rather, we classify households in terms of whether there are both male and female adults (dual-adult households), only female adults, or only male adults. Because the latter are very rarely found in our study areas, our sample and analysis compare dual-adult and female-only households.
} 


\section{MEASURING WOMEN'S EMPOWERMENT IN AGRICULTURE}

\section{Defining and Measuring Empowerment}

Because the concept of empowerment is so personal, each person has a unique definition of what it means to be empowered based on his or her life experiences, personality, and aspirations. For example, drawing on the qualitative case studies collected in each pilot country, a 39-year-old Guatemalan woman defines an empowered person as "someone who has the power to decide - to say, if they have land, 'Well, I can go farm, I can grow crops, I can plant seeds' - or if they have animals, to say 'I can sell them without going to ask permission.' This is a person who has the power to decide about their things, their life, their actions." A Ugandan man, age 46, says, "People who are empowered 'see change in their lives."

Naturally, context and culture also shape one's definition of empowerment. In Uganda, women interviewed in the qualitative case studies related empowerment as the ability to improve quality of life, whether fiscally or in relation to autonomy, or as decisionmaking capacity and tended to define empowerment as "someone who is independent." Women in Guatemala generally defined empowerment as "decisionmaking capability" and "equality" with men. For example, a 63-year-old woman said, "Being empowered, it means that the woman can do things too, not just the man." Women in Bangladesh tended to view empowerment more narrowly, related to their financial position, as directly resulting from "having money" and assets as well as cooperatively "succeeding" at work. In Bangladesh, individuals cited a communal, rather than a singular, understanding of empowerment focused on the family unit rather than the individual woman or man - which includes the ability to work jointly and well together. Therefore, doing work and income-generating activities successfully empowers not just an individual but an entire family (Becker 2012).

Reflecting the multiple experiences and views of empowerment, there are many definitions of empowerment in the literature (see Ibrahim and Alkire 2007 for a comprehensive review). Three definitions that are commonly cited are found in Kabeer (2001), Alsop, Bertelsen, and Holland (2006), and Narayan (2002). Kabeer (2001) defines empowerment as expanding people's ability to make strategic life choices, particularly in contexts in which this ability had been denied to them. Alsop, Bertelsen, and Holland describe empowerment as "a group's or individual's capacity to make effective choices, that is, to make choices and then to transform those choices into desired actions and outcomes" $(2006,10)$. This definition has two components - the component related to Amartya Sen's (1989) concept of agency (the ability to act on behalf of what you value and have reason to value) - and the component related to the institutional environment, which offers people the ability to exert agency fruitfully (Alkire 2008; Ibrahim and Alkire 2007). Narayan defines empowerment as "the expansion of assets and capabilities of poor people to participate in, negotiate with, influence, control, and hold accountable institutions that affect their lives" (2002, vi; 2005, 5), stressing four main elements of empowerment: access to information, inclusion and participation, accountability, and local organizational capacity. A focus on individual choice can limit the definition of empowerment, especially in cultural contexts wherein community and mutuality are valued. Both Kabeer and Alsop also include agency and capacity - the ability to act on one's choices. Narayan's definition is broader as it includes the relationship between people and institutions. Mahmud, Shah, and Becker (2012) note that a crucial element of empowerment relates to access to and control of material, human, and social resources. In defining empowerment in agriculture, it is important to consider the ability to make decisions as well as the material and social resources needed to carry out those decisions. In addition, although women's empowerment is a multidimensional process that draws from and affects many aspects of life, including family relationships, social standing, physical and emotional health, and economic power, the focus of the WEAI is on those aspects of empowerment that relate directly to agriculture - an area that has been relatively neglected in studies of empowerment. 


\section{Choosing Indicators for Measuring Empowerment}

In choosing indicators for measuring empowerment, a number of issues need to be addressed. ${ }^{5}$

\section{Direct or Indirect}

Direct measures of empowerment generally focus on the expansion of an individual's ability to advance the goals and ends he or she values rather than acting solely to avoid social condemnation or direct coercion. Indirect, or proxy, measures of empowerment traditionally focus on the possession of resources necessary for empowerment or the determinants of being empowered, such as education or asset ownership, rather than on empowerment itself. Many studies use both direct and indirect measures of empowerment. The WEAI emphasizes direct measures of empowerment (such as decisionmaking power over assets), although survey modules also collect indirect measures (such as the size of the asset bundle). We obtain information on indirect or proxy indicators of empowerment because it is vital for policymakers to examine how direct measures of empowerment are affected by various determinants. Both goals are advanced by constructing a measure that reflects empowerment as directly as possible and subsequently analyzing its determinants.

\section{Intrinsic or Extrinsic}

Do we measure the empowerment that people value or the powers that they have even if they do not value these? The questions about personal decisionmaking about agricultural production assets and use of discretionary income in the WEAI relate to the power that the respondent actually has. However, the questions about relative autonomy in production, which are patterned after Ryan and Deci $(2000,2011)$ capture the agency that the respondent values. To further capture intrinsic concepts, the quantitative survey used to construct the WEAI was followed by qualitative case studies that sought to elicit definitions of empowerment from men and women themselves.

\section{Universal or Context-Specific}

Empowerment is inherently context-specific, that is, shaped by socioeconomic, cultural, and political conditions, which can make comparison across countries problematic (Malhotra and Schuler 2005). To measure and track changes in empowerment in (initially) the 19 countries of the Feed the Future Initiative, researchers must use indicators that can be compared across contexts and across time. Although it is valid to ask whether meaningful international indicators of empowerment exist, the development and piloting of the WEAI has been a step toward the construction of such comparable indicators that are also valid in local contexts. Most of the individual-level direct indicators of empowerment included in the pilot survey, as well as a few of the household-level indicators, are based, in varying degrees, on the empowerment indicators recommended by Ibrahim and Alkire (2007) and others (Kabeer 1999, 2001; Malhotra and Schuler 2005). These recommendations are the result of an extensive review of hundreds of indicators used to measure empowerment in more than 30 recent cross-country studies conducted by researchers in the fields of economics, sociology, and psychology, and were based on several criteria, most notably international comparability. ${ }^{6}$ In devising indicators regarding control of productive resources, the WEAI uses general lists of assets, agricultural activities, and expenditure categories, although these lists are modified to be relevant to the local context when implemented in different

\footnotetext{
${ }^{5}$ This discussion draws heavily on Ibrahim and Alkire (2007).

${ }^{6}$ The international comparability of many indicators in the pilot survey is unambiguous (Seymour 2011). For example, the household-level modules almost entirely comprise standard household survey questions and include many indicators that closely mirror individual-level indicators. These household-level indicators were included in the pilot largely for validation purposes, that is, to test whether the evaluation of empowerment changes depending on how or to whom the question is posed or to examine whether responses to questions are influenced by household attributes such as wealth but are not included in the Women's Empowerment in Agriculture Index (WEAI) itself. We recommend that these indicators, even if not used in the WEAI itself, be included for validation purposes (for example, to assess whether or not the respondent should be asked questions pertaining to a particular asset) and for the analysis of covariates.
} 
countries. For example, the survey in Bangladesh asked about aquaculture activities, which are not prevalent in Uganda or Guatemala.

\section{Level of Application}

Although indicators of empowerment may be measured at the household, group, community, and national level, this study focuses on the individual level. In particular, because we are also interested in measuring the empowerment of women relative to men within the same household, the WEAI collects indicators of empowerment for a primary male and a primary female in dual-adult households.

\section{Individual or Collective}

Our measures of empowerment capture individual agency, not group agency, although group agency can also be inferred using individual data. ${ }^{7}$

\section{Who Assesses: Self or Others?}

Empowerment has objective and subjective dimensions (Holland and Brook 2004, 1, cited in Ibrahim and Alkire 2007). However, some researchers question the validity of self-reported indicators, since they may be subject to biases due to adaptive preferences, the frame of reference, mood, the sequence of the questionnaire, the presence of other household members during the interview, or information available to the respondent. On the other hand, because empowerment is such an individually located concept, not using self-reported indicators may undermine the entire measurement exercise. The WEAI survey includes both objective and self-reported indicators. For example, an objective indicator would be membership in groups; a related self-reported indicator would be whether the individual is comfortable speaking in public. ${ }^{8}$

\section{Quantitative or Qualitative}

The WEAI is constructed using quantitative data. However, the survey instruments and overall WEAI analyses have been validated and contextualized using qualitative case studies to explore the concepts of empowerment, particularly about 5DE. From previous experience with the Multi-dimensional Poverty Index (Alkire and Santos 2010) and now with the WEAI, it has been found that qualitative case studies are important in capturing what people experience in their own words and understanding what empowerment means within different contexts. Using quantitative and qualitative data is not a trade-off: rather, we complement the quantitative data collected with qualitative methods for meaning and interpretation.

\section{Measuring Empowerment in Agriculture: The Five Domains of Empowerment in Agriculture}

The early literature on empowerment typically used one global measure for empowerment. For example, parents' education was often used to measure agency or decisionmaking within the household (Alkire 2007); husband's age and educational seniority have also been used to connote male control over women (for example, Cain 1984; Miller 1981). However, it is possible that agency differs across different spheres of life and can exist simultaneously in different ways. For example, a person can be fully employed as a wife and mother, excluded from the labor force by social conventions, and recently empowered to vote by

\footnotetext{
${ }^{7}$ Depending on sampling strategy, it may be possible to infer group agency from individual data (see Ibrahim and Alkire 2007). For example, one can obtain measures of the individual woman's agency within the group(s) to which she belongs, such as a producers' organization, but unless the group is also considered one of the stratification units for sampling, we may not be able to infer whether the group itself is empowered.

${ }^{8}$ Short of doing biometric measurements (for example, to detect agitation or nervousness), self-reports may be the most cost-effective and feasible way of obtaining information on some indicators used in the WEAI as it is administered in a field setting.
} 
political processes. Because such distinctions have policy relevance, it is important to identify and compare agency achievements in different domains rather than in one alone (Alkire 2007, 166). Because agency and empowerment are experienced with different tasks and can be described and measured with different domains, Alkire (2005) suggests that most measures of agency and empowerment should be domain specific. For the WEAI, USAID initially defined five domains that reflected priorities from its agricultural programs, as follows:

1. Production: This dimension concerns decisions about agricultural production and refers to sole or joint decisionmaking about food and cash crop farming, livestock and fisheries, and autonomy in agricultural production, with no judgment on whether sole or joint decisionmaking was better or reflected greater empowerment.

2. Resources: This dimension concerns ownership of, access to, and decisionmaking power about productive resources such as land, livestock, agricultural equipment, consumer durables, and credit.

3. Income: This dimension concerns sole or joint control over the use of income and expenditures.

4. Leadership: This dimension concerns leadership in the community, here measured by membership in economic or social groups and comfort speaking in public.

5. Time: This dimension concerns the allocation of time to productive and domestic tasks and satisfaction with the time available for leisure activities.

These domains also reflect aspects of empowerment found in the literature. The first domain follows directly from Kabeer's (2001) or Alsop, Bertelsen, and Holland's (2006) definitions of empowerment as ability to make choices, in this case in key areas of agricultural production. The resource domain reflects control over assets that enable one to act on those decisions: a woman may decide to plant trees, but if she does not have rights to the land or credit to purchase inputs, she may not be able to do so. Thus, the resource domain combines both whether the woman can potentially make decisions over the asset - because her household possesses it - and whether, in fact, she decides how to use it. Control over income is a key domain for exercising choice, and it reflects whether a person is able to benefit from her or his efforts. This is especially important in agriculture because, in many cases, even where women produce crops or livestock, they are marketed by men who then keep most of the income. The leadership domain captures key aspects of inclusion and participation, accountability, and local organizational capacity, which Narayan (2002) cites as key elements of empowerment. Finally, time, like income, reflects the ability of women to enjoy the benefits from agricultural production. Women's time constraints not only are a burden on women themselves but can negatively affect the care and welfare of children and other family members as well. Thus, agricultural innovations that greatly increase labor burdens may have a negative effect, even if incomes increase, whereas labor-saving technologies may benefit women even if they do not improve production or incomes. Labor-saving technologies that reduce the time women need to spend on domestic work may also give them more freedom to choose among activities - choices that are empowering if these options had not been available in the past. The remainder of this section briefly describes the indicators used for each of the domains and their grounding in the theoretical and empirical literature on gender and agriculture.

The 5DE are measured using 10 indicators with their corresponding weights, which the remainder of this section introduces (see Table 2.1). Full definitions of the indicators, based on the original survey questions, are provided in the appendix. Each indicator is designed to measure whether each individual reached a certain threshold (has adequate achievement) with respect to each indicator. 
Table 2.1-The domains, indicators, and weights in the Women's Empowerment in Agriculture Index

\begin{tabular}{llc}
\hline Domain & Indicator & Weight \\
\hline Production & Input in productive decisions & $1 / 10$ \\
& Autonomy in production & $1 / 10$ \\
\cline { 2 - 3 } Resources & Ownership of assets & $1 / 15$ \\
& Purchase, sale, or transfer of assets & $1 / 15$ \\
& Access to and decisions about credit & $1 / 15$ \\
\cline { 2 - 3 } Income & Control over use of income & $1 / 5$ \\
\cline { 2 - 3 } Leadership & Group member & $1 / 10$ \\
& Speaking in public & $1 / 10$ \\
\cline { 2 - 3 } Time & Workload & $1 / 10$ \\
& Leisure & $1 / 10$ \\
\hline
\end{tabular}

Source: Authors' creation.

\section{Agricultural Production}

Two indicators are used in this domain. The first, input in productive decisions, is constructed from answers regarding participation in decisionmaking: (1) whether the individual had sole or joint input into making decisions about (a) food crop farming, (b) cash crop farming, (c) livestock raising, and (d) fish culture, and (2) the extent to which the individual feels he or she can make his or her own personal decisions about the following aspects of household life if he or she wanted to: (a) agricultural production, (b) which inputs to buy, (c) which types of crops to grow for agricultural production, (d) when to take or who would take crops to market, and (e) whether to engage in livestock raising. An individual has adequacy in this indicator if he or she participates and has at least some input in decisions or if someone else makes the decisions but the individual feels he or she could.

The second is a measure of autonomy that reflects a person's ability to act on what he or she values. This indicator probes the person's own understanding of the situation and how he or she balances different motivations - to avoid punishment or social disapproval and to act on his or her own values (Alkire 2007). The indicator adapts the measure of autonomy developed by psychologists Richard Ryan, E. L. Deci, Valery Chirkov, and others working in Self-determination Theory (see Chirkov, Ryan, and Deci 2011). A subindex is constructed from answers to the following: (1) My actions in [area of decisionmaking] are partly because I will get in trouble with someone if I act differently, (2) Regarding [area of decisionmaking] I do what I do so others don't think poorly of me, and (3) Regarding [area of decisionmaking] I do what I do because I personally think it is the right thing to do. The areas of decisionmaking refer to (1) agricultural production, (2) which inputs to buy, (3) which types of crops to grow, (4) when to take or who would take crops to market, and (5) livestock production. An individual is adequate on autonomy if his or her actions are relatively more motivated by his or her own values than by coercion or fear of others' disapproval. Note that this autonomy indicator, unlike decisionmaking indicators, captures the situation of women living in female-only households, who may indeed be empowered as sole decisionmakers but whose autonomy may still be deeply constrained by social norms or force of circumstance. It also reflects the situation in joint households - a joint decision may be more or less autonomous, depending on circumstances. 
Both my husband and me take decisions collectively.-Female, Bangladesh, age 40

She is powerless if she does not do work properly, does not follow the words of husband, does not follow the word of parent-in-law.-Male, Bangladesh, age 56

Ifeel like things in the house you should sit down, discuss and agree so that there is no quarrel. -Female, Uganda, age 40

\section{Access to and Control of Productive Resources}

Three indicators comprise this domain: (1) ownership of land and assets; (2) decisions regarding the purchase, sale, or transfer of land and assets; and (3) access to and decisions about credit.

The first indicator examines whether an individual reports having sole or joint ownership of land and assets (including agricultural land, large and small livestock, fishponds, farm equipment, house, household durables, cell phone, nonagricultural land, and means of transportation). A person is considered to have adequate achievements if he or she reports having sole or joint ownership of at least one major asset (that is, not including poultry, nonmechanized equipment, or small consumer durables). Although some might argue that sole ownership is more indicative of empowerment than is joint ownership, recent qualitative work in Uganda (Bomuhangi, Doss, and Meinzen-Dick 2011) indicates that land is often held jointly; women can be more empowered if they have joint ownership of a valuable asset (such as land) than if they have sole ownership of a minor asset.

The second indicator, defined with similar assets, asks who the person is who can make decisions regarding the purchase, sale, or transfer of land and assets. This recognizes that in many societies, full ownership of assets may not apply, but holding other bundles of rights - especially rights of control over purchase and disposal of assets - can also be empowering. As with the first indicator, a person has adequacy in this area if he or she participates (or can participate) in decisions to buy, sell, or transfer the asset, conditional on the household's owning it.

The third indicator examines decisionmaking about whether to obtain credit and how to use the proceeds from credit from various sources (nongovernmental organizations, formal and informal lenders, friends or relatives, rotating savings and credit associations). To have adequacy on this indicator, a person must belong to a household that has access to credit (even if they did not use credit), and if the household used a source of credit, the person participated in at least one decision about it.

\footnotetext{
Mostly single people are empowered, widows or widowers, since they have rights over their property.-Female, Uganda, age 30
}

I am the one who makes the decision but I consult my wife.-Male, Guatemala, age 40

The agricultural land is most valuable among all assets to me because I get a whole year of food from it and I get money from selling crops.-Female, Bangladesh, age 35

\section{Control Over the Use of Income}

This domain is commonly covered by such nationally representative household surveys as DHS. The single indicator for this dimension measures the degree of input into decisions about the use of income generated from (1) food crops, (2) cash crops, (3) livestock production, (4) nonfarm activities, (5) wage and salary work, and (6) fish culture, as well as the extent to which the individual feels he or she can make his or her own personal decisions regarding wage or salary employment and major and minor 
household expenditures. ${ }^{9}$ A person is considered adequate on this indicator if he or she has input into decisions about income generated, conditional on participation in the activity.

Some men use the money to drink - and the things you are supposed to do together are not possible because he has drunk the money. As women we suffer with the responsibilities.-Female, Uganda, age 30

[Being] powerful or mighty means those who have much money and know people. But the most important is the money. Everything is possible if money is available.-Male, Bangladesh, age 68

\section{Leadership in the Community}

The fourth domain comprises two indicators: (1) whether the person belongs to an economic or social group and (2) whether the person feels comfortable speaking out in public. Recognizing the value of social capital as a resource, the group member indicator shows whether the person is a member of at least one group, encompassing a wide range of social and economic groups. It is possible that a person may not want to join a group because of social and cultural norms that discourage participation in activities outside the household, as demonstrated by the quote in the box below from a 23-year-old Bangladeshi woman or because family members do not approve.

Whether the person is comfortable speaking up in public consists of responses to questions about the person's ease in speaking up in public to help decide on infrastructure (like small wells, roads) to be built, to ensure proper payment of wages for public work or other similar programs, and to protest the misbehavior of authorities or elected officials. Although it does not cover the entire range of possibilities for public engagement, this variable presents some indication of the respondent's empowerment on exerting voice and engaging in collective action.

Those who are stronger are women; they are the ones who advise men and take care of their families. This role is now ours. -Female, Uganda, age 40

[A leader is] good mannered, able to work well with the community, not oppress the people, be a listener, give people good advice and speak openly on issues.-Female, Uganda, age 23

I am not involved in any group. . . I am not interested in any group and do not want to engage. I am a woman; I only do the work of [the] household.-Female, Bangladesh, age 23

\section{Time Allocation}

The final domain consists of two indicators measuring the allocation of time to productive and domestic tasks and satisfaction with the time available for leisure activities. The first indicator, productive and domestic workload, is derived from a detailed 24-hour time allocation module based on the Lesotho Time Budget Study (Lesotho 2003). ${ }^{10}$ Respondents are asked to recall the time spent on primary and secondary

\footnotetext{
${ }^{9}$ The pilot included only minor household expenditures; however, we recommend including major household expenditures as well.

${ }^{10}$ The Lesotho Time Budget Study is part of the Lesotho Budget Survey, which can be accessed at http://surveynetwork.org/home/index.php?q=activities/catalog/surveys/ihsn/426-2002-002. This was a nationally representative government survey that collected time-use data for 8,182 adults in addition to information about socioeconomic and living conditions. According to Lawson (2012), the Lesotho time-use survey adopts one of the better methods of collecting time-use data by asking people to complete a time diary during one day. The diary contains different preprinted activities and preprinted time intervals of 15 minutes, for a 24-hour period. This diary is completed by the respondent, who draws a line on the appropriate row in the diary that reflects the specific activity undertaken and the hours during which this was done. By adopting such an approach, recall problems are minimized, and the use of time diaries is simplified. In the WEAI pilot, respondents did not keep diaries, but survey interviewers used similar grids of preprinted activities and time intervals.
} 
activities during the previous 24 hours. The individual is considered inadequate (have an excessive workload) if he or she worked more than 10.5 hours in the previous 24 hours, with hours worked defined as the sum of the time in work-related tasks as the primary activity plus 50 percent of the time in workrelated tasks as the secondary activity.

The last indicator asks whether the individual is subjectively satisfied with his or her available time for leisure activities such as visiting neighbors, watching TV, listening to the radio, seeing movies, or doing sports. A person is adequate on this indicator if he or she is satisfied with the time available for leisure.

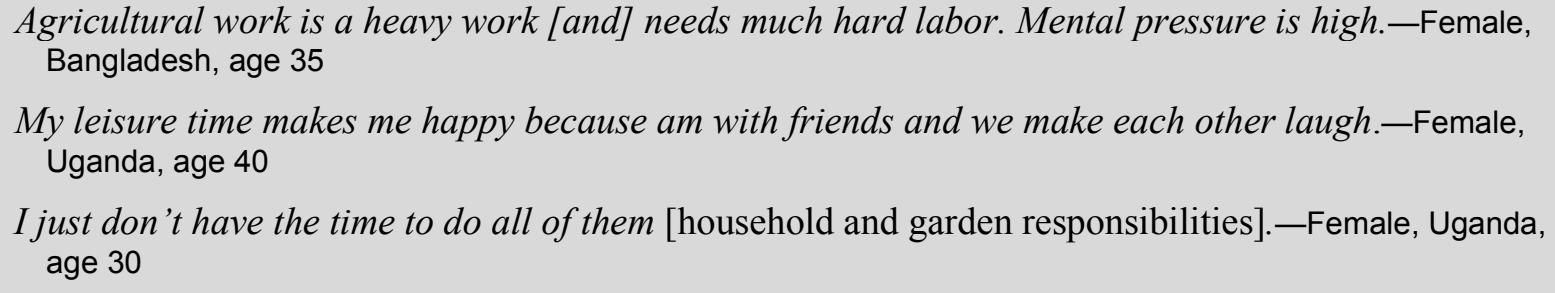

I just don't have the time to do all of them [household and garden responsibilities].-Female, Uganda, age 30

Each person is given a binary score in each of the 10 indicators, reflecting whether she has adequate or inadequate achievements in each indicator. An empowerment score is then generated for her, in which the weights of those indicators in which she enjoys adequacy are summed to create a score that lies between 0 and 100 percent. All in all, a woman or man is defined as empowered in 5DE if she or he has adequate achievements in four of the five domains or is empowered in some combination of the weighted indicators that reflect 80 percent total adequacy or more. The rationale behind the choice of the 80 percent cut-off for determining total adequacy is discussed in the Computing 5DE section.

\section{Women's Empowerment and Gender Parity}

Although the WEAI was originally intended to measure women's empowerment alone, it became clear that by focusing only on women in isolation from the men in their households, the index would be missing an important piece that contributes to disempowerment or conversely to empowerment: gender equality. The importance of gender equality is highlighted prominently in the United Nations' Millennium Development Goals, commonly accepted as a framework for measuring development progress. Closing gender gaps specifically - which typically favors males - has also been seen to contribute to women's empowerment.

It has been well documented (for example, Klasen and Lamanna 2008; World Bank 2011) that gender inequalities at the societal or aggregate level impose societal costs in forgone growth in per capita incomes. A number of indexes also measure gender inequality at the societal level (for example, the Global Gender Gap Index of the World Economic Forum [Hausmann, Tyson, and Zahidi 2011], the Gender Inequality Index produced by the United Nations Development Programme as part of the Human Development Report [hdr.undp.org/en/statistics/gii/], and the Social Institutions and Gender Index of the Organisation for Economic Co-operation and Development [Branisa, Klasen, and Ziegler 2009]). Why, then, do we need to look at intrahousehold gender inequality?

A large body of evidence now demonstrates that failing to pay attention to intrahousehold gender inequality has costs for attaining development objectives (see Alderman et al. 1995; Haddad, Hoddinott, and Alderman 1997; Quisumbing 2003). Studies on child nutritional status (Smith et al. 2003) and child schooling (Quisumbing and Maluccio 2003) use indicators of differences in age, education, and assets at marriage between the husband and wife within the same household as indicators of intrahousehold bargaining. Husband's age and educational seniority have also been used to connote male control over women (for example, Cain 1984; Miller 1981, cited in Quisumbing and Hallman 2005). Educational differences can be viewed as a proxy for differences in earning power, which influences bargaining power 
(for example, Sen 1989). For example, Smith et al. (2003) base their measure of women's decisionmaking power relative to their male partners (usually their husbands) on four underlying indicators: whether a woman works for cash, her age at first marriage, the age difference between her and her husband, and the educational difference between her and her husband.

Intrahousehold inequality has specifically been shown to have costs for agricultural productivity: Udry (1996) has shown, for example, that yields on female-managed plots are less than those on malemanaged plots within the same household, owing to lower input application on female-managed plots. Peterman et al. (2011) show that using headship as a proxy for gender differences within households may also lead to underestimation of gender differences in agricultural productivity. Efforts to increase women's assets may succeed, but without measuring changes in men's assets, we know nothing about gender asset inequality. Research evaluating the long-term impact of agricultural interventions in Bangladesh found that although many development programs have succeeded in increasing women's assets, in programs that do not deliberately target women, men's assets also increase and do so faster than women's assets, resulting in growing gender asset inequality within the same household (Quisumbing and Kumar 2011).

Thus, an important innovation of the WEAI is that it also contains a measure of gender parity, based on differences in empowerment between the primary male and primary female adult within each household. The GPI is a relative inequality measure that reflects the inequality in 5DE profiles between the primary adult male and female in each dual-adult household. In most but not all cases, the primary and secondary male and female are husband and wife; however, men and women can be classified as the primary male and female decisionmakers regardless of their relationship to each other. By definition, households without a primary adult male and female pair are excluded from this measure, and thus the aggregate WEAI uses the mean value of dual-adult households for the GPI. The GPI shows the percentage of women who achieve parity with their male counterparts. In cases of gender disparity, the GPI reflects the relative empowerment gap between the female's 5DE score and the male's. The GPI can thus be increased either by increasing the percentage of women who enjoy gender parity or, for those women who are less empowered than the male in their household, by reducing the empowerment gap between the male and female of the same household.

We are two people and differ in our opinions. When he tells me to, I keep silent.-Female, Bangladesh, age 60

Yes, I think myself powerful. But I do what my husband tells me to do anytime. I do as he tells me. It is no rare incident in this case.-Female, Bangladesh, age 23 


\section{THE CONCEPT OF MULTIDIMENSIONAL INDEXES}

The motivation to empower women working in agriculture has been well established in previous sections as being of intrinsic value to the women's lives as well as instrumentally important to agricultural growth and related development objectives. But why is a multidimensional index required - and one using this methodology in particular? Is it not more accurate and precise to look at each of the indicators separately, within each context, and try to understand the barriers and the progress to women's empowerment differently in each place? The current section addresses this question as well as related questions, such as why the WEAI was designed to be comparable across countries and why the particular methodology (Alkire-Foster) was chosen. Section 8 describes how the WEAI was constructed; this section focuses on why.

The first reason the WEAI was constructed is to create a simple, intuitive, and visible headline figure that can be compared across places and across times. Although detailed analyses are necessary, possible, and inevitable, a well-designed index can answer questions, such as, Did women's empowerment in agriculture increase in relevant zones since 2012? And, in which zones are women most empowered in agriculture; in which least? Empowerment has often been overlooked or not taken as a policy goal in part because it has been difficult to quantify and to compare across contexts. The WEAI seeks to be accurate enough for use at this level (Szekely 2005).

Furthermore, the headline figure can be understood. The 5DE convey the percentage of women who are empowered and the intensity of disempowerment. The GPI shows the percentage of women who enjoy gender parity and the gap between women and men. These numbers are easy to understand and operationalize. They can also be compared by groups. They will show changes over time. And they provide incentives to reduce both the incidence and intensity of disempowerment. Similarly, the GPI creates incentive to reduce both the incidence of disparity between women and men, and the gap. Empowerment is a complex and dynamic concept, and one indicator alone does not suffice. Rather, empowerment in agriculture occurs when a woman has adequate achievements across a set of different conditions. More precisely, she needs the joint distribution of advantages to exceed some threshold. The WEAI has a multidimensional internal structure but communicates it simply and provides consistent policy incentives.

The Alkire-Foster methodology was used because it not only underlies that headline figure and intuitive partial indexes but also enables readers to pull the headline figure apart into its 10 indicators. Simply put, the 5DE index immediately enables readers to understand how women are empowered and disempowered. This is because the index can be broken down to show women's achievements in each indicator and domain, enabling readers to see at a glance the areas requiring improvement.

A further motivation for a multidimensional index of empowerment is to monitor advancements across all key components of empowerment using a coherent framework. Empowerment entails adequate levels of productive resources, credit, decisionmaking authority, control over income, voice, time, and intrahousehold parity. Because of the Alkire-Foster methodology properties, the headline 5DE index can be broken down to show how empowerment changed over time by each indicator. Both 5DE and the GPI can be further broken down by regions, ethnic affiliations, household types, and other variables to compare empowerment and gender equity across population groups.

A vital and unprecedented contribution of the WEAI is the GPI, which reflects gender parity between the primary male and primary female living in the same household. This index provides a finegrained understanding of gender differentials in empowerment. From the same micro data, it is possible to compare the gap by other variables, such as age differences, marital status, household types, main modes of production, household income, educational status of male or female, and so on. It is also possible to study the gap between average achievements among disempowered women and men rather than looking at the household level. Thus, the GPI presents an innovative index, and the data from which it is constructed allow detailed analyses of gender differentials in empowerment in agriculture. 
In the WEAI and its subindexes, an individual is empowered if he or she enjoys adequate achievements in 80 percent of the weighted indicators or more. But we can also explore the range of achievements among empowered and disempowered women more closely. Each woman has an empowerment score, which is the percentage of domains (or, equivalently, weighted indicators) in which she has achieved adequacy. It is then easy to identify who has achieved adequacy in less than 40 percent of the domains, for example. If we consider this group to be the most disempowered, then it becomes possible to target the group, for example, for special services. The situation of the most disempowered can be further analyzed to facilitate targeting: Where do these women live? What are their educational and wealth levels and their social groups? In what kind of production are they primarily engaged? What are their age and educational differentials from their spouses? And so on. It is also possible to identify the women who are disempowered and are deprived in any one particular indicator, such as control over income, to provide specific interventions related to this indicator.

As each WEAI indicator is a direct measure of a particular kind of empowerment, the WEAI does not itself include variables such as education and wealth, which are often thought to be proxies for empowerment. This adds tremendous value because it is possible to see starkly how empowerment in agriculture in fact relates to achievements in these other variables and to ascertain any regular relationships across contexts.

Finally, the WEAI is a first, rather than a final, attempt. In future academic work and also for the ongoing improvement of the index, it will be necessary to ascertain more precisely its comparability across contexts, its accuracy in reflecting local conceptions of empowerment, its strengths and oversights in different contexts, and its policy relevance. Such analyses will spark further constructive engagement as to how to improve the WEAI to better shape policy and reflect improvements in women's empowerment in agriculture. 


\section{QUESTIONNAIRE DEVELOPMENT AND CASE STUDIES}

\section{Structure and Design ${ }^{11}$}

In the design phase, a review of survey instruments containing potential indicators for 5DE, as well as supporting household modules, was undertaken to assess the range of tools with proven success in different cultural settings. These included both publicly available standard questionnaires such as DHS and World Bank Living Standards Measurement Surveys, studies on measures of empowerment (Narayan 2005; Kishor and Subaiya 2008; Alsop, Bertelsen, and Holland 2006; Ibrahim and Alkire 2007), and numerous surveys implemented by IFPRI and other research organizations focusing on gender indicators in certain domains (for example, time use or autonomy measures). This review was presented to a group of gender and agriculture experts in July 2011 at IFPRI to solicit feedback on the feasibility, specificity, and generalizability of different combinations of indicators. Following this process, general instruments at the household level and individual level were drafted by IFPRI to include variations of promising modules identified at the expert workshop.

The individual-level questionnaire is the primary instrument for measuring empowerment and contains modules designed to elicit responses on 5DE. The pilot version included experiments using alternative phrasing of questions to allow validation and comparison of responses across different modes of question formation to better guide the choice of questions to be included in the final index questionnaire. The main objective of this exercise was to select the most consistent and robust indicators possible while at the same time seeking to streamline length and complexity of survey administration. Another consideration was the ability or the feasibility of the indicators to show change over time and the potential for Feed the Future interventions to have a measurable impact on the indicators. Therefore, the pilot instrument contained seven modules, one for the identification of the respondent, followed by one focused on each domain, and an additional module on decisionmaking. The decision was made early on that the individual questionnaire (and thus empowerment in agriculture) would be administered to women and men in the same households so that a truely comparative gender indicator could be developed.

The household-level questionnaire solicits background information on household demographics, living standards, and related outcomes to allow analysis of the correlates of and conditioning factors that affect individual empowerment. The household questionnaire also contains alternative measures of individual-level outcomes so that men's and women's responses can be validated at the household level. The final questionnaire includes informed consent and eight modules on the following topics:

(1) household identification, (2) household demographics, (3) dwelling characteristics, (4) employment and labor force activities, (5) land and agriculture, (6) livestock, (7) business and entrepreneurship, and (8) consumption and consumption habits.

The individual questionnaire modules drew on past IFPRI surveys on household information and individual-level survey modules on agricultural decisionmaking, assets, credit, and income as well as OPHI questions related to relative autonomy that drew from Ryan and Deci (2000) and Chirkov, Ryan, and Deci (2011) for cross-country work. The time use module drew on a similar module in the Lesotho Budget Survey (Lesotho 2003), specifically allowing for both primary and secondary activities in any 15minute period. ${ }^{12}$

The pilot survey instruments were subsequently adapted for country-specific piloting and later shortened to include only the indicators used to construct the WEAI. ${ }^{13}$

\footnotetext{
${ }^{11}$ As previously mentioned, the concept and choice of domains for the WEAI were broadly established by USAID based on its priorities for Feed the Future programming in 19 focus countries. Questionnaire design for the pilot instruments was an iterative process led by IFPRI with input from USAID, OPHI, the field survey teams, and other experts on gender research methods.

${ }^{12}$ See http://surveynetwork.org/home/index.php?q=activities/catalog/surveys/ihsn/426-2002-002.

${ }^{13}$ The survey instruments along with other documentation are available at http://www.ifpri.org/publication/womensempowerment-agriculture-index.
} 
Following preliminary results from the pilot surveys, a second round of quantitative and qualitative data collection was undertaken to validate, contextualize, and explore concepts of empowerment, particularly to deepen our understanding of the five hypothesized domains of empowerment. The narrative guides for this exercise were developed by the IFPRI and OPHI teams and included the application of the individual pilot questionnaire, followed by and interspersed with semistructured narratives. One objective was to explore respondent understanding of certain aspects of empowerment, for example, by asking, "What does it mean to be empowered? For example, if there was someone in your community who you think is empowered, how would you describe them? Can you think of a time when you felt empowered?" or "What qualities do you think makes a 'leader'? Do you feel like you are a leader (why and why not?)?" Respondents were also asked to show how they understood the ways questions were phrased or to give views surrounding assumptions made in coding the quantitative results, for example, "Sometimes assets are owned by one person in the household; other times they are owned by the whole household. Ideally, how would assets be owned in your household?" or "Which activities that we asked about do you most enjoy, and which do you most dislike? Which would you consider 'work' and which would you consider 'leisure'?" The qualitative interview guides were meant to be a framework from which to explore women's and men's stories rather than be a strict set of questions to be administered with set answers. Further information about the sampling and fieldwork aspects of the case studies is included below.

\section{Choice of Pilot Countries and Local Adaptations}

As the WEAI is designed to be a tool applicable in many cultural settings, it was important that pilot country choice reflect relevant regional differences. Based on the scope and time line envisaged for development of the index and the experience of IFPRI in field research within the focus countries, Bangladesh was selected to represent South Asia, Guatemala to represent Latin America, and Uganda to represent Africa south of the Sahara. ${ }^{14}$ Consideration was given to the stage of Feed the Future programming and monitoring in each country as well as the research environment for ethical reviews, acceptability of field research, and established relationships with survey teams in each of the three countries. Following this selection, modifications were made to the pilot questionnaires to reflect local conditions. These modifications were generally of two types. First and most common, response codes were changed to reflect local conditions (for example, including polygamous marriage structures in Uganda, changing assets lists to reflect commonly held durables and production assets between countries, and changing recall periods to reflect crop cycles in a region or country). Second, in some cases, additional modules were included to capture country-specific productive activities that were deemed important to gender and agriculture (for example, in Bangladesh, a module was added to specifically measure men's and women's participation in and decisionmaking about aquaculture). These local adaptations are an essential part of questionnaire design and should be done in consultation with local partners, using previously implemented household surveys in the country and region if possible.

\footnotetext{
${ }^{14}$ Other Feed the Future focus countries in Latin America are Nicaragua, Honduras, and Haiti. Other focus countries in South Asia are Nepal, Cambodia, and Tajikistan. Other focus countries in Africa south of the Sahara are Ethiopia, Ghana, Kenya, Liberia, Mali, Malawi, Mozambique, Rwanda, Senegal, Tanzania, and Zambia. For more information about Feed the Future focus countries, see http://www.feedthefuture.gov/countries.
} 


\section{Training and Field Partners}

For the pilot fieldwork, IFPRI built on existing relationships, partnering with local firms that had extensive experience working on household surveys: Data Analysis and Technical Assistance, Ltd. (Bangladesh); Vox Latina (Guatemala); and Associates Research Uganda Limited (Uganda). A weeklong training of enumerators, including field pretests, was conducted in each country with support from IFPRI staff. During this process, questionnaires were further revised and additions were made to an enumeration manual that served as a guide and a reference to enumerators. ${ }^{15}$ The case study training consisted of a two-day training using a selection of the same enumerators who completed the pilot surveys, including a pilot test on the second day. Emphasis in training was given to translations and particularly how to interpret questions in the local language to convey complex concepts such as empowerment across different dialects. ${ }^{16}$

\footnotetext{
${ }^{15}$ An example copy of the enumeration manual for Uganda is included in the documents found on the IFPRI website.

16 The qualitative study was documented using photos and videos, and separate informed consent was obtained for this. Photographers accompanying survey teams attended the case study enumerator training so they would better understand the objectives and process of the study and fieldwork.
} 


\section{FIELD IMPLEMENTATION CONSIDERATIONS}

\section{Ethics Review and Informed Consent}

Research plans and instruments were submitted for ethics review and approved at IFPRI in Washington, DC, as well as in Uganda at the Ugandan National Council of Science and Technology and in Guatemala at Zugueme. No further review was required in Bangladesh since biological specimens were not collected. As part of the ethics review, guidelines around informed consent of interview participants were reviewed. In all pilot surveys and case studies, informed consent pages were translated into local languages, and copies were left with respondents so that they retained the contact information for the study. ${ }^{17}$ Particular care was taken in modifying informed consent for the case study narrative, as the case studies included photographs and in some cases video footage. To protect the identity of the case study respondents, pseudonyms are used in the presentation of results.

\section{Sampling}

The budget permitted a pilot of 350 households (625 individuals) in Guatemala and Uganda and 450 households (800 individuals) in Bangladesh. Because the objective of the survey was to produce empowerment measures for women, and for women in relation to men in their households, the pilot sampled only female-only and dual-adult households (that is, those with male and female adults). The sampling strategy oversampled single-female households (approximately 20 percent of total samples) to obtain sufficient sample sizes for analysis. The Bangladesh pilot was conducted in the districts of Khulna, Madaripur, Barguna, Patuakhali, and Jessore, in the south/southwestern part of Bangladesh close to the Indian border. The Guatemala pilot was conducted in the Western Highlands, in the departamentos (departments) of Quetzaltengo, San Marcos, Huehuetenango, El Quiché, and Totonicapán, areas with a high concentration of indigenous populations. The Uganda pilot covered five spatially dispersed rural districts in the north (Kole and Amuru), central (Masaka and Luwero), and eastern (Iganga) regions of the country. The results are therefore not representative of the countries as a whole; rather they reflect Feed the Future zones of influence or priority areas and should be interpreted accordingly. Figure 5.1 depicts the sample areas in each country.

Within each preselected administrative area mentioned above, sampling was based on probability proportional to population size (PPS) methodology. In Bangladesh, 5 villages were selected from each of the preselected rural districts using PPS, and 18 households were randomly selected from each village (14 dual adult and 4 female adult only) for a total of 450 households (800 individuals). Household selection was based on a two-page village census conducted prior to fieldwork. In Guatemala, 25 aldeas were selected using PPS from the 5 preselected departamentos, and 14 households were randomly selected from each aldea ( 11 dual adult and 3 female adult only) for a total sample size of 350 households ( 625 individuals). Household selection was based on village listings by household type, conducted in advance of the pilot survey. In Uganda, 5 parishes and 25 local council areas were selected from 5 preselected districts in two stages using PPS sampling, and 14 households were randomly selected from each local council (11 dual adult and 3 female adult only) for a total of 350 households (625 individuals). Similar to Guatemala, household selection in Uganda was based on local council listings conducted in advance of the pilot survey. Further details and instructions about how enumerators completed the sampling based on listings are included in the enumerator manual.

The case studies were done after the quantitative survey was completed. Sampling for the case study narratives was done with the objective of selecting men and women with variation in household type (single female or dual adult) as well as in WEAI scores. In each country, enumerators worked with local leaders in two villages to purposefully select a total of 14 women and 6 men (20 per country) to be case study participants. Selection was split between women and men who were perceived to have high,

\footnotetext{
${ }^{17}$ Examples of this informed consent are found in the questionnaires available on the IFPRI webpage.
} 
medium, and low empowerment levels in agriculture. In total, 60 case study narratives were collected and transcribed into English with accompanying photographs and, in some cases, video footage. The pilot (or quantitative) portions of their data were entered and scored in the same way as the pilot data. These individuals' scores were checked to see whether they agreed with the general narrative and local perceptions (self-perceptions and perceptions of local leaders) of a person's empowerment. However, these data were not used in the computation of the WEAI results for each country.

\section{Household Structure and Choice of Primary and Secondary Respondents}

An important issue in measurement and monitoring of the WEAI is who is being measured or tracked. ${ }^{18}$ Therefore, for the pilot, a number of important distinctions were made. The first is what unit qualifies as a household and the second is who qualifies as an interview participant, or a primary or secondary respondent. Rural households residing in the Feed the Future zones of influence, regardless of the scope of their productive activities, were included in the sample.

\section{Figure 5.1-Maps of WEAI pilot survey areas}

\section{Figure 5.1a-Bangladesh}

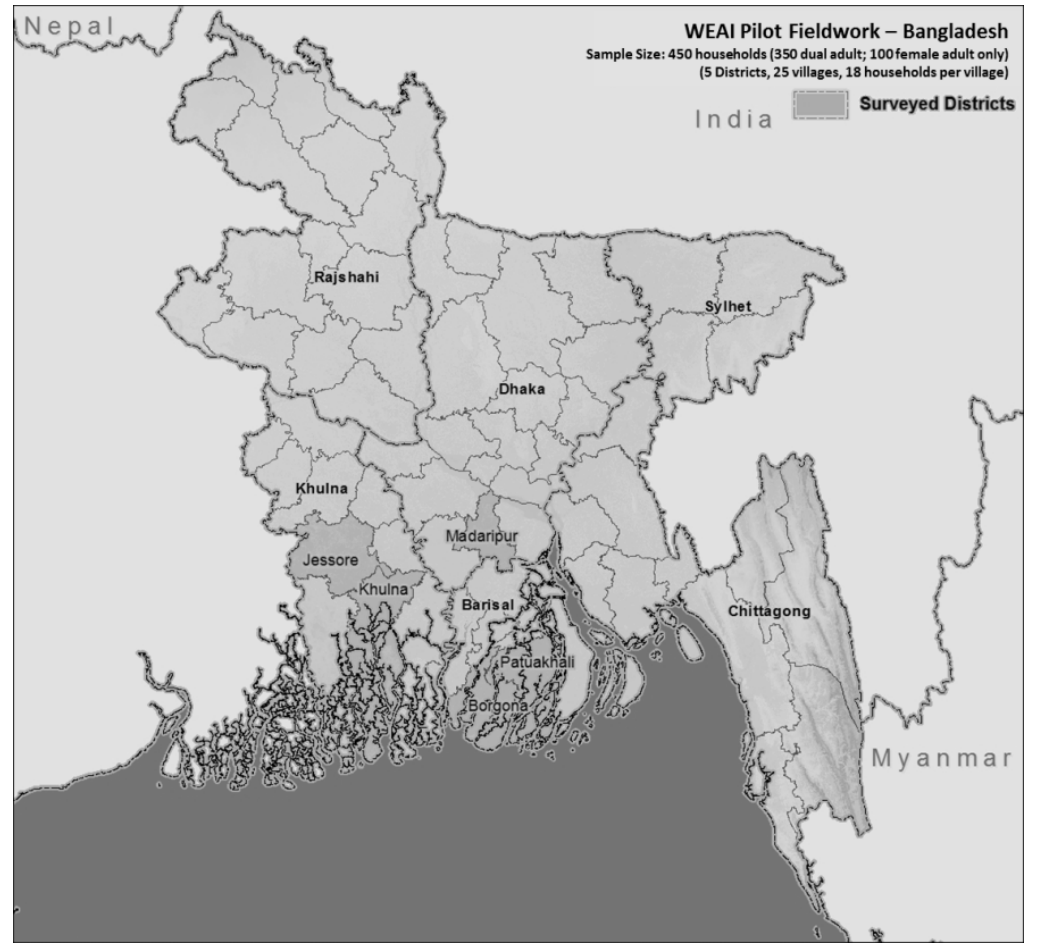

\footnotetext{
${ }^{18}$ Feed the Future monitoring aims to move away from characterizing households based on headship, in light of a growing literature on the diverse nature of family and household structure in many regions of the world.
} 


\section{Figure 5.1b-Guatemala}

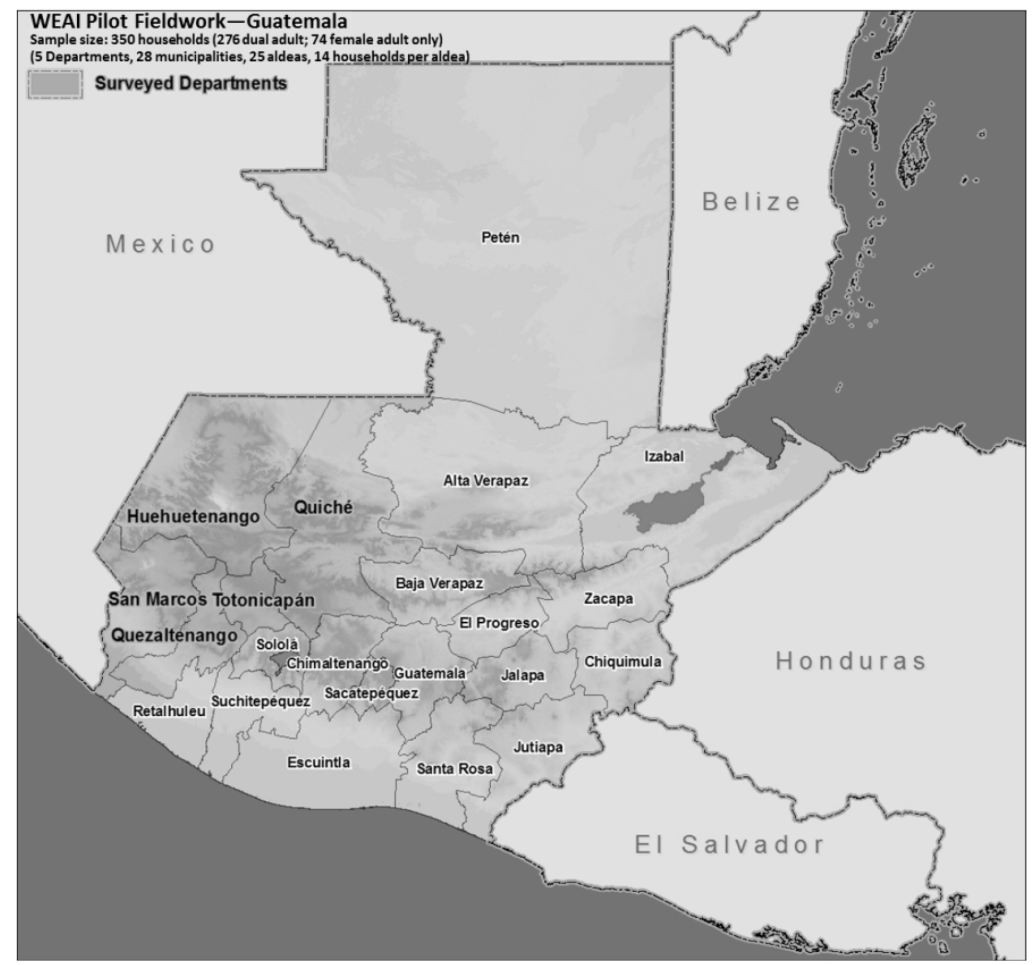

\section{Figure 5.1c-Uganda}

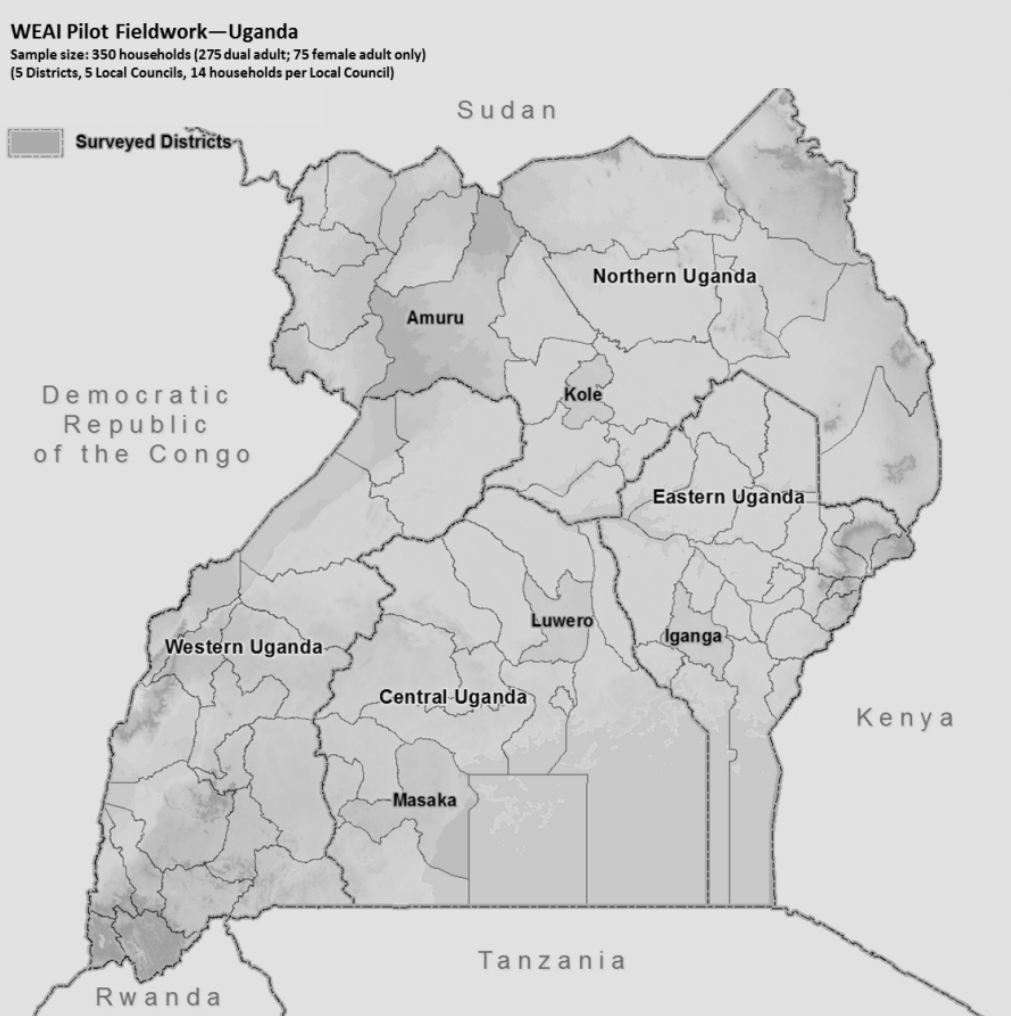

Sources: Hijmans 2011; Lehner, Verdin, and Jarvis 2006. 
For this survey, a household is a group of people who live together and take food from the same pot. The important part of this definition is that the group of individuals shares at least some common resources and makes some common budget and expenditure decisions. A household member is someone who has lived in the household at least six months and at least three days in each week in those months. Even those persons who are not blood relations (such as servants, lodgers, or agricultural laborers) are members of the household if they meet these qualifications, and alternatively, individuals who sleep in the household but do not bear any costs for food or do not take food from the same pot are not considered household members. This definition, including more specific examples and guidelines, is found in the survey enumeration manual and embedded in questionnaires. In some cases, it may make sense to add or subtract from the definition used in the pilot or to substitute an alternative definition for a certain context; however, the most important part is that enumerators have the same understanding of definitions so that implementation is consistent across households. Research from IFPRI and others has found that household definition can have significant impacts on variation of outcome indicators, particularly surrounding labor and consumption (Beaman and Dillon 2012).

Primary and secondary respondents are those who self-identify as the primary members responsible for decisionmaking, both social and economic, within the household. They are usually husband and wife; however, they can be other household members as long as there is one male and one female age 18 or older. For example, one might find a widowed mother and her adult son as the primary female and male respondents. It may also be the case that there is only one primary respondent if that person is female and there is no adult male present in the household. In the case that the WEAI is used to track empowerment over time, it will be important to make sure that this information is collected for the same member for follow-up surveys. As noted above, male-only households are possible, but rarely are found. Because of our focus on women's empowerment, they were excluded from the pilot.

\section{Field Implementation of Pilot Surveys and Case Studies}

The pilot surveys were all fielded from September to November 2011. Bangladesh and Uganda fieldwork took place during four weeks in September 2011, whereas fieldwork in Guatemala took place during four weeks from October to November. Teams in Uganda and Guatemala were language-group specific to account for local indigenous and ethnic-group dialects, and enumerators in all pilot countries traveled in male and female pairs. Questionnaires were checked for accuracy by field supervisors and subsequently entered using Microsoft Access or Statistical Package for the Social Sciences and checked for accuracy using Stata programs. The case studies were all fielded in January 2012, and audio recordings were transcribed and reviewed by IFPRI staff. Both survey efforts included proper mobilization and sensitization of local leaders to convey the intent of the research and gain appropriate local approval for data collection. 


\section{STATISTICAL ANALYSIS OF THE RAW DATA}

The following sections describe the statistical analyses that informed the selection of a short list of the piloted household survey questions for the WEAI.

\section{Sample Sizes: Nonresponse and Nonparticipation Considerations}

To maintain the decomposability properties of the WEAI, responses are necessary for every indicator of the WEAI for each individual.

Our analysis separately considered nonresponse and nonparticipation for two types of questions. The first type applies to all arenas of a respondent's life (for example, How would you rate your available time for leisure activities such as visiting neighbors, watching TV, listening to the radio, seeing movies, or doing sports?). The second poses a question in reference to only certain arenas of the respondent's life (for example, how much input did you have in making decisions about food crop farming?). In the former, a nonresponse leads to the respondent being dropped from the sample, and for the latter, nonresponse or nonparticipation in every relevant arena leads to the same outcome; however, if the respondent participates in some activity, then they will be retained. To maintain a sufficiently large sample size for robust analysis, individual questions or arenas with high nonresponse or nonparticipation rates were excluded from consideration in the WEAI.

In general, nonresponse rates for modules B (decisionmaking), C (productive capital), E (leadership), and G (autonomy in decisionmaking) are extremely low. Nonparticipation rates in these modules vary considerably across arenas. This implies that respondents typically participate in only a subset of the listed activities, for example, types of decisions for modules B and G, assets for module C (productive capital), lending sources for module C (productive capital), or groups for module $\mathrm{E}$.

These results speak to the necessity of aggregating responses across arenas when constructing indicators for the WEAI. Indeed, shifting the focus of our analysis to aggregate participation rates (that is, the percentage of respondents who participate in at least one arena relative to the total number of male or female respondents) significantly increases participation rates in all modules - rates are generally greater than 75 percent. In modules $\mathrm{C}$ (productive capital) and $\mathrm{E}$ (leadership), aggregate participation rates generally remain at less than 50 percent.

For the time allocation module (F), complete time use data (that is, summing to 24 hours) were collected for all respondents except for one male, who refused the module.

\section{Data Quality and Measurement Error}

An initial examination of the pilot survey data, on receipt of the data from the survey firms, revealed a multitude of data entry and field errors. After careful cleaning of the data by IFPRI personnel with the help of technicians from the survey firms, three issues remained. First, module G (autonomy in decisionmaking) was not accurately implemented in all three countries in the pilot. After discussion with the authors, in Bangladesh, a second round of phone interviews was conducted to collect accurate responses. In Uganda and Guatemala, this was not possible, and thus the pilot data for these questions should be used cautiously. Subsequently, the questions were reworded and enumerator-training materials were prepared to support this innovative module.

The other two questionnaire issues remain in the final survey. The extensive time use module identifies adequacy if the respondent has worked less than 10.5 hours in the past 24 hours. That is, it takes the past 24 hours as representative of the person's average workload across the past year and scores them as adequate or inadequate based on this particular day. The past 24 hours may not actually have been representative - if it was a weekend, during the slack season, or a household emergency, then work levels may be outliers from the average. Thus, in many cases, women's adequacy or inadequacy scores in time poverty may be misidentified. This could be problematic for monitoring in general and particularly if the survey is taken at different seasons of the year (once in harvest, once during the slack season). Ideally a 
short time use module would be implemented that reflects the average workload across a longer period than 24 hours; at a minimum it would be useful to add a question about whether the day was part of a peak agricultural season, regular agricultural season, or fallow or slack season when there is little cultivation.

The other question in the time use domain asks about subjective satisfaction with leisure; however, in the pilot studies in Bangladesh and Guatemala, men's subjective satisfaction with leisure was lower than women's, perhaps because of different frames of references between men and women. That is, it is possible that some women had adapted their preferences for leisure to what seemed possible within their circumstances and so reported higher satisfaction rates, whereas their actual hours of leisure per day might be lower. This may pose challenges in using the question for monitoring purposes, because if a woman's frame of reference changes, her reported satisfaction might go down, but that may not reflect a decrease in leisure time itself. Ideally, a more objective question might be used.

Many of the individual-level questionnaire modules contain questions focused on similar aspects of decisionmaking in similar, overlapping arenas. By comparing individual responses to such questions, we can judge the consistency of responses. Such comparisons are possible between modules B (decisionmaking), C (resources), and G (autonomy in decisionmaking) in certain overlapping arenas having to do with agricultural production. Specifically, for each overlapping arena, we can compare whether an individual reported at least input into very few decisions in module B, making a decision in at least one of the module $\mathrm{C}$ decisions (that is, use, sale, purchase, and so on), and at least a joint decision in module G. The results of these comparisons are generally positive. Across every overlapping arena except for livestock-raising, greater than 55 percent of responses are consistent, and for most questions, the percentage of consistent responses is much higher. For questions concerning livestock-raising, consistency of responses is mixed. On one hand, B-C and B-G consistency is strong (60 and 78 percent, respectively). On the other hand, only 46 percent of cases show consistent responses between modules $\mathrm{C}$ and G. For questions concerning wage and salary employment, in particular, consistency of responses is very high, as roughly 87 percent of cases are consistent.

Another metric of consistency is obtained by comparing the responses of men and women from the same household. These sorts of comparisons are possible for certain questions in modules $\mathrm{C}$ (decisionmaking) and G (autonomy in decisionmaking). Two types of criteria are used. First, we consider instances of identically corresponding responses, for example, if the husband indicates he solely made the decision, the wife indicates her spouse made the decision. Second, we look at cases of unambiguously contradicting responses, for example, if the husband and wife indicate that they solely made the same decision.

Across all possible comparisons in modules $\mathrm{C}$ and $\mathrm{G}$, male and female responses identically correspond in 43 percent of cases; responses to the same questions unambiguously contradict each other in only 28 percent of cases. Together these results imply that although males and females in the same household may not exactly agree about how decisions are made, their perspectives are more likely to agree than to be at complete odds with each other.

A further metric of reliability, designed to measure the internal consistency of questions such as some of those in modules B and G, is Cronbach's alpha (Cronbach 1951). In nearly all of the cases, the value of Cronbach's alpha for these questions is greater than .85 , although for certain question groupings in module B in Bangladesh, the value of Cronbach's alpha is approximately .71 and .79, respectively. Generally speaking, values above 0.70 imply internal consistency. 


\section{Association Analysis}

It is essential to understand the associations among WEAI indicators. A high correlation could result in an implicitly greater than intended weight's being assigned to an indicator pair. This would need to be considered and justified explicitly. ${ }^{19}$

Given the high rates of nonresponse and nonparticipation across arenas for the questions used to construct the WEAI, analysis of the association between individual arena-specific questions can be only partial. The following analysis makes use of the aggregate indicators used to construct the WEAI. As all of the aggregate indicators are dichotomous variables, tetrachoric correlation analysis would be appropriate if the assumption could be made that the distribution is bivariate normal. ${ }^{20}$ In nearly all cases, tetrachoric correlation coefficients are less than .44. In the two extreme cases (input into productive decisions - control over use of income and ownership of assets - purchase, sale, or transfer of assets), the tetrachoric correlation coefficients remain less than .67. Thus, the indicators used to construct the WEAI are not highly correlated based on tetrachoric correlation analysis.

\footnotetext{
${ }^{19}$ This issue deserves further thought. Most composite indexes aim to have high correlations. Multidimensional AlkireFoster-style measures have no fixed rule regarding high or low correlations but study the associations to ascertain that the weights are appropriate. For the WEAI, because the weights were fixed a priori by the United States Agency for International Development, the subindex construction and indicator cut-offs were managed such that the weights on the sub-indicators and the cut-offs chosen were consistent with the USAID weights. However, it would be inaccurate to say that we are looking for low correlations across the board. Finally, we call these associations, not correlations, because not all measures are cardinal.

${ }^{20}$ The assumption that the distribution is bivariate normal cannot always be justified. Analyses across a variety of measures (odds ratio, Cramer's V for $2 \times 2$, and chi-square) yield the same overall conclusions, although each measure does not give exactly the same type of information. For example, chi-square gives no information about the strength or direction of association, just whether it is significant. Patterns from the cross-tabulations are clear but take a lot of space to present, whereas the tetrachoric correlation coefficients are compact to present but rely on the assumption of bivariate normality. All analyses present results that are consistent with our conclusion above.
} 


\section{INDEX OPTIONS}

\section{Indicators}

This section describes the indicators used for 5DE of the WEAI, how they are constructed, and the cutoffs that are set.

\section{Agricultural Production}

In the arena of agricultural production we use two indicators: input in productive decisions and relative autonomy in making productive decisions.

\section{Input in Productive Decisions}

As mentioned above, input in productive decisions is constructed from answers regarding participation in decisionmaking: (1) if an individual participated in the activity, how much input did the individual have in making decisions about (a) food crop farming, (b) cash crop farming, (c) livestock raising, and (d) fish culture, and (2) to what extent does the individual feel he or she can make his or her own personal decisions regarding the following aspects of household life if he or she wanted to: (a) agricultural production, (b) which inputs to buy, (c) which types of crops to grow for agricultural production, (d) when to take or who should take crops to market, and (e) whether to engage in livestock raising. Although these categories may be modified, the same analytical procedure will apply, albeit with relevant modification.

We combine two indicators, one for having input on decisions and another for whether one could make personal decisions if one wanted to. The reason is that someone's not making decisions in an arena does not necessarily mean he or she is disempowered; the person may have no interest in participating in decisions. To consider only one of those questions would be to neglect relevant information ${ }^{21}$; therefore, the two questions are aggregated into one indicator. ${ }^{22}$ For example, if a wife takes care of finances because her husband has no interest in finances but the husband feels that he could have input if he wanted to, then both would be empowered in that indicator.

The answer scale for the question regarding input in decisions is $1=$ no input, $2=$ input into very few decisions, 3 = input into some decisions, $4=$ input into most decisions, and $5=$ input into all decisions. For each activity, a sub-indicator was created that considers the individual adequate if he or she participates in that activity and has at least input into some decisions related to that activity.

The answer scale for questions regarding the extent to which the individual feels he or she can participate in decisions is $1=$ not at all, $2=$ small extent, $3=$ medium extent, and $4=$ to a high extent. For each type of decision a sub-indicator was created that considers the respondent adequate if he or she makes the decisions or if the respondent feels that he or she could participate in the decisionmaking to at least a medium extent.

For both questions, we opted for thresholds at the middle of the answer scale. Setting higher thresholds would be perhaps too strict since most agricultural production tends to be a group activity, whereas lower thresholds would be too flexible in considering as adequate people with almost no participation in decisions. ${ }^{23}$

\footnotetext{
${ }^{21}$ Although the first question might be seen as measuring objective input whereas the second measures perceptions, limiting the score to only the first question is not a viable option in practice, because of missing observations for the first question. In two of our three pilot areas, a significant part of the sample did not participate in any agricultural activity (27 percent of women in Bangladesh and 45 percent in Guatemala).

${ }_{22}$ Because most individuals do not participate in all activities mentioned in the question regarding input in decisions, there is a high number of missing observations in these questions. Therefore, it is not possible to use an exploratory factor analysis to test the validity of aggregating these two sets of questions, since there are not enough observations to produce reliable results.

${ }^{23}$ Undertaking agricultural production solely (by oneself) would not have been a realistic definition of autonomy because most agricultural production involves labor or other inputs from other family members - perhaps not for the smallest plots, but certainly for larger plots (or herds).
} 
All of these sub-indicators are then aggregated into the indicator "input in productive decisions." The respondent is considered adequate on input in productive decisions if he or she is considered adequate in at least two of the sub-indicators described above; in other words, the individual is considered adequate if there are at least two types of decisions in which he or she has some input in decisions, makes the decision, or feels he or she could make it to a medium extent if he or she wanted to. ${ }^{24}$ When the cutoff is set at a minimum of two types of decisions, the proportion of women with adequate input in productive decisions is 70.4 percent of respondents in Bangladesh, 52.0 percent in Guatemala, and 92.9 in Uganda. $^{25}$

\section{Relative Autonomy in Productive Decisions}

The Relative Autonomy Indicator (RAI) measures the ability of a person to act on what he or she values, to have his or her own intrinsic motivations prevail over motivations to please others or avoid punishment, for example. This indicator probes the person's own understanding of the situation and enables the respondent to easily explain the different motivations that influence activities (Alkire 2007).

RAI is constructed from answers to the following: (1) My actions in [activity area] are partly because I will get in trouble with someone if I act differently, (2) Regarding [activity area] I do what I do so others don't think poorly of me, and (3) Regarding [activity area] I do what I do because I personally think it is the right thing to do. The activity areas refer to (1) agricultural production, (2) which inputs to buy, (3) which types of crops to grow, (4) when to take or who should take crops to market, and (5) livestock production. The answer scale for these questions is $1=$ never true, $2=$ not very true, $3=$ somewhat true, and $4=$ always true.

Each of the three questions mentioned above is aimed at capturing a different kind of motivation: external (coerced), introjected (trying to please), and identified (own values), respectively. ${ }^{26}$ External motivations occur when one's action is effectively coerced. Introjected motivations are those in which the respondent acts to please others or to avoid blame - regardless of whether or not he or she personally values this particular course of action. Identified motivations, which are here associated with empowerment, occur when the person's actions are shaped based on his or her own values. Because motivations are often mixed in real life-we act in part to please others as well as based on our own personal convictions-RAI enables the respondent to articulate the extent to which his or her actions are shaped by all three motivations. If the motivation related to the person's own values are relatively stronger than the others, then the person has adequacy in autonomy.

To check the validity of the responses, we assume that the coerced and trying-to-please regulations are positively correlated with one another and that both are negatively correlated with motivation drawing on one's own values. To test if our questions were good proxies for these theoretical constructs, we computed the polychoric correlations between the answers to these questions. In data from Bangladesh, the three theoretical hypotheses (positive correlation between questions 1 and 2, negative correlation between questions 1 and 3, and negative correlation between questions 2 and 3) are verified. In data from Guatemala, the three questions are positively correlated, which means that only one of the hypotheses is verified. In Uganda, only one of the hypotheses is not verified, namely, the negative

\footnotetext{
${ }^{24}$ Note that households or individuals who are not involved in agriculture but are involved in other nonagricultural enterprises might appear disempowered in this domain because the survey focuses on agriculture and does not capture all other economic activities.

${ }^{25}$ Proportions of the pilot sample were computed considering three categories: adequate, inadequate, and missing information. Therefore, the percentages presented throughout this section refer to the full sample and not only to the sample of individuals for whom we have information regarding each indicator.

${ }^{26}$ According to Ryan and Deci (2000, 235-236), external regulation "is the classic case of extrinsic motivation in which people's behavior is controlled by specific external contingencies. People behave to attain a desired consequence such as tangible rewards or to avoid a threatened punishment. ... Whereas with external regulation the control of behavior comes from contingent consequences that are administered by others, with introjected regulation the contingent consequences are administered by the individuals to themselves. The prototypic examples are contingent self-worth (pride) or threats of guilt and shame." Identification "is the process through which people recognize and accept the underlying value of a behavior. By identifying with a behavior's value, people have more fully internalized its regulation; they have more fully accepted it as their own."
} 
correlation between external and identified regulation. However, recall that the pilot data on this question collected in Guatemala and Uganda are to be used with caution.

An exploratory factor analysis (EFA) was performed to test whether answers to each of the three questions (questions 1 to 3 listed above) regarding different areas of decisionmaking converged in the same factor and whether factors discriminate well so answers to different types of questions refer to different motivations (external, introjected, and identified). When all the data from the three pilot surveys were considered jointly, EFA showed a good convergence and discrimination among the three types of questions. When EFA was performed for each country separately, the results were ambiguous. This is probably because the ratio of observations to items (questions) in these samples is very low: 3.8 for Bangladesh, 3.4 for Guatemala, and 1.2 for Uganda.

For each area of decisionmaking, Ryan and Deci's (2000, 2011) Relative Autonomy Index (RAI) is computed. This index corresponds to the weighted sum of the different types of regulations' subscales. The conventional weights are -2 for external regulation (coercion), -1 for introjected regulation (tryingto-please), and in this case 3 for identified regulation (own values). ${ }^{27}$ The index varies between -9 and 9 . A RAI value that is greater than 0 means that the individual acts moved more by their own values than by coercion or others' influence.

All of these area-specific relative autonomy indexes are then aggregated into the indicator "autonomy in production." The respondent is considered to have adequate autonomy in production if his or her RAI is greater than 1 in at least one of the five areas of decisionmaking.

This indicator had high missing values for Bangladesh (17 percent) and Guatemala (24 percent), where a significant proportion of the sample had reported not being involved in any agricultural activity, namely, 23 percent in Bangladesh and 35 percent in Guatemala. In line with treatment with other indicators, those respondents for whom the indicator autonomy in production was missing and who had reported not participating in any agricultural activity (food crop farming, cash crop farming, livestock raising, and fishing or fish culture) were considered adequate. ${ }^{28}$

Under this definition of autonomy in production, 89.8 percent of women in Bangladesh are adequate, as are 66.3 percent in Guatemala and 82.3 percent in Uganda.

\section{Resources}

To capture the individual's control over productive resources, three indicators are used: ownership of assets, decisionmaking about productive resources, and access to and decisionmaking about credit.

\section{Ownership of Land and Assets}

The ownership indicator examines whether an individual has sole or joint ownership of land and assets, based on a comprehensive list of assets (including agricultural land, large and small livestock, fishponds, farm equipment, house, large and small household durables, cell phone, nonagricultural land, and means of transportation). A person is considered adequate in this area if he or she reports having sole or joint ownership, conditional on the household's owning those assets. ${ }^{29}$ Furthermore, for the individual to be considered adequate in this domain, ownership cannot be limited to minor assets only (poultry, nonmechanized equipment, or small consumer durables).

\footnotetext{
${ }^{27}$ As the cross-cultural applicability of the Relative Autonomy Indicator has already been explored extensively, we used the conventional weights.

${ }^{28}$ We considered other alternative criteria to identify the part of the sample that was not eligible for assessment of the Relative Autonomy Indicator in agricultural productive decisions and, hence, reduce the number of missing values. One of these criteria was to consider adequate those individuals who lived in households where none of the respondents reported having spent any time in agricultural activities (farming and fishing) on the day before the interview. However, probably due to seasonality, that was the case for the majority of the respondents in Bangladesh and Guatemala.

${ }^{29}$ Self-reported ownership is used rather than any externally imposed definitions of ownership or reference to titles and other documentation (see Doss et al. 2011).
} 
First, for each type of major asset, we created an indicator to reflect if someone in the household reports owning that type of asset. Then, these indicators were summed across assets, creating the indicator of household ownership, which measures the number of assets that the household owns across all asset types. Second, for each type of asset we created an indicator of an individual's ownership, which equals 1 if the individual, alone or jointly, owns the majority of that type of asset.

The asset-specific indicators are aggregated into the indicator of the respondent's ownership of assets. According to this indicator, an individual is adequate on ownership if he or she owns at least one asset, as long as it is not only chickens, ducks, turkeys, pigeons, nonmechanized farm equipment, or small consumer durables. There was some discussion about whether cell phones should also be classified as minor assets, but they were finally included among the major assets that would count for empowerment because of the important spillover effects associated with the ownership of a cell phone. There are only 19 individuals who have no other major assets besides cell phones, 8 in Bangladesh, 2 in Uganda, and 9 in Guatemala.

The individuals who live in households that do not own any type of asset are considered inadequate on ownership.

Using this definition of ownership of assets, the proportion of women with adequate ownership is 90.7 percent in Bangladesh, 84.6 percent in Guatemala, and 88.0 percent in Uganda.

\section{Decisions Regarding the Purchase, Sale, or Transfer of Land and Assets}

In many societies, full ownership of assets may not apply, but holding other bundles of rights - especially control rights over the purchase and disposal of assets - can also be empowering. We therefore asked, "Who is the person who can decide regarding the purchase, sale, or transfer of land and assets?" As in the ownership indicator, a person has adequacy in this area if the household owns any of those assets and if he or she participates in decisions to buy, sell, or transfer the asset, conditional on the household's owning it. The pilot questionnaire included questions about rights to bequeath the asset as well as rights to the asset on marital dissolution, but these were excluded from the WEAI owing to the high degree of nonresponse; possibly these are future events, and an individual may not have knowledge of those rights except as determined by local norms, which may not be likely to vary significantly across households in a given locality (for example, Fafchamps and Quisumbing [2002] for Ethiopia).

Based on the results of EFA performed by asset, there is strong empirical evidence to support the clustering of the exchange rights (to sell, to give, and to rent), and there is some empirical evidence to support the clustering of those exchange rights and the right to buy.

Although the ownership indicator covers all types of assets, this indicator refers only to agricultural productive assets, namely, agricultural land; large livestock; small livestock; chickens, ducks, turkeys, and pigeons; fishponds or fishing equipment; nonmechanized farm equipment; and mechanized farm equipment.

First, for each type of right (sell, give, rent, and buy) and asset, an indicator is created that equals 1 if the respondent has, alone or jointly, that right over that type of asset; otherwise the indicator is 0 . Second, for each type of agricultural asset the types of rights are aggregated into an indicator of whether the individual has those rights over that asset. This indicator assumes the value 1 if the respondent has, alone or jointly, at least one of the rights considered — to sell, to give, to rent, or to buy — over that type of asset. Third, these indicators of rights are aggregated across types of assets, generating the indicator "purchase, sale, or transfer of assets." This indicator classifies the individual as adequate if he or she has at least one type of right over at least one type of agricultural asset. Individuals who live in households that do not own any type of agricultural asset are considered inadequate and, hence, are assigned the value 0 for this indicator. In Uganda, 84.0 percent of the women are adequate; the percentages are 68.4 in Bangladesh and 60.6 in Guatemala. ${ }^{30}$

\footnotetext{
${ }^{30}$ Note that ownership covers all assets and the indicator for decisionmaking rights covers only agricultural assets. Therefore, some people who own nonagricultural assets do not report having decisionmaking rights over agricultural assets.
} 


\section{Access to and Decisions about Credit}

This indicator examines decisionmaking about credit: whether to obtain credit and how to use the credit obtained from various sources (nongovernmental organizations, formal and informal lenders, friends or relatives, rotating savings and credit associations). To have adequacy on this indicator, a person must belong to a household that has access to credit and if the household used a source of credit, must have participated in at least one decision about it.

First, the indicator "access to credit" is created, which assumes the value of 1 if the respondent lives in a household that has taken a loan in the past 12 months from at least one of the potential sources of credit. A very large proportion of the women in the sample live in households that did not use any source of credit: 50.0 percent in Bangladesh, 70.3 percent in Uganda, and 74.0 percent in Guatemala. Unfortunately, the pilot survey did not collect information about the reasons the household did not use any type of credit. The new version of the questionnaire will include questions to assess whether the household is credit constrained.

Second, for each potential source of credit, types of decisions are aggregated into an indicator that assumes the value 1 if the respondent makes, alone or jointly, at least one of the decisions consideredborrowing or how to use the credit - for that particular source of credit. Finally, these indicators are aggregated across potential sources of credit, generating the indicator "access to and decisions about credit." The respondent is classified as adequate on credit if he or she makes at least one decision relative to credit from at least one source of credit. Individuals who live in households that do not use any source of credit are considered inadequate on access to credit and, hence, are assigned the value 0 for this indicator.

Using this definition of access to and decisions about credit, the proportion of adequate women is 39.6 percent in Bangladesh, 20.3 percent in Guatemala, and 24.3 percent in Uganda.

\section{Income}

To capture the individual's control over income and expenditures, only one indicator is used that reflects the individual's role in decisionmaking regarding the use of income.

\section{Control over Use of Income}

Control over use of income is constructed from answers regarding input into decisions about the use of income: (1) if an individual participated in the activity, how much input did the individual have in decisions about the use of income generated from (a) food crop farming, (b) cash crop farming, (c) livestock raising, and (d) fish culture, and (2) to what extent does the individual feel he or she can make his or her own personal decisions regarding the following aspects of household life if he or she wanted to: (a) his or her wage or salary employment and (b) major and minor household expenditures. ${ }^{31}$

The answer scale for the question regarding input in decisions is $1=$ no input, $2=$ input into very few decisions, 3 = input into some decisions, $4=$ input into most decisions, and $5=$ input into all decisions. For each activity an indicator is created that considers the individual adequate on input in decisions about the use of income if he or she participates in that activity and has at least some input into decisions related to that activity.

The answer scale for the question regarding the extent to which the individual feels he or she can participate in decisions is $1=$ not at all, $2=$ small extent, $3=$ medium extent, and $4=$ to a high extent. For each type of decision an indicator is created that considers the respondent adequate if he or she makes the decisions himself or herself or if the respondent feels that he or she could participate in the decisionmaking at least to a medium extent.

Then, all of these sub-indicators are aggregated into the indicator for control over income. The respondent is considered adequate on control over use of income if he or she is considered adequate in at least one of the sub-indicators described above, as long as it is not making decisions regarding household

\footnotetext{
${ }^{31}$ The pilot included only minor household expenditures; however, we recommend including major household expenditures as well.
} 
minor expenditures. The proportion of women with adequate control over use of income is 75.6 percent in Bangladesh, 52.3 percent in Guatemala, and 79.1 percent in Uganda. The percentage of women who feel that they can make decisions only regarding household expenditures is 12.4 percent in Bangladesh, 32.0 in Guatemala, and 15.1 in Uganda.

Initially, we considered including in this domain an indicator of whether the individual has some extra money that he or she alone decides how to use. However, a comparison across countries gave unexpected results: Guatemala has the worst headcount ratios, although it is the least poor, whereas Bangladesh performs best, although it has the highest level of poverty. Therefore, we decided against the use of the indicator, because it did not seem to accurately capture income control.

\section{Leadership}

This domain aims to capture the individual's potential for leadership and influence in his or her community. Two indicators are used as proxies for that potential: active membership in community groups and comfort speaking in public.

\section{Group Membership}

Recognizing the value of social capital as a resource, this shows whether the person is an active member of at least one group, including (1) agriculture producers' or marketing groups, (2) water users' groups, (3) forest users' groups, (4) credit or microfinance groups; (5) mutual help or insurance groups (including burial societies), (6) trade and business associations, (7) civic or charitable groups, (8) local government groups, (9) religious groups, and (10) other women's groups. Group membership is deliberately not restricted to formal agriculture-related groups because other types of civic or social groups provide important sources of networks and social capital that are empowering in themselves and may also be an important source of agricultural information or inputs (Meinzen-Dick et al. 2012).

The percentage of women with adequate group membership is 34.7 in Bangladesh, 47.7 in Guatemala, and 62.9 in Uganda. Because nominal membership does not necessarily translate into effective participation (Agarwal 2001), additional questions were included in the pilot about whether the respondent had ever been in a leadership position in each group, how much input the respondent had in making decisions in this group, and how many of the past five meetings the respondent had attended. However, including these as indicators resulted in too high a threshold; very few men or women were empowered in this domain, according to that indicator. Less than 30 percent of women reported having ever been in a leadership position in any group.

\section{Speaking in Public}

The indicator of whether the person is comfortable speaking up in public is constructed based on responses to questions regarding the person's ease in speaking up in public for three reasons: (1) to help decide on infrastructure (such as small wells, roads) to be built, (2) to ensure proper payment of wages for public work or other similar programs, and (3) to protest the misbehavior of authorities or elected officials. A question about speaking up to intervene in a family dispute was also considered; however, it eventually was not included because this may be considered part of the private rather than the public domain. The answer scale for these questions is $1=$ no, not at all comfortable, $2=y e s$, but with a great deal of difficulty, $3=y e s$, but with a little difficulty, $4=y e s$, fairly comfortable, and $5=y e s$, very comfortable.

For each of the three reasons, an indicator of the individual's comfort in speaking for that specific reason was created. The answer 2, yes, but with a great deal of difficulty, is the cut-off. So the respondent is comfortable speaking in public if he or she does not answer no, not at all comfortable. The three reason-specific indicators are aggregated into the indicator "speaking in public." The respondent is considered adequate in speaking in public if he or she is comfortable speaking in public for at least one of the first three reasons listed above. The percentage of women adequate in speaking in public is 67.3 in Bangladesh, 64.3 in Guatemala, and 83.7 in Uganda. 
We considered the inclusion of other indicators in the leadership domain, namely, voting decisions, direct questions soliciting opinions about whether the respondent thought he or she could change things, and investing in the community.

An individual would be considered adequate on voting decision if he or she made the decision about whom to vote for, conditional on having voted in the last election. According to this indicator, 95.4 percent of women in Guatemala and 98.3 percent of women in Uganda have adequacy. We also observed that in Bangladesh, 23.0 percent of women who voted in the last election would have been inadequate because they did not decide whom to vote for, compared to 33.9 percent of men. Having quite a volatile indicator with very high rates of adequacy with little variation on the one hand, but with very low rates in Bangladesh, is sensible if we were extremely confident that this was reflecting an underlying condition of political empowerment, but not being confident of this, we did not include it. Furthermore, voting behavior is only tangentially linked to agriculture.

The indicator that reflects the feeling that one can change things would consider the respondent adequate if he or she feels that an individual like him- or herself can generally change things in the community where he or she lives if he or she wants to, even if with difficulty. Again, we dropped this indicator because the answers did not seem consistent: whereas in Guatemala and Uganda the percentage of adequate men is much higher than the percentage of adequate women (differences of 21.5 percentage points in Guatemala and 5.4 percentage points in Uganda), in Bangladesh the percentage of adequate women is 62.7 percent, compared to 19.7 percent of men.

An individual would be classified as adequate on investing in the community if in the past 12 months he or she (1) contributed money or time to building small wells or maintaining irrigation facilities in the community, (2) contributed money or time to building or maintaining roads in the community, (3) contributed money or time to town development projects or public works projects in the community, (4) contributed money or time to building or maintaining the local mosque/church/temple, (5) gave money to any other family because someone in the family was sick, (6) helped another family out with agricultural labor, and/or (7) helped another family out when that family needed help with childcare. This indicator was dropped because the focus of the WEAI is on leadership in groups and activities that are more directly related to agriculture, not the maintenance of public infrastructure.

\section{Time}

The time allocation domain includes two indicators: workload and leisure. The first refers to the allocation of time to productive and domestic tasks; the second captures the individual's satisfaction with the time available for leisure activities.

\section{Workload}

The productive and domestic workload is derived from a detailed 24-hour time allocation module in which respondents are asked to recall the time spent on primary and secondary activities in the 24 hours prior to the interview, starting at 4:00 a.m. on the day before the interview. The amount of hours worked is defined as the sum of the time the individual reported spending on work-related tasks as the primary activity plus 50 percent of the time she or he reported spending on work-related tasks as the secondary activity. The definition of work-related tasks includes wage and salary employment, own business work, farming, construction, shopping/getting service, fishing, weaving/sewing, textile care, cooking, domestic work, caring for children/adults/elderly, commuting, and traveling. The individual is defined as adequate on workload if the number of hours he or she worked per day was less than the time poverty line of 10.5 hours in the previous 24 hours. This cut-off was based on a methodology similar to that of Bardasi and Wodon (2006), who used a lower threshold equal to 1.5 times the median of the total individual working hours distribution and a higher threshold equal to 2 times the median, which was equivalent to 10.07 
hours per day and 13.4 hours per day for the lower and the higher thresholds, respectively, using data from Guinea. ${ }^{32}$

Under these conditions, the percentage of women with manageable workloads is 81.1 in Bangladesh, 62.0 in Guatemala, and 55.7 in Uganda. We recognize that a 24-hour recall does not adequately represent time allocation, especially in an agricultural society. If the previous day was a holiday, the workload might have been less (or even greater if there was extra food preparation or other domestic work). The observations for which the reference day for the time-use module was a holiday or a nonworking day are not dropped because that would imply a sample reduction of approximately 25 percent. More problematic from the standpoint of an agricultural index is the issue of seasonality of labor, which cannot be captured in 24-hour recall. However, recall of time allocation longer than 24 hours generally has higher recall error, and the recommended revisiting of households on multiple days was not possible, so we have used this approach provisionally, but, as was mentioned above, an alternative time use module could also be considered (Harvey and Taylor 2000). ${ }^{33}$

\section{Leisure Time}

Respondents were asked to rank their level of satisfaction with the time available for leisure activities such as visiting neighbors, watching TV, listening to the radio, seeing movies, or doing sports from $1=$ not satisfied to $10=$ very satisfied . The indicator "leisure time" considers the respondent adequate if he or she ranks his or her level of satisfaction equal to or higher than 5, which means he or she is indifferent to or satisfied with the time available for leisure. The percentage of women with adequate leisure time is 65.8 in Bangladesh, 83.1 in Guatemala, and 68.3 in Uganda. As this is a subjective question, it reflects respondents' frames of reference as well as their actual achievements. Male and female reference standards may differ, making gendered and trend comparisons problematic. For example, in Bangladesh men's dissatisfaction with their leisure was higher than women's. In large-scale multipurpose household surveys, a more accurate short time-use module could be used for both time-use questions, and survey administration could be staggered to better capture seasonality.

\footnotetext{
${ }^{32}$ In the Bardasi and Wodon (2006) study, the upper and lower thresholds for adults were expressed in hours per week (70.5 and 94 hours per week for the lower and higher thresholds, respectively); we express the thresholds in hours per day for comparability with the thresholds used in this study.

${ }^{33}$ There are different guidelines for collecting time-use data in studies that focus on time allocation and those that collect time allocation data in the context of a multi-topic household survey. The former focuses on obtaining information about time use over a period of time, typically requiring multiple visits. For example, Eurostat's official time-use guidelines (see http://epp.eurostat.ec.europa.eu/cache/ITY OFFPUB/KS-RA-08-014/EN/KS-RA-08-014-EN.PDF) state, "It is recommended that the survey days/dates be representative of, and cover a full 12-month period, i.e., 365 consecutive days, preferably including potentially problematic days and periods like Christmas and New Year." A similar point is made for developing countries on page 48 of http://unstats.un.org/unsd/publication/SeriesF/SeriesF 93E.pdf: "Given the likely cyclical pattern of activities over a year, the time period for a time-use survey is ideally taken to be 12 months. The 12 -month period may be a calendar year, or it may be any other 12-month period (for example, from June 1 of one year to May 31 of the following year)." The need for the time-use data to reflect women's achievements across seasons is, of course, of paramount importance when the time-use data are interpreted as accurate at the individual level as in the case of the WEAI. In almost all time-use studies, data are taken as accurate at the group level (women), not at the individual level as required by the WEAI. A study of time-use surveys in Mexico, India, and Benin found that the modules required specially trained enumerators; in India they visited four times to capture seasonality. There were also guidelines (if yesterday was a funeral/holiday) about which day to pick, which was not done in the pilot but should be included in future time-use surveys (see http://www.levyinstitute.org/undp-levy-conference/papers/paper Vacarr.pdf).
} 


\section{COMPUTING THE WOMEN'S EMPOWERMENT IN AGRICULTURE INDEX}

The WEAI is composed of two subindexes: one measures 5DE for women, and the other measures gender parity in empowerment within the household (GPI). The weights of the 5DE and GPI subindexes are 90 percent and 10 percent, respectively. The choice of weights for the two subindexes is somewhat arbitrary but reflects the emphasis on 5DE while still recognizing the importance of gender equality as an aspect of empowerment and the different magnitudes of the indices. The total WEAI score is the weighted sum of the country- or regional-level 5DE and GPI. Improvements in either 5DE or the GPI will increase the WEAI.

\section{The 5DE Index}

This subindex assesses whether women are empowered across the five domains examined in the WEAI. For the women who are disempowered, it also shows the percentage of domains in which they meet the required threshold and thus experience sufficiency or adequacy. The 5DE subindex captures women's empowerment within their households and communities.

Although our final goal is a measure of empowerment, we construct 5DE in such a way that disempowerment can be analyzed. The advantage of this construction is that it allows us to identify the critical indicators that must be addressed to increase empowerment. This enables decisionmakers to focus on the situation of the disempowered. We begin by computing a disempowerment index across the five domains $\left(M_{0}\right)$; then we compute $5 \mathrm{DE}$ as $\left(1-M_{0}\right){ }^{34}$

\section{Identification of the Disempowered}

There are two equivalent notations that can be used to describe the construction of 5DE. One focuses on the percentage of empowered women and adequacies among the disempowered. The other notation focuses on the percentage of disempowered women and the percentage of domains in which they lack adequate achievements. In this section, we use the second notation, as it is consistent with the $M_{0}$ measurement (Alkire and Foster 2011).

The first step is to code all adequacy indicators described in the previous section such that they assume the value 1 if the individual is inadequate in that indicator.

An inadequacy score is computed for each person, according to his or her inadequacies across all indicators. The inadequacy score of each person is calculated by summing the weighted inadequacies experienced so that the inadequacy score for each person lies between 0 and 1 . The score increases as the number of inadequacies of the person increases and reaches its maximum of 1 when the person experiences inadequacy on all 10 indicators. A person who has no inadequacy on any indicator receives a $c_{\mathrm{i}}$ score equal to 0 . Formally,

$$
c_{i}=w_{1} I_{1}+w_{2} I_{2}+\ldots+w_{d} I_{d}
$$

where $I_{i}=1$ if the person has an inadequate achievement in indicator $i$ and $I_{i}=0$ otherwise, and $w_{i}$ is the weight attached to indicator $i$ with $\sum_{i=1}^{d} w_{i}=1$.

A second cut-off or threshold is used to identify the disempowered. The disempowerment cut-off is the share of (weighted) inadequacies a woman must have to be considered disempowered, and we will denote it by $k$. For those whose inadequacy score is less than or equal to the disempowerment cut-off, even if it is not 0 , their score is replaced by 0 , and any existing inadequacies are not considered in the "censored headcounts." We refer to this important step as censoring the inadequacies of the empowered (see Alkire and Foster 2011; Alkire, Foster, and Santos 2011). To differentiate the original inadequacy

\footnotetext{
${ }^{34}$ For more details about the positive construction of $\left(1-M_{0}\right)$ - in this case with respect to Bhutan's Gross National Happiness Index — see Alkire et al. (2012).
} 
score from the censored one, we use the notation $c_{i}(k)$ for the censored inadequacy score. Note that when $c_{i}>k$, then $c_{i}(k)=c_{i}$, but if $c_{i} \leq k$, then $c_{i}(k)=0 . c_{i}(k)$ is the inadequacy score of the disempowered. ${ }^{35}$

\section{Computing 5DE}

As mentioned above, we start by computing the five domains of disempowerment index $\left(M_{0}\right)$. Following the structure of the Adjusted Headcount measure of Alkire and Foster (2011), $M_{0}$ combines two key pieces of information: (1) the proportion or incidence of individuals (within a given population) whose share of weighted inadequacies is more than $k$ and (2) the intensity of their inadequacies - the average proportion of (weighted) inadequacies they experience.

Formally, the first component is called the disempowered headcount ratio $\left(H_{p}\right)$ :

$$
H_{p}=\frac{q}{n}
$$

Here $q$ is the number of individuals who are disempowered, and $n$ is the total population.

The second component is called the intensity (or breadth) of disempowerment $\left(A_{p}\right)$. It is the average inadequacy score of disempowered individuals and can be expressed as follows:

$$
A_{p}=\frac{\sum_{i=1}^{n} c_{i}(k)}{q}
$$

where $c_{i}(k)$ is the censored inadequacy score of individual $i$ and $q$ is the number of disempowered individuals.

$M_{0}$ is the product of both: $M_{0}=H_{p} \times A_{p}$. Finally, 5DE is easily obtained:

$$
5 D E=1-M_{0} .
$$

Although we built 5DE based on $M_{0}$, it can also be expressed as

$$
5 D E=H_{e}+H_{p} \times A_{e}
$$

where $H_{e}$ is the empowered headcount ratio, which equals $\left(1 H_{p}-H_{p}\right)$; and $A_{e}$ is the average adequacy score of disempowered individuals, which equals $\left(1-A_{p}\right)$.

The 5DE score can thus be improved by increasing the percentage of empowered women or, for those women who are not yet empowered, by increasing their adequacy scores.

A higher disempowerment cut-off implies a lower number of disempowered individuals and, hence, a higher empowered headcount ratio and a higher 5DE. ${ }^{36}$ Given the main purpose of the WEAI, tracking change in women's empowerment, it was important to establish a cut-off that would result in baseline indexes that would allow a reasonable scope for improvement: too high a disempowerment cutoff could result in too few individuals' being classified as disempowered (and potentially with very little room for improvement); too low a cut-off might suggest that it is too easy to achieve empowerment, resulting in an indicator with very little sensitivity. After exploring the sensitivity of the empowerment classification for different cut-offs, we selected the disempowerment cut-off of 20 percent. An individual is disempowered if his or her inadequacy score is greater than 20 percent. This is the same as saying that an individual is identified as empowered in $5 \mathrm{DE}$ if he or she has adequate achievements in four of the five

\footnotetext{
${ }^{35}$ In the WEAI, we define the disempowerment cut-off as strict $\left(c_{i}>k\right)$; in previous work, we have defined the cut-off as weak $\left(c_{i}>k\right)$ (Alkire and Foster 2011).

${ }^{36}$ Note that the empowerment cut-off is equal to (100\% disempowerment cut-off). In this section we have explained identification with reference to a disempowerment cut-off. This is equivalent to saying that if a woman enjoys adequacy in 80 percent or more of the indicators, she is empowered.
} 
domains, enjoys adequacy in some combination of the weighted indicators that sum to 80 percent or more, or has an adequacy score of 80 or greater.

\section{Breaking Down $M_{0}$ by Domains and Indicators}

Having measured empowerment, we now need to increase it. To do so, it is useful to understand how women are disempowered in different contexts. A key feature of $M_{0}$ is that once the disempowered have been identified (in other words, once $M_{0}$ has been computed), one can decompose $M_{0}$ into its componentcensored indicators to reveal how people are disempowered - the composition of inadequacies they experience.

To decompose by indicators, compute the censored headcount ratio in each indicator. The censored headcount ratio for a particular indicator is obtained by adding up the number of disempowered people who are deprived on that indicator and dividing by the total population. Once all the censored headcount ratios have been computed, it can be verified that the weighted sum of the censored headcount ratios also generates the country's $M_{0}$. That is, if the $M_{0}$ is constructed from all 10 indicators, then

$$
M_{\text {country }}=w_{1} \mathrm{CH}_{1}+w_{2} \mathrm{CH}_{2}+\cdots+w_{10} \mathrm{CH}_{10} \text {. }
$$

Here $w_{1}$ is the weight of indicator $1, \mathrm{CH}_{1}$ is the censored headcount ratio of indicator 1 , and so on for the other nine indicators, with $\sum_{i=1}^{d} w_{i}=1$. It is called censored because the inadequacies of women who are not identified as disempowered are not included so as to focus attention on disempowered women.

The percentage contribution of each indicator to overall disempowerment is computed as follows:

$$
\text { Contribution of indicator i to } M_{0}=\frac{w_{i} \mathrm{CH}_{i}}{M_{0 \text { country }}} \times 100 \text {. }
$$

The contributions of all indicators will sum to 100 percent. Whenever the contribution to disempowerment of a certain indicator greatly exceeds its weight, this suggests that there is a relatively high inadequacy in this indicator in the sample under analysis. The disempowered are more inadequate in this indicator than in others. Such indicators with high inadequacy point to areas for intervention to increase empowerment.

\section{Decomposing by Population Subgroups}

Another key feature of $M_{0}$ (and of 5DE) is that it can be decomposed by population subgroups such as regions or ethnic groups, depending on the sample design. For example, if there are two subgroups by which the survey is representative, eastern and western, the formula for their decomposition is

$$
M_{0_{\text {country }}}=\frac{n_{E}}{n} \times M_{0_{E}}+\frac{n_{W}}{n} \times M_{0_{W}} \text {, }
$$

where $E$ denotes eastern, $W$ denotes western, $n_{E} / n$ is the population of eastern areas divided by the total population, and similarly the population of western areas divided by the total population is $n_{W} / n$ (and $n_{E}+n_{W}=n$ ). This relationship can be extended for any number of groups as long as their respective populations add up to the total population. formula:

The contribution of each group to overall disempowerment can be computed using the following

$$
\text { Contribution of eastern areas to } M_{0_{\text {country }}}=\frac{\frac{n_{U}}{n} \times M_{0_{E}}}{M_{0_{\text {country }}}} \times 100 \text {. }
$$


Whenever the contribution to disempowerment of a region or some other group widely exceeds its population share, this suggests that some regions or groups may bear a disproportionate share of poverty.

\section{Gender Parity Index (GPI)}

The GPI is a relative inequality measure that reflects the inequality in 5DE profiles between the primary adult male and female in each household. By definition, households without a primary adult male are excluded from this measure, and thus the aggregate WEAI uses the mean GPI value of dual-adult households.

Similar to 5DE, we compute the GPI to celebrate gender parity in a positive sense; however, its construction immediately facilitates analysis of households that lack gender parity.

For the purpose of constructing the GPI, the score of those whose inadequacy score is less than or equal to the disempowerment cut-off of $k$ is replaced by the value of $k$, which is 20 percent. To differentiate this censored inadequacy score from the censored score used to compute 5DE, we use the notation $c^{\prime}{ }_{i}(k)$ for the new censored inadequacy score. Note that when $c_{i}>k$, then $c^{\prime}{ }_{i}(k)=c_{i}$, but if $c_{i} \leq k$, then $c^{\prime}{ }_{i}(k)=k$.

Each dual-adult household is classified on gender parity. Households are considered to lack parity if the female is disempowered and her censored inadequacy score is higher than the censored inadequacy score of her male counterpart. Put differently, a household enjoys parity if the woman is empowered or, if she is not empowered, her adequacy score is greater than or equal to that of the male in her household.

The GPI combines two key pieces of information: (1) the percentage of women who have not yet achieved empowerment or gender parity relative to their male counterparts (within a given population) and (2) the extent of the inequality between those women who lack parity and the men with whom they live. $\left(H_{G P I}\right)$ :

The first component corresponds to the proportion of gender parity-inadequate households

$$
H_{G P I}=\frac{h}{m},
$$

where $h$ is the number of households classified as inadequate in gender parity and $m$ is the total of dualadult households in the population.

Formally, the second component is called the average empowerment gap; it is the average percentage gap between the censored inadequacy scores of the women and men living in households that lack gender parity $\left(I_{G P I}\right)$ :

$$
I_{G P I}=\frac{1}{h} \sum_{j=1}^{h} \frac{c^{\prime} j_{j}(k)^{W}-c^{\prime} j_{j}(k)^{M}}{1-c{ }^{\prime}(k)^{M}},
$$

where $c^{\prime}{ }_{j}(k)^{W}$ and $c^{\prime}{ }_{j}(k)^{M}$ are the censored inadequacy scores of the primary woman and man, respectively, living in household $j$, and $h$ is the number of households that are gender parity inadequate.

The GPI is computed as follows:

$$
G P I=1-\left(H_{G P I} \times I_{G P I}\right) .
$$

The GPI score can thus be improved by increasing the percentage of women who have gender parity (reducing $H_{G P I}$ ) or, for those women who are less empowered than men, by reducing the empowerment gap between the male and female of the same household (reducing $I_{G P I}$ ). 


\section{PILOT FINDINGS}

In this section, we present the WEAI, and its subindexes, the 5DE and the GPI, for each country pilot.

To identify the areas that contribute most to women's disempowerment, we decompose the women's disempowerment index $\left(M_{0}\right)$ by domain and indicator. For comparison purposes, we present $M_{0}$ and its decomposition also for the sample of men.

\section{Southwestern Bangladesh Pilot}

The WEAI for the sample areas in southwestern Bangladesh is 0.762. It is a weighted average of the 5DE subindex value of 0.746 and the GPI subindex value of 0.899 . The results are presented in Table 9.1.

Table 9.1-Bangladesh pilot WEAI

\begin{tabular}{|c|c|c|}
\hline \multirow[b]{2}{*}{ Indexes } & \multicolumn{2}{|c|}{ Southwestern Bangladesh } \\
\hline & Women & Men \\
\hline Disempowered headcount $(\mathrm{H})$ & $61.0 \%$ & $59.8 \%$ \\
\hline Average inadequacy score $(A)$ & $41.6 \%$ & $33.7 \%$ \\
\hline Disempowerment Index $\left(M_{0}\right)$ & 0.254 & 0.201 \\
\hline 5DE Index $\left(1-M_{0}\right)$ & 0.746 & 0.799 \\
\hline Number of observations & 436 & 338 \\
\hline Percentage of data used & $96.9 \%$ & $96.6 \%$ \\
\hline Percentage of women with no gender parity $\left(H_{G P I}\right)$ & $40.2 \%$ & \\
\hline Average Empowerment Gap $\left(I_{G P I}\right)$ & $25.2 \%$ & \\
\hline Gender Parity Index & 0.899 & \\
\hline Number of women in dual households & 350 & \\
\hline Percentage of data used & $94.6 \%$ & \\
\hline WEAI & 0.762 & \\
\hline
\end{tabular}

Source: Author's calculations.

Notes: WEAI = Women's Empowerment in Agriculture Index; 5DE = five domains of empowerment.

The 5DE for Bangladesh shows that 39.0 percent of women are empowered. In the pilot areas, the 61.0 percent of women who are not yet empowered have, on average, inadequate achievements in 41.6 percent of domains. Thus, women's $M_{0}$ is 61.0 percent $\times 41.6$ percent $=0.254$ and $5 \mathrm{DE}$ is $1-0.254=39.0$ percent $+(61.0$ percent $\times[1-41.6$ percent $])=0.746$. In these pilot areas, 59.8 percent of men are not yet empowered. The average inadequacy score among these men is 33.7 . So men's $M_{0}$ is 59.8 percent $\times 33.7$ percent $=0.201$ and men's 5DE is $1-0.201=0.799$.

Based on the decomposition of the disempowerment measure (see Table 9.2), the domains in the Bangladesh sample areas that contribute most to women's disempowerment are weak leadership (30.6 percent) and lack of control over resources (21.6 percent). Approximately half of the women in the survey are not yet empowered and do not belong to any group. Forty-five percent of women are not yet empowered and lack access to credit and the ability to make decisions about it, and 28 percent have little decisionmaking power over the purchase, sale, or transfer of assets.

The configuration of men's deprivations in empowerment is strikingly different from women's in the pilot regions of Bangladesh (see Figure 9.1). The lack of leadership and influence in the community contribute much more to men's disempowerment than to women's, as does time poverty. On the other hand, men report very little disempowerment in control over income and in decisionmaking around agricultural production compared to women. 
Table 9.2-Bangladesh 5DE, decomposed by dimension and indicator

\begin{tabular}{|c|c|c|c|c|c|c|c|c|c|c|}
\hline \multirow[b]{2}{*}{ Statistics } & \multicolumn{2}{|c|}{ Production } & \multicolumn{3}{|c|}{ Resources } & \multirow{2}{*}{$\begin{array}{c}\text { Income } \\
\text { Control } \\
\text { over use } \\
\text { of } \\
\text { income }\end{array}$} & \multicolumn{2}{|c|}{ Leadership } & \multicolumn{2}{|c|}{ Time } \\
\hline & $\begin{array}{c}\text { Input in productive } \\
\text { decisions }\end{array}$ & $\begin{array}{l}\text { Autonomy in } \\
\text { production }\end{array}$ & $\begin{array}{l}\text { Ownership of } \\
\text { assets }\end{array}$ & $\begin{array}{c}\text { Purchase, } \\
\text { sale, or } \\
\text { transfer } \\
\text { of assets }\end{array}$ & $\begin{array}{c}\text { Access to } \\
\text { and } \\
\text { decisions } \\
\text { on credit }\end{array}$ & & $\begin{array}{l}\text { Group } \\
\text { member }\end{array}$ & $\begin{array}{l}\text { Speaking } \\
\text { in public }\end{array}$ & Workload & Leisure \\
\hline \multicolumn{11}{|l|}{ Women } \\
\hline $\begin{array}{l}\text { Censored } \\
\text { headcount }\end{array}$ & 0.259 & 0.053 & 0.092 & 0.280 & 0.450 & 0.248 & 0.491 & 0.284 & 0.147 & 0.259 \\
\hline$\%$ Contribution & $10.2 \%$ & $2.1 \%$ & $2.4 \%$ & $7.4 \%$ & $11.8 \%$ & $19.5 \%$ & $19.4 \%$ & $11.2 \%$ & $5.8 \%$ & $10.2 \%$ \\
\hline Contribution & 0.026 & 0.005 & 0.006 & 0.019 & 0.030 & 0.050 & 0.049 & 0.028 & 0.015 & 0.026 \\
\hline $\begin{array}{l}\% \text { Contribution by } \\
\text { dimension }\end{array}$ & \multicolumn{2}{|l|}{$12.3 \%$} & \multicolumn{3}{|c|}{$21.6 \%$} & $19.5 \%$ & \multicolumn{2}{|c|}{$30.6 \%$} & \multicolumn{2}{|c|}{$16.0 \%$} \\
\hline \multicolumn{11}{|l|}{ Men } \\
\hline $\begin{array}{l}\text { Censored } \\
\text { headcount }\end{array}$ & 0.083 & 0.024 & 0.053 & 0.201 & 0.456 & 0.027 & 0.494 & 0.399 & 0.225 & 0.263 \\
\hline$\%$ Contribution & $4.1 \%$ & $1.2 \%$ & $1.8 \%$ & $6.7 \%$ & $15.1 \%$ & $2.6 \%$ & $24.5 \%$ & $19.8 \%$ & $11.2 \%$ & $13.1 \%$ \\
\hline Contribution & 0.008 & 0.002 & 0.004 & 0.013 & 0.030 & 0.005 & 0.049 & 0.040 & 0.022 & 0.026 \\
\hline $\begin{array}{l}\% \text { Contribution by } \\
\text { dimension }\end{array}$ & \multicolumn{2}{|l|}{$5.3 \%$} & \multicolumn{3}{|c|}{$23.5 \%$} & $2.6 \%$ & \multicolumn{2}{|c|}{$44.3 \%$} & \multicolumn{2}{|c|}{$24.2 \%$} \\
\hline
\end{tabular}

Source: Authors' calculations.

Note: $\quad 5 \mathrm{DE}=$ five domains of empowerment. 
Figure 9.1-Contribution of each indicator to disempowerment in Bangladesh sample

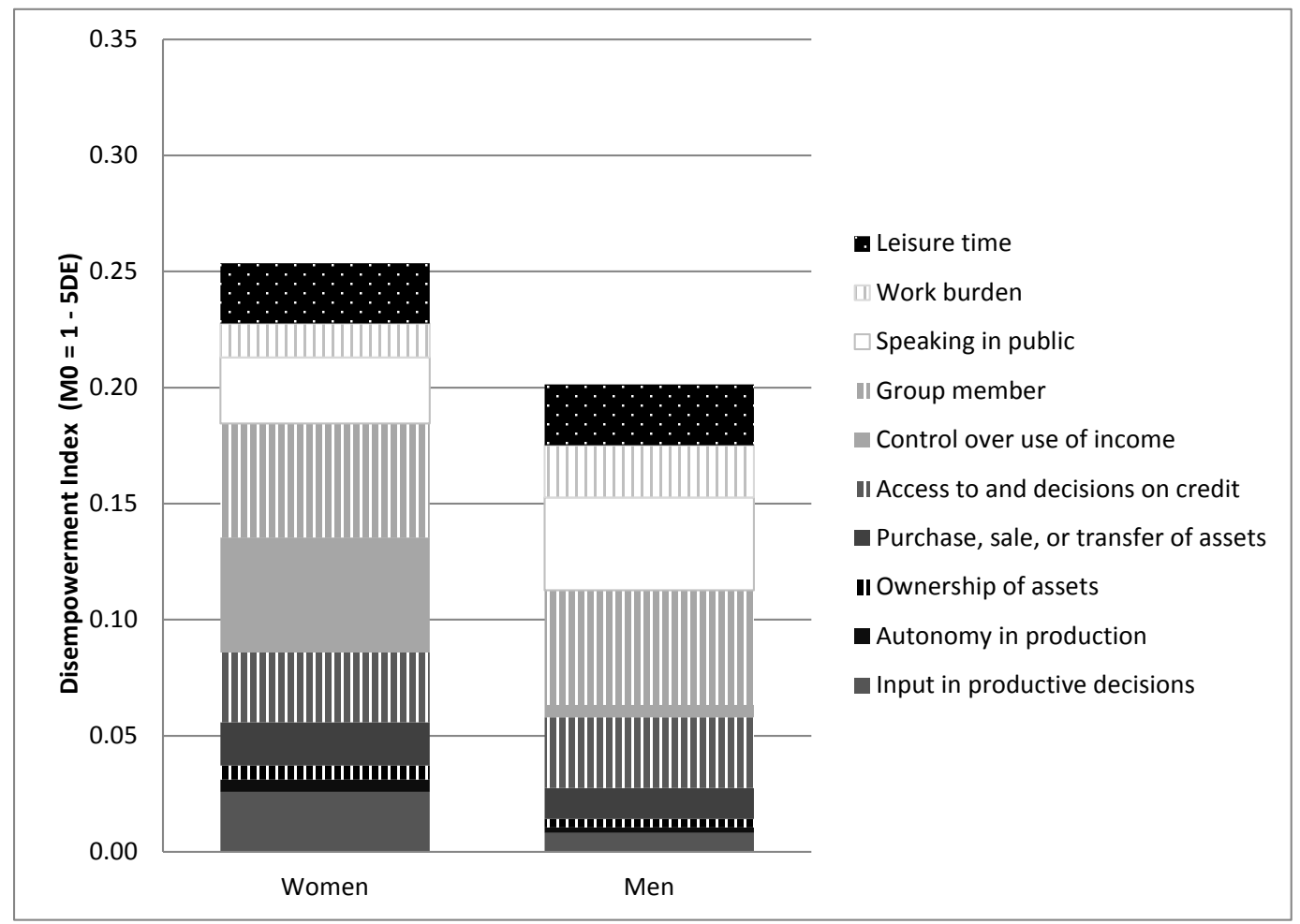

Source: Authors' calculations.

Note: $\quad \mathrm{M} 0=$ disempowerment index; $5 \mathrm{DE}=$ five domains of empowerment.

The GPI, meanwhile, shows that 59.8 percent of women have gender parity with the primary males in their households. Of the 40.2 percent of women who are less empowered, the empowerment gap between them and the males in their households is quite large at 25.2 percent. Thus, the overall GPI in the pilot area is $(1-[40.2$ percent $\times 25.2$ percent $])$ or 0.899 .

\section{Western Highlands of Guatemala Pilot}

The WEAI for the sample areas in the Western Highlands of Guatemala is 0.702. It is a weighted average of the 5DE subindex value of 0.690 and the GPI subindex value of 0.813 (see Table 9.3).

The 5DE for Guatemala shows that the empowered headcount ratio is 28.7 percent among women and 60.9 percent among men. The disempowered women have, on average, inadequate achievements in 43.5 percent of dimensions. Thus, the women's $M_{0}$ is $(1-28.7$ percent $) \times 43.5$ percent $=0.310$ and $5 \mathrm{DE}$ is $1-0.310=28.7$ percent $+([1-28.7$ percent $] \times[1-43.5$ percent $])=0.690$. The 39.1 percent of men who are not yet empowered have an average inadequacy score of 32.9 percent. So men's $M_{0}$ is 39.1 percent $\times 32.9$ percent $=0.129$ and $5 \mathrm{DE}$ is $1-0.129=0.871$.

The decomposition of Guatemala's 5DE (see Table 9.4) shows that the domains that contribute most to Guatemalan women's disempowerment are lack of leadership in the community (23.7 percent) and control over the use of income (23.7 percent). More than 60 percent of women are not yet empowered and lack access to credit and the ability to make decisions about it, 45.1 percent are not group members, and 36.7 percent lack sole or joint decisionmaking power over income. 
Table 9.3-Guatemala pilot WEAI

\begin{tabular}{|c|c|c|}
\hline \multirow[b]{2}{*}{ Indexes } & \multicolumn{2}{|c|}{ Western Highlands Guatemala } \\
\hline & Women & Men \\
\hline Disempowered headcount $(\mathrm{H})$ & $71.3 \%$ & $39.1 \%$ \\
\hline Average inadequacy score $(A)$ & $43.5 \%$ & $32.9 \%$ \\
\hline Disempowerment Index $\left(M_{0}\right)$ & 0.310 & 0.129 \\
\hline $5 \mathrm{DE}$ Index $\left(1-M_{0}\right)$ & 0.690 & 0.871 \\
\hline Number of observations & 237 & 197 \\
\hline Percentage of data used & $67.7 \%$ & $71.4 \%$ \\
\hline Percentage of women with no gender parity $\left(H_{G P I}\right)$ & $64.2 \%$ & \\
\hline Average Empowerment Gap $\left(I_{G P I}\right)$ & $29.1 \%$ & \\
\hline Gender Parity Index & 0.813 & \\
\hline Number of women in dual households & 276 & \\
\hline Percentage of data used & $67.8 \%$ & \\
\hline WEAI & 0.702 & \\
\hline
\end{tabular}

Source: Authors' calculations.

Notes: WEAI = Women's Empowerment in Agriculture Index; 5DE = five domains of empowerment.

The configuration of men's deprivations in empowerment is similar to that of women's in the pilot regions of Guatemala, but men have uniformly more empowerment than women on all of the indicators (see Figure 9.2). The main difference is that lack of control over income contributes less to men's disempowerment than to women's, whereas the lack of control over resources contributes relatively more. 
Table 9.4-Guatemala 5DE, decomposed by dimension and indicator

\begin{tabular}{|c|c|c|c|c|c|c|c|c|c|c|}
\hline \multirow[b]{2}{*}{ Statistics } & \multicolumn{2}{|c|}{ Production } & \multicolumn{3}{|c|}{ Resources } & \multirow{2}{*}{$\begin{array}{c}\text { Income } \\
\text { Control } \\
\text { over use } \\
\text { of } \\
\text { income }\end{array}$} & \multicolumn{2}{|c|}{ Leadership } & \multicolumn{2}{|c|}{ Time } \\
\hline & $\begin{array}{l}\text { Input in } \\
\text { productive } \\
\text { decisions }\end{array}$ & $\begin{array}{l}\text { Autonomy } \\
\text { in } \\
\text { production }\end{array}$ & $\begin{array}{l}\text { Ownership } \\
\text { of assets }\end{array}$ & $\begin{array}{l}\text { Purchase, } \\
\text { sale, or } \\
\text { transfer of } \\
\text { assets }\end{array}$ & $\begin{array}{c}\text { Access to } \\
\text { and } \\
\text { decisions } \\
\text { on credit }\end{array}$ & & $\begin{array}{l}\text { Group } \\
\text { member }\end{array}$ & $\begin{array}{l}\text { Speaking } \\
\text { in public }\end{array}$ & Workload & Leisure \\
\hline \multicolumn{11}{|l|}{ Women } \\
\hline Censored headcount & 0.283 & 0.321 & 0.122 & 0.274 & 0.612 & 0.367 & 0.451 & 0.283 & 0.257 & 0.097 \\
\hline$\%$ Contribution & $9.1 \%$ & $10.3 \%$ & $2.6 \%$ & $5.9 \%$ & $13.2 \%$ & $23.7 \%$ & $14.6 \%$ & $9.1 \%$ & $8.3 \%$ & $3.1 \%$ \\
\hline Contribution & 0.208 & 0.032 & 0.008 & 0.018 & 0.041 & 0.073 & 0.045 & 0.028 & 0.026 & 0.010 \\
\hline $\begin{array}{l}\text { \% Contribution by } \\
\text { dimension }\end{array}$ & \multicolumn{2}{|l|}{$19.5 \%$} & \multicolumn{2}{|c|}{$21.7 \%$} & & $23.7 \%$ & \multicolumn{2}{|l|}{$23.7 \%$} & \multicolumn{2}{|l|}{$11.4 \%$} \\
\hline \multicolumn{11}{|l|}{ Men } \\
\hline Censored headcount & 0.046 & 0.203 & 0.036 & 0.142 & .350 & 0.117 & 0.239 & 0.071 & 0.051 & 0.091 \\
\hline$\%$ Contribution & $3.6 \%$ & $15.8 \%$ & $1.8 \%$ & $7.4 \%$ & $18.2 \%$ & $18.2 \%$ & $18.6 \%$ & $5.5 \%$ & $3.9 \%$ & $7.1 \%$ \\
\hline Contribution & 0.005 & 0.020 & 0.002 & 0.009 & 0.023 & 0.023 & 0.024 & 0.007 & 0.005 & 0.009 \\
\hline $\begin{array}{l}\text { \% Contribution by } \\
\text { dimension }\end{array}$ & \multicolumn{2}{|l|}{$19.3 \%$} & \multicolumn{3}{|c|}{$27.4 \%$} & $18.2 \%$ & \multicolumn{2}{|l|}{$24.1 \%$} & \multicolumn{2}{|l|}{$11.1 \%$} \\
\hline
\end{tabular}

Source: Authors' calculations.

Note: $\quad 5 \mathrm{DE}=$ five domains of empowerment 
Figure 9.2-Contribution of each indicator to disempowerment in Guatemala sample

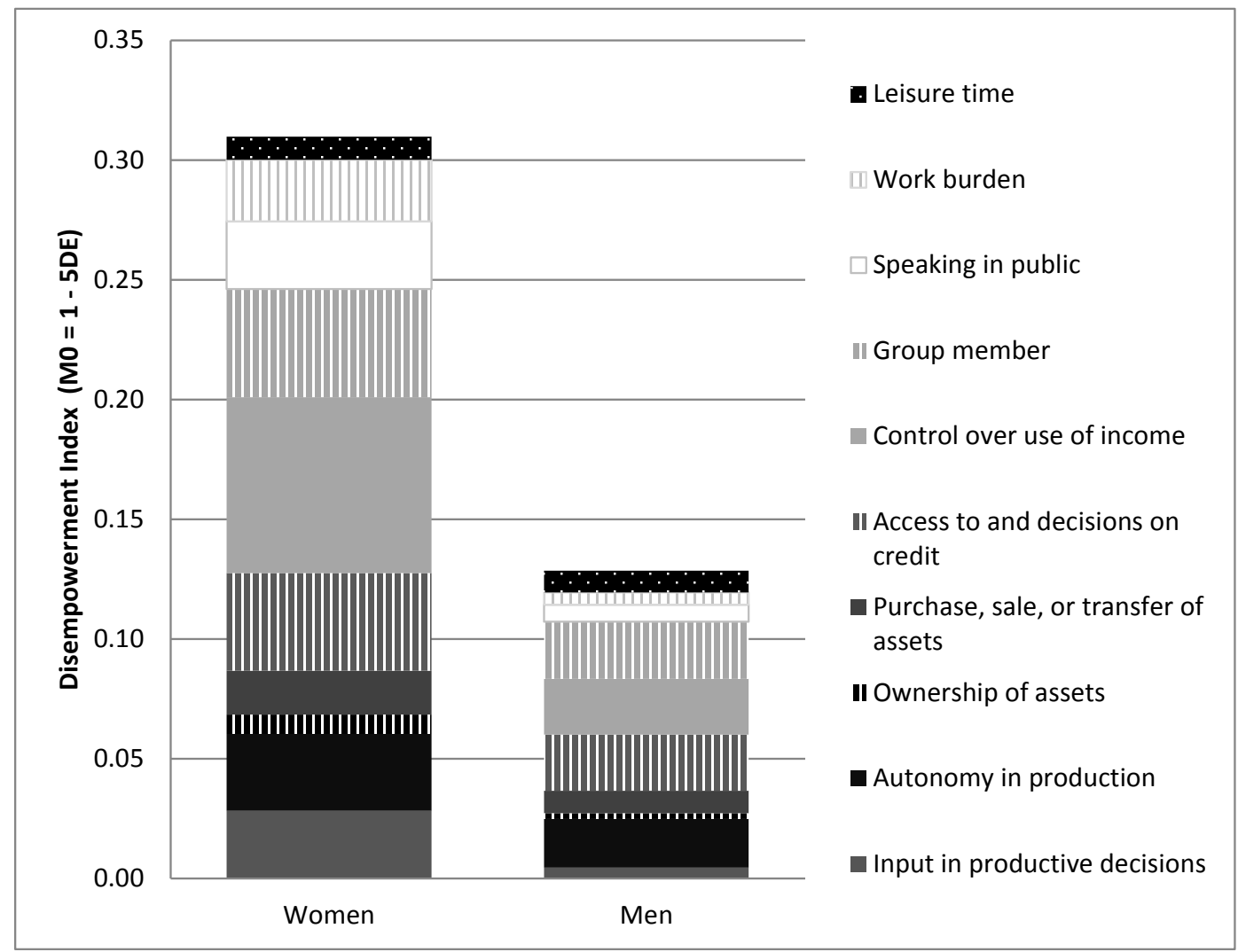

Source: Authors' calculations.

Notes: $\quad \mathrm{M} 0=$ disempowerment index; $5 \mathrm{DE}=$ five domains of empowerment.

The GPI for the Western Highlands of Guatemala shows that 35.8 percent of women have gender parity with the primary males in their households. The 64.2 percent of women who are less empowered have a quite large empowerment gap between them and the males in their households of 29.1 percent. Thus, the overall GPI is $(1-[64.2$ percent $\times 29.1$ percent $])$, or 0.813 .

\section{Uganda Pilot}

The WEAI for the pilot districts in Uganda is 0.800. It is a weighted average of the 5DE subindex value of 0.789 and the GPI subindex value of 0.898 (see Table 9.5).

The 5DE for Uganda shows that 43.3 percent of women and 63.0 percent of men are empowered. The 56.7 percent of women who are not yet empowered have an average achieved empowerment in 62.8 percent of dimensions $(1-37.2$ percent $)$. Thus, women's 5DE is 43.3 percent $+(56.7$ percent $\times 62.8$ percent $)=0.789$. The average inadequacy share among the 37.0 percent of men who are still disempowered is 32.8 percent. So men's $5 \mathrm{DE}$ is $1-(37.0$ percent $\times 32.8$ percent $)=0.878$. 
Table 9.5-Uganda pilot WEAI

\begin{tabular}{lcc}
\hline & \multicolumn{2}{c}{ Uganda } \\
\cline { 2 - 3 } Indexes & Women & Men \\
\hline Disempowered headcount $(H)$ & $56.7 \%$ & $37.0 \%$ \\
Average inadequacy score $(\mathrm{A})$ & $37.2 \%$ & $32.8 \%$ \\
Disempowerment Index $\left(M_{0}\right)$ & 0.211 & 0.122 \\
5DE Index $\left(1-M_{0}\right) \quad$ Number of observations & 0.789 & 0.878 \\
$\quad$ Percentage of data used & 335 & 262 \\
Percentage of women with no gender parity $\left(H_{G P I}\right)$ & $95.7 \%$ & $95.3 \%$ \\
Average Empowerment Gap $\left(I_{G P I}\right)$ & $45.6 \%$ & \\
Gender Parity Index $\quad 22.4 \%$ & \\
$\quad$ Number of women in dual households & 0.898 & \\
WEAl Percentage of data used & 275 & \\
\hline
\end{tabular}

Source: Authors' calculations.

Notes: WEAI = Women's Empowerment in Agriculture Index; 5DE = five domains of empowerment.

The domains that contribute most to women's disempowerment are time burden (26.3 percent) and lack of control over resources (23.1 percent). According to these pilot results, 48.7 percent of women are not yet empowered and lack access to or decisionmaking ability over credit, 30.7 percent do not have a manageable workload, and 31.9 percent are not members of any group (see Table 9.6 and Figure 9.3).

The configuration of men's deprivations in empowerment is somewhat different from women's in the pilot regions of Uganda. The lack of decisionmaking around agricultural production contributes much more to men's disempowerment than to women's ( 22 percent vs. 9 percent).

The GPI for the selected districts of Uganda shows that 54.4 percent of women have gender parity with the primary males in their households. Of the 45.6 percent of women who are less empowered, the empowerment gap between them and the males in their households is 22.4 percent. Thus, the overall GPI is $(1-[45.6$ percent $\times 22.4$ percent $])$, or 0.898 . 
Table 9.6-Uganda 5DE, decomposed by dimension and indicator

\begin{tabular}{|c|c|c|c|c|c|c|c|c|c|c|}
\hline \multirow[b]{2}{*}{ Statistics } & \multicolumn{2}{|c|}{ Production } & \multicolumn{3}{|c|}{ Resources } & \multirow{2}{*}{$\begin{array}{c}\text { Income } \\
\text { Control } \\
\text { over use } \\
\text { of } \\
\text { income }\end{array}$} & \multicolumn{2}{|c|}{ Leadership } & \multicolumn{2}{|c|}{ Time } \\
\hline & $\begin{array}{l}\text { Input in } \\
\text { productive } \\
\text { decisions }\end{array}$ & $\begin{array}{l}\text { Autonomy } \\
\text { in } \\
\text { production }\end{array}$ & $\begin{array}{l}\text { Ownership } \\
\text { of assets }\end{array}$ & $\begin{array}{l}\text { Purchase, } \\
\text { sale, or } \\
\text { transfer of } \\
\text { assets }\end{array}$ & $\begin{array}{c}\text { Access to } \\
\text { and } \\
\text { decisions } \\
\text { on credit }\end{array}$ & & $\begin{array}{l}\text { Group } \\
\text { member }\end{array}$ & $\begin{array}{l}\text { Speaking } \\
\text { in public }\end{array}$ & $\begin{array}{l}\text { Work } \\
\text { burden }\end{array}$ & $\begin{array}{l}\text { Leisure } \\
\text { time }\end{array}$ \\
\hline \multicolumn{11}{|l|}{ Women } \\
\hline Censored headcount & 0.060 & 0.131 & 0.104 & 0.140 & 0.487 & 0.206 & 0.319 & 0.146 & 0.307 & 0.248 \\
\hline$\%$ Contribution & $2.8 \%$ & $6.2 \%$ & $3.3 \%$ & $4.4 \%$ & $15.4 \%$ & $19.5 \%$ & $15.1 \%$ & $6.9 \%$ & $14.6 \%$ & $11.7 \%$ \\
\hline Contribution & 0.006 & 0.013 & 0.007 & 0.009 & 0.032 & 0.041 & 0.032 & 0.015 & 0.031 & 0.025 \\
\hline $\begin{array}{l}\% \text { Contribution by } \\
\text { dimension }\end{array}$ & \multicolumn{2}{|l|}{$9.0 \%$} & \multicolumn{2}{|c|}{$23.1 \%$} & & $19.5 \%$ & \multicolumn{2}{|l|}{$22.1 \%$} & \multicolumn{2}{|c|}{$26.3 \%$} \\
\hline \multicolumn{11}{|l|}{ Men } \\
\hline Censored headcount & 0.042 & 0.225 & 0.011 & 0.053 & 0.309 & 0.084 & 0.218 & 0.038 & 0.126 & 0.149 \\
\hline$\%$ Contribution & $3.5 \%$ & $18.5 \%$ & $0.6 \%$ & $2.9 \%$ & $17.0 \%$ & $13.8 \%$ & $17.9 \%$ & $3.1 \%$ & $10.4 \%$ & $12.3 \%$ \\
\hline Contribution & 0.004 & 0.023 & 0.001 & 0.004 & 0.021 & 0.017 & 0.022 & 0.004 & 0.013 & 0.015 \\
\hline $\begin{array}{l}\% \text { Contribution by } \\
\text { dimension }\end{array}$ & \multicolumn{2}{|l|}{$22.0 \%$} & \multicolumn{3}{|c|}{$20.5 \%$} & $13.8 \%$ & \multicolumn{2}{|l|}{$21.0 \%$} & \multicolumn{2}{|c|}{$22.6 \%$} \\
\hline
\end{tabular}

Source: Authors' calculations.

Note: $\quad 5 \mathrm{DE}=$ five domains of empowerment 
Figure 9.3-Contribution of each indicator to disempowerment in Uganda sample

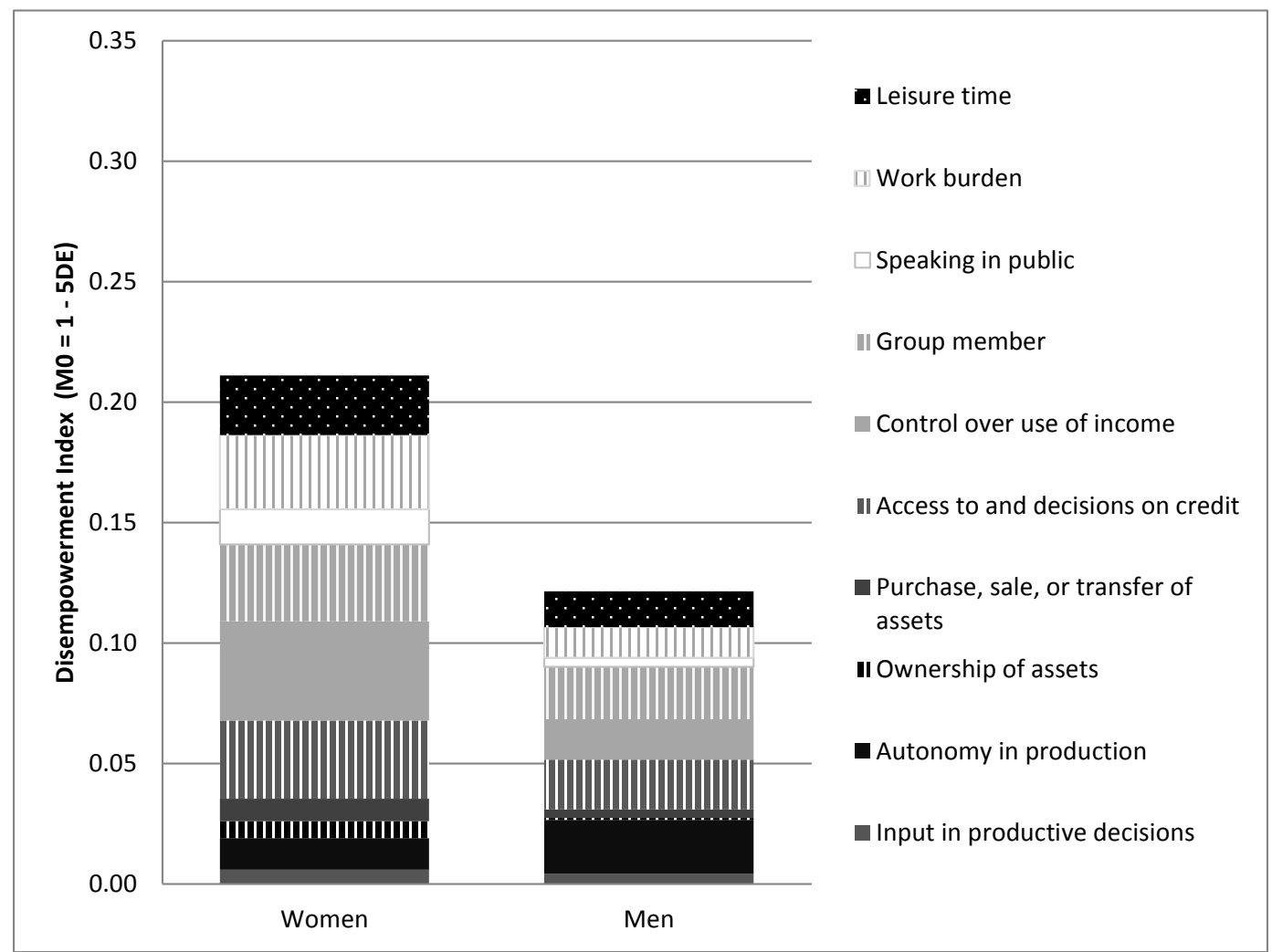

Source: Authors' calculations.

Notes: $\quad \mathrm{M} 0=$ disempowerment index $; 5 \mathrm{DE}=$ five domains of empowerment.

\section{Insights from Pilot Findings}

Although the pilot studies had limited sample size and are not representative of the full USAID Feed the Future zones of influence, let alone the full countries, the pilot results are illustrative of the kinds of insights that the WEAI can provide. In Bangladesh, for example, a high proportion of men are not empowered, and the domains in which men and women lack empowerment differ considerably, whereas in the other countries, men are more likely than women to be empowered in every domain. Disaggregating the components of the WEAI can be further used to identify key areas of disempowerment (for men as well as women), which can be used to prioritize interventions that address key areas of disempowerment. Further disaggregation of the index can be used to identify regional variations to further tailor strategies to redress empowerment gaps. 


\section{CORRELATION WITH OTHER MEASURES}

The 5DE deliberately focused only on issues of empowerment in agriculture. The precision of the measure creates a strength for analysis: We can easily scrutinize how empowerment in women's specific agricultural roles relates to their wealth, their levels of education, and their empowerment in other areas. The pilot survey also included questions related to these other household and individual characteristics. This section examines the relationship between empowerment and those characteristics. In particular, we analyze the cross-tabulations between empowerment and the following characteristics:

- Individual age group

- Individual education level, defined as the highest grade of education completed

- Wealth quintile to which the household belongs

- Household hunger score

- Decisionmaking and autonomy on other domains such as serious health problems, protection from violence, expression of religious faith, definition of daily tasks, and the use of family planning

Two of these indicators require introduction: The wealth index divides the respondents of the survey into five quintiles according to their relative command over a range of household assets. As in DHS, the wealth index was constructed using principal components analysis, taking into account assets, dwelling characteristics, and other indicators. ${ }^{37}$

A household hunger score was also computed following the methodology of the USAID Food and Nutrition Technical Assistance (FANTA-2) project (see Deitchler et al. 2011).

A first observation concerns the decisionmaking versus autonomy questions. The decisionmaking questions reflect whether the respondent makes the decision or feels she could participate in making the decision if she wanted to. On the other hand, autonomy questions reflect the extent to which the respondent's motivation for decisionmaking reflects her values rather than social pressure or direct coercion. Across the three pilots the autonomy questions distinguish more strongly between women who are empowered and those who are nonempowered on the WEAI than do the decisionmaking questions. For example, in Uganda, the average percentage difference between decisionmaking scores for women who are not empowered by the WEAI is 9.2 percent, whereas for autonomy it is 12.7 percent; in Guatemala the distinction is more marked, with a 6.0 percent difference for the decisionmaking questions and a 29.7 percent difference for autonomy questions. In Bangladesh the pattern is less marked and more varied across domains.

Although the strength of association varies, in all three pilots across all six domains of decisionmaking and autonomy, women who were empowered by the WEAI had higher empowerment in the six domains in all but one instance (decisionmaking regarding protection from violence in Bangladesh), and in that it was only very slightly higher among disempowered women. As measures of association we present Cramer's V and the phi coefficient. ${ }^{38}$ To assess the statistical significance of the

${ }^{37}$ The full list of indicators used to calculate the wealth index includes number of household members per sleeping room (or total room if the number of sleeping rooms is unavailable), rooftop material of dwelling, floor material of dwelling, main source of drinking water for household, main type of toilet used by household, access to electricity, main source of cooking fuel for household, agricultural land (pieces or plots), large livestock, small livestock, fishpond or fishing equipment, mechanized farm equipment, nonfarm business equipment, house (and other structures), large consumer durables, small consumer durables, cell phone, other land not used for agricultural purposes, means of transportation, and whether the household employs a household servant.

${ }^{38}$ We present Cramer's V for associations between empowerment and characteristics with more than two categories, namely, age group, education level, health quintile, and household hunger score. For associations between empowerment and decisionmaking and autonomy, characteristics that were coded as dichotomous variables, we present the phi coefficient as a measure of association. 
association between empowerment and these characteristics we computed Pearson's chi-square and Fisher's exact test for the hypothesis that the rows and columns in a two-way table are independent. The results of these tests should be interpreted carefully since in some cases, for instance, in the Guatemala pilot, the number of missing observations is not unimportant.

\section{Southwestern Bangladesh Pilot}

The tabulations between the condition of empowerment and age, education level, wealth quintile to which the household belongs, and household hunger score are displayed in Table 10.1. ${ }^{39}$

Table 10.1 - Tabulations between empowerment and individual and household's characteristicsBangladesh pilot

\begin{tabular}{|c|c|c|c|c|c|c|}
\hline \multirow[b]{3}{*}{ Characteristics } & \multicolumn{6}{|c|}{ Empowered } \\
\hline & \multicolumn{3}{|c|}{ Women } & \multicolumn{3}{|c|}{ Men } \\
\hline & Yes & No & Missing & Yes & No & Missing \\
\hline \multicolumn{7}{|l|}{ Age group } \\
\hline $16-25$ & $\begin{array}{c}26 \\
32.50\end{array}$ & $\begin{array}{c}54 \\
67.50\end{array}$ & 1 & $\begin{array}{c}6 \\
20.69\end{array}$ & $\begin{array}{c}23 \\
79.31\end{array}$ & 2 \\
\hline $26-45$ & $\begin{array}{c}107 \\
43.32\end{array}$ & $\begin{array}{c}140 \\
56.68\end{array}$ & 11 & $\begin{array}{c}77 \\
44.00\end{array}$ & $\begin{array}{c}98 \\
56.00\end{array}$ & 8 \\
\hline $46-55$ & $\begin{array}{c}24 \\
41.38\end{array}$ & $\begin{array}{c}34 \\
58.62\end{array}$ & 2 & $\begin{array}{c}26 \\
44.83\end{array}$ & $\begin{array}{c}32 \\
55.17\end{array}$ & 0 \\
\hline $56-65$ & $\begin{array}{c}11 \\
30.56\end{array}$ & $\begin{array}{c}25 \\
69.44\end{array}$ & 0 & $\begin{array}{c}17 \\
38.64\end{array}$ & $\begin{array}{c}27 \\
61.36\end{array}$ & 2 \\
\hline$>65$ & $\begin{array}{c}2 \\
13.33\end{array}$ & $\begin{array}{c}13 \\
86.67\end{array}$ & 0 & $\begin{array}{c}10 \\
31.25\end{array}$ & $\begin{array}{c}22 \\
68.75\end{array}$ & 0 \\
\hline Total & $\begin{array}{c}170 \\
38.99\end{array}$ & $\begin{array}{l}266 \\
61.01\end{array}$ & 14 & $\begin{array}{c}136 \\
40.24\end{array}$ & $\begin{array}{c}202 \\
59.76\end{array}$ & 12 \\
\hline Cramer's V & 0.142 & & & 0.147 & & \\
\hline $\begin{array}{l}\text { Pearson chi }{ }^{2} \text { (statistic } \\
\text { and p-value) }\end{array}$ & 8.73 & 0.068 & & 7.37 & 0.122 & \\
\hline Fisher's exact ( $p$-value) & & 0.067 & & & 0.118 & \\
\hline \multicolumn{7}{|l|}{ Education } \\
\hline Less than primary & $\begin{array}{c}103 \\
39.46\end{array}$ & $\begin{array}{c}158 \\
60.54\end{array}$ & 8 & $\begin{array}{c}76 \\
38.19\end{array}$ & $\begin{array}{c}123 \\
61.81\end{array}$ & 7 \\
\hline Primary & $\begin{array}{c}65 \\
38.69\end{array}$ & $\begin{array}{c}103 \\
61.31\end{array}$ & 5 & $\begin{array}{c}46 \\
39.66\end{array}$ & $\begin{array}{c}70 \\
60.34\end{array}$ & 5 \\
\hline Secondary & $\begin{array}{c}2 \\
33.33\end{array}$ & $\begin{array}{c}4 \\
66.67\end{array}$ & 0 & $\begin{array}{c}10 \\
71.43\end{array}$ & $\begin{array}{c}4 \\
28.57\end{array}$ & 0 \\
\hline University or above & $\begin{array}{c}0 \\
0.00\end{array}$ & $\begin{array}{c}1 \\
100.0\end{array}$ & 1 & $\begin{array}{c}4 \\
44.44\end{array}$ & $\begin{array}{c}5 \\
55.56\end{array}$ & 0 \\
\hline Total & $\begin{array}{c}170 \\
38.99\end{array}$ & $\begin{array}{c}266 \\
61.01\end{array}$ & 14 & $\begin{array}{c}136 \\
40.24\end{array}$ & $\begin{array}{c}202 \\
59.76\end{array}$ & 12 \\
\hline Cramer's V & 0.042 & & & 0.134 & & \\
\hline $\begin{array}{l}\text { Pearson chi }{ }^{2} \text { (statistic } \\
\text { and p-value) }\end{array}$ & 0.751 & 0.861 & & 6.093 & 0.107 & \\
\hline Fisher's exact ( $p$-value) & & 0.984 & & & 0.109 & \\
\hline
\end{tabular}

\footnotetext{
${ }^{39}$ We also ran polychoric correlations, but we do not present the results in Table 10.1 as they were rarely significant.
} 
Table 10.1-Continued

\begin{tabular}{|c|c|c|c|c|c|c|}
\hline \multirow[b]{3}{*}{ Characteristics } & \multicolumn{6}{|c|}{ Empowered } \\
\hline & \multicolumn{3}{|c|}{ Women } & \multicolumn{3}{|c|}{ Men } \\
\hline & Yes & No & Missing & Yes & No & Missing \\
\hline \multicolumn{7}{|l|}{ Wealth index } \\
\hline 1st quintile & $\begin{array}{c}20 \\
21.28\end{array}$ & $\begin{array}{c}74 \\
78.72\end{array}$ & 5 & $\begin{array}{c}13 \\
23.64\end{array}$ & $\begin{array}{c}42 \\
76.36\end{array}$ & 5 \\
\hline 2nd quintile & $\begin{array}{c}34 \\
40.00\end{array}$ & $\begin{array}{c}51 \\
60.00\end{array}$ & 4 & $\begin{array}{c}29 \\
42.65\end{array}$ & $\begin{array}{c}39 \\
57.35\end{array}$ & 4 \\
\hline 3rd quintile & $\begin{array}{c}34 \\
38.20\end{array}$ & $\begin{array}{c}55 \\
61.80\end{array}$ & 1 & $\begin{array}{c}24 \\
34.78\end{array}$ & $\begin{array}{c}45 \\
65.22\end{array}$ & 1 \\
\hline 4th quintile & $\begin{array}{c}39 \\
47.56\end{array}$ & $\begin{array}{c}43 \\
52.44\end{array}$ & 1 & $\begin{array}{c}37 \\
49.33\end{array}$ & $\begin{array}{c}38 \\
50.67\end{array}$ & 2 \\
\hline 5th quintile & $\begin{array}{c}43 \\
50.00\end{array}$ & $\begin{array}{c}43 \\
50.00\end{array}$ & 3 & $\begin{array}{c}33 \\
46.48\end{array}$ & $\begin{array}{c}38 \\
53.52\end{array}$ & 0 \\
\hline Total & $\begin{array}{c}170 \\
38.99\end{array}$ & $\begin{array}{c}266 \\
61.01\end{array}$ & 14 & $\begin{array}{c}136 \\
40.24\end{array}$ & $\begin{array}{c}202 \\
59.76\end{array}$ & 12 \\
\hline Cramer's V & 0.211 & & & 0.181 & & \\
\hline $\begin{array}{l}\text { Pearson chi }{ }^{2} \text { (statistic } \\
\text { and } p \text {-value) }\end{array}$ & 19.37 & 0.001 & & 11.05 & 0.026 & \\
\hline Fisher's exact ( $p$-value) & & 0.000 & & & 0.024 & \\
\hline \multicolumn{7}{|l|}{ Household hunger score } \\
\hline Little to no hunger & $\begin{array}{c}147 \\
39.84\end{array}$ & $\begin{array}{c}222 \\
60.16\end{array}$ & 13 & $\begin{array}{c}125 \\
41.39\end{array}$ & $\begin{array}{c}177 \\
58.61\end{array}$ & 11 \\
\hline Moderate hunger & $\begin{array}{c}20 \\
34.48\end{array}$ & $\begin{array}{c}38 \\
65.52\end{array}$ & 1 & $\begin{array}{c}10 \\
29.41\end{array}$ & $\begin{array}{c}24 \\
70.59\end{array}$ & 1 \\
\hline Severe hunger & $\begin{array}{c}3 \\
33.33\end{array}$ & $\begin{array}{c}6 \\
66.67\end{array}$ & 0 & $\begin{array}{c}1 \\
50.00\end{array}$ & $\begin{array}{c}1 \\
50.00\end{array}$ & 0 \\
\hline Total & $\begin{array}{c}170 \\
38.99\end{array}$ & $\begin{array}{c}266 \\
61.01\end{array}$ & 14 & $\begin{array}{c}136 \\
40.24\end{array}$ & $\begin{array}{c}202 \\
59.76\end{array}$ & 12 \\
\hline Cramer's V & 0.041 & & & 0.075 & & \\
\hline $\begin{array}{l}\text { Pearson chi }{ }^{2} \text { (statistic } \\
\text { and } p \text {-value) }\end{array}$ & 0.73 & 0.695 & & 1.90 & 0.386 & \\
\hline Fisher's exact ( $p$-value) & & 0.755 & & & 0.354 & \\
\hline
\end{tabular}

Source: Authors' calculations.

In Bangladesh, age was significantly associated with women's empowerment. Table 10.1 shows that more than 40 percent of women aged 26 to 55 were empowered, compared to less than 33 percent of those in younger or older age categories. This may reflect the relative lack of power of younger females, who are typically daughters-in-law, and much older women, who may now be dependent on sons for support. This relationship was not significant among men.

In education, most of the women in the sample had completed either a primary education or less: only six women had a secondary education, and one had a tertiary education. Interesting to note, the relationship between education and empowerment in agriculture was insignificant for both men and women: 39 percent of women with less than a primary school education were empowered, and the same percentage of women who had completed primary school were empowered. Among the seven women who had attained a secondary school and higher education, only two women were empowered. So in this pilot area, women's empowerment in agriculture was not defined by whether they had completed primary school. 
Wealth was significantly associated with empowerment, but it was not sufficient to ensure it: 21 percent of women in the poorest quintile were empowered, compared to 50 percent in the richest 20 percent of the population. Fifty percent of women in the top wealth quintile were not yet empowered, indicating that greater wealth increases empowerment but does not guarantee it.

In Bangladesh, the relationship between empowerment in agriculture and living in a household reporting a higher hunger score was not statistically significant for women or men.

Results displayed in Table 10.2 show that women who were empowered by 5DE reported slightly higher decisionmaking and autonomy in all areas of decision considered, with the exception of decisionmaking regarding protection from violence. However, only a few of these relationships were statistically significant. So we found evidence that women who were empowered in agriculture reported (1) greater decisionmaking and autonomy about religious faith, (2) higher decisionmaking regarding family planning, and (3) higher autonomy in protection from violence. In decisionmaking regarding family planning the association was statistically significant at the 1 percent level: 73 percent of women who were empowered in agriculture felt they could make family planning decisions, compared to 61 percent of women who were not empowered in agriculture.

Table 10.2 - Tabulations between empowerment and answers to decisionmaking and autonomy questions-Bangladesh pilot

\begin{tabular}{|c|c|c|c|c|c|c|c|c|c|c|}
\hline \multirow[b]{2}{*}{$\begin{array}{l}\text { Decisionmaking and } \\
\text { autonomy questions }\end{array}$} & \multicolumn{2}{|c|}{ Empowered } & \multirow[b]{2}{*}{$\begin{array}{l}\text { Phi } \\
\text { coefficient }\end{array}$} & \multicolumn{2}{|c|}{ Pearson chi ${ }^{2}$} & \multirow[b]{2}{*}{$\begin{array}{c}\text { Fisher's exact } \\
\text { p-value }\end{array}$} & \multirow[b]{2}{*}{$\begin{array}{l}\text { t No. } \\
\text { obs. }\end{array}$} & \multicolumn{3}{|c|}{ Missing } \\
\hline & Yes & No & & Statistic & $\begin{array}{c}\mathrm{p}- \\
\text { value }\end{array}$ & & & Emp. & $\begin{array}{l}\text { Dec.I } \\
\text { Aut. }\end{array}$ & Both \\
\hline \multicolumn{11}{|c|}{ Percent of WOMEN who feel they can make decisions regarding } \\
\hline $\begin{array}{l}\text { Minor household } \\
\text { expenditures }\end{array}$ & 64.12 & 60.90 & 0.0323 & 0.46 & 0.500 & 0.544 & 436 & 14 & 0 & 0 \\
\hline Serious health problems & 55.88 & 52.26 & 0.0355 & 0.55 & 0.459 & 0.491 & 436 & 14 & 0 & 0 \\
\hline Protection from violence & 32.94 & 33.08 & 0.0014 & 0.00 & 0.976 & 1.000 & 436 & 14 & 0 & 0 \\
\hline Religious faith & 74.12 & 64.66 & 0.0992 & 4.29 & 0.038 & 0.045 & 436 & 14 & 0 & 0 \\
\hline Daily tasks & 83.53 & 79.70 & 0.0478 & 1.00 & 0.318 & 0.379 & 436 & 14 & 0 & 0 \\
\hline Family planning & 72.94 & 60.53 & 0.1273 & 7.06 & 0.008 & 0.010 & 436 & 14 & 0 & 0 \\
\hline \multicolumn{11}{|c|}{ Percent of WOMEN with RAl above 1 regarding } \\
\hline $\begin{array}{l}\text { Minor household } \\
\text { expenditures }\end{array}$ & 79.75 & 74.59 & 0.0598 & 1.46 & 0.227 & 0.235 & 407 & 13 & 29 & 1 \\
\hline Serious health problems & 76.79 & 72.98 & 0.0428 & 0.76 & 0.383 & 0.423 & 416 & 14 & 20 & 0 \\
\hline Protection from violence & 74.76 & 64.81 & 0.1045 & 2.89 & 0.089 & 0.103 & 265 & 9 & 171 & 5 \\
\hline Religious faith & 77.44 & 69.80 & 0.0842 & 2.90 & 0.088 & 0.091 & 409 & 14 & 27 & 0 \\
\hline Daily tasks & 78.92 & 74.13 & 0.0547 & 1.27 & 0.260 & 0.295 & 425 & 12 & 11 & 2 \\
\hline Family planning & 72.46 & 69.47 & 0.0324 & 0.35 & 0.557 & 0.623 & 328 & 10 & 108 & 4 \\
\hline \multicolumn{11}{|c|}{ Percent of MEN who feel they can make decisions regarding } \\
\hline $\begin{array}{l}\text { Minor household } \\
\text { expenditures }\end{array}$ & 68.38 & 68.81 & 0.0046 & 0.01 & 0.933 & 1.000 & 338 & 12 & 0 & 0 \\
\hline $\begin{array}{l}\text { Serious health } \\
\text { problems }\end{array}$ & 64.71 & 70.79 & 0.0642 & 1.39 & 0.238 & 0.283 & 338 & 12 & 0 & 0 \\
\hline $\begin{array}{l}\text { Protection from } \\
\text { violence }\end{array}$ & 58.82 & 66.34 & 0.0764 & 1.98 & 0.160 & 0.169 & 338 & 12 & 0 & 0 \\
\hline Religious faith & 82.35 & 83.17 & 0.0106 & 0.04 & 0.845 & 0.884 & 338 & 12 & 0 & 0 \\
\hline Daily tasks & 80.15 & 79.21 & 0.0114 & 0.04 & 0.834 & 0.891 & 338 & 12 & 0 & 0 \\
\hline Family planning & 55.88 & 50.99 & 0.0481 & 0.78 & 0.377 & 0.437 & 338 & 12 & 0 & 0 \\
\hline
\end{tabular}


Table 10.2-Continued

\begin{tabular}{|c|c|c|c|c|c|c|c|c|c|c|}
\hline \multirow[b]{2}{*}{$\begin{array}{l}\text { Decisionmaking and } \\
\text { autonomy questions }\end{array}$} & \multicolumn{2}{|c|}{ Empowered } & \multirow[b]{2}{*}{$\begin{array}{c}\text { Phi } \\
\text { coefficient }\end{array}$} & \multicolumn{2}{|c|}{ Pearson $\mathrm{chi}^{2}$} & \multirow[b]{2}{*}{$\begin{array}{c}\text { Fisher's exact } \\
\text { p-value }\end{array}$} & \multirow[b]{2}{*}{$\begin{array}{l}\text { No. } \\
\text { obs. }\end{array}$} & \multicolumn{3}{|c|}{ Missing } \\
\hline & Yes & No & & Statistic & $\begin{array}{c}p- \\
\text { value }\end{array}$ & & & Emp. & $\begin{array}{l}\text { Dec.I } \\
\text { Aut. }\end{array}$ & Both \\
\hline \multicolumn{11}{|c|}{ Percent of MEN with RAI above 1 regarding } \\
\hline $\begin{array}{l}\text { Minor household } \\
\text { expenditures }\end{array}$ & 90.84 & 85.64 & 0.0777 & 1.97 & 0.161 & 0.173 & 326 & 11 & 12 & 1 \\
\hline $\begin{array}{l}\text { Serious health } \\
\text { problems }\end{array}$ & 89.23 & 88.54 & 0.0107 & 0.04 & 0.847 & 1.000 & 322 & 12 & 16 & 0 \\
\hline $\begin{array}{l}\text { Protection from } \\
\text { violence }\end{array}$ & 91.51 & 86.71 & 0.0741 & 1.45 & 0.228 & 0.244 & 264 & 11 & 74 & 1 \\
\hline Religious faith & 86.26 & 85.42 & 0.0118 & 0.05 & 0.831 & 0.872 & 323 & 12 & 15 & 0 \\
\hline Daily tasks & 89.52 & 86.46 & 0.0454 & 0.65 & 0.420 & 0.486 & 316 & 11 & 22 & 1 \\
\hline Family planning & 83.49 & 84.00 & 0.0069 & 0.01 & 0.912 & 1.000 & 259 & 9 & 79 & 3 \\
\hline
\end{tabular}

Source: Author's calculations.

Notes: No. obs. = number of observations; Emp. Dec./Aut. = Empowered, Decisionmaking/Autonomy; RAI = Relative Autonomy Indicator.

It is curious that in Bangladesh men who were empowered in agriculture reported lower decisionmaking about minor household expenditures, health problems, protection from violence, and expression of religious faith. However, none of these relationships was statistically significant. In fact, there was no statistical evidence of a relationship between men's empowerment in agriculture and decisionmaking and autonomy in any of the areas considered.

\section{Western Highlands of Guatemala Pilot}

The tabulations between the condition of empowerment and age, education level, wealth quintile to which the household belongs, and household hunger score are displayed in Table 10.3.

Table 10.3 - Tabulations between empowerment and individual and household's characteristicsGuatemala pilot

\begin{tabular}{|c|c|c|c|c|c|c|}
\hline \multirow[b]{3}{*}{ Characteristics } & \multicolumn{6}{|c|}{ Empowered } \\
\hline & \multicolumn{3}{|c|}{ Women } & \multicolumn{3}{|c|}{ Men } \\
\hline & Yes & No & Missing & Yes & No & Missing \\
\hline \multicolumn{7}{|l|}{ Age group } \\
\hline $16-25$ & $\begin{array}{c}3 \\
9.38\end{array}$ & $\begin{array}{c}29 \\
90.63\end{array}$ & 19 & $\begin{array}{c}9 \\
64.29\end{array}$ & $\begin{array}{c}5 \\
35.71\end{array}$ & 7 \\
\hline $26-45$ & $\begin{array}{c}45 \\
36.89\end{array}$ & $\begin{array}{c}77 \\
63.11\end{array}$ & 54 & $\begin{array}{c}62 \\
57.94\end{array}$ & $\begin{array}{c}45 \\
42.06\end{array}$ & 41 \\
\hline $46-55$ & $\begin{array}{c}11 \\
28.95\end{array}$ & $\begin{array}{c}27 \\
71.05\end{array}$ & 22 & $\begin{array}{c}27 \\
72.97\end{array}$ & $\begin{array}{c}10 \\
27.03\end{array}$ & 12 \\
\hline $56-65$ & $\begin{array}{c}4 \\
14.29\end{array}$ & $\begin{array}{c}24 \\
85.71\end{array}$ & 11 & $\begin{array}{c}13 \\
56.52\end{array}$ & $\begin{array}{c}10 \\
43.48\end{array}$ & 12 \\
\hline$>65$ & $\begin{array}{c}5 \\
29.41\end{array}$ & $\begin{array}{c}12 \\
70.59\end{array}$ & 7 & $\begin{array}{c}9 \\
56.25\end{array}$ & $\begin{array}{c}7 \\
43.75\end{array}$ & 7 \\
\hline Total & $\begin{array}{c}68 \\
28.69\end{array}$ & $\begin{array}{c}169 \\
71.31\end{array}$ & 113 & $\begin{array}{c}120 \\
60.91\end{array}$ & $\begin{array}{c}77 \\
39.09\end{array}$ & 79 \\
\hline Cramer's V & 0.231 & & & 0.125 & & \\
\hline \multicolumn{2}{|c|}{ Pearson chi ${ }^{2}$ (statistic and $p$-value) } & 12.68 & 0.013 & 3.06 & 0.549 & \\
\hline
\end{tabular}


Table 10.3-Continued

\begin{tabular}{|c|c|c|c|c|c|c|}
\hline \multirow[b]{3}{*}{ Characteristics } & \multicolumn{6}{|c|}{ Empowered } \\
\hline & \multicolumn{3}{|c|}{ Women } & \multicolumn{3}{|c|}{ Men } \\
\hline & Yes & No & Missing & Yes & No & Missing \\
\hline Fisher's exact ( $p$-value) & & 0.009 & & & 0.540 & \\
\hline \multicolumn{7}{|l|}{ Education } \\
\hline \multirow[t]{2}{*}{ Less than primary } & 51 & 143 & 92 & 83 & 59 & 59 \\
\hline & 26.29 & 73.71 & & 58.45 & 41.55 & \\
\hline \multirow[t]{2}{*}{ Primary } & 10 & 16 & 18 & 28 & 15 & 17 \\
\hline & 38.46 & 61.54 & & 65.12 & 34.88 & \\
\hline \multirow[t]{2}{*}{ Secondary } & 1 & 0 & 0 & 1 & 0 & 0 \\
\hline & 100.00 & 0.00 & & 100.0 & 0.00 & \\
\hline University or above & 0 & 0 & 0 & 0 & 0 & 2 \\
\hline \multirow[t]{2}{*}{ Total } & 62 & 159 & 110 & 112 & 74 & 78 \\
\hline & 28.05 & 71.95 & & 60.22 & 39.78 & \\
\hline Missing information & 6 & 10 & 3 & 8 & 3 & 3 \\
\hline Cramer's V & 0.139 & & & 0.083 & & \\
\hline Pearson chi ${ }^{2}$ (statistic and p-value) & 4.259 & 0.119 & & 1.276 & 0.528 & \\
\hline Fisher's exact ( $p$-value) & & 0.112 & & & 0.687 & \\
\hline \multicolumn{7}{|l|}{ Wealth index } \\
\hline \multirow[t]{2}{*}{ 1st quintile } & 12 & 40 & 25 & 17 & 18 & 11 \\
\hline & 23.08 & 76.92 & & 48.57 & 51.43 & \\
\hline \multirow[t]{2}{*}{ 2nd quintile } & 12 & 31 & 19 & 24 & 13 & 21 \\
\hline & 27.91 & 72.09 & & 64.86 & 35.14 & \\
\hline \multirow[t]{2}{*}{ 3rd quintile } & 13 & 31 & 23 & 24 & 19 & 14 \\
\hline & 29.55 & 70.45 & & 55.81 & 44.19 & \\
\hline \multirow[t]{2}{*}{ 4th quintile } & 13 & 30 & 27 & 22 & 10 & 20 \\
\hline & 30.23 & 69.77 & & 68.75 & 31.25 & \\
\hline \multirow[t]{2}{*}{ 5th quintile } & 18 & 37 & 19 & 33 & 17 & 13 \\
\hline & 32.73 & 67.27 & & 66.00 & 34.00 & \\
\hline \multirow[t]{2}{*}{ Total } & 68 & 169 & 113 & 120 & 77 & 79 \\
\hline & 28.69 & 71.31 & & 60.91 & 39.09 & \\
\hline Cramer's V & 0.075 & & & 0.148 & & \\
\hline Pearson chi ${ }^{2}$ (statistic and p-value) & 1.32 & 0.858 & & 4.32 & 0.364 & \\
\hline Fisher's exact ( $p$-value) & & 0.855 & & & 0.376 & \\
\hline \multicolumn{7}{|l|}{ Household hunger score } \\
\hline \multirow[t]{2}{*}{ Little to no hunger } & 60 & 130 & 81 & 93 & 65 & 60 \\
\hline & 31.58 & 68.42 & & 58.86 & 41.14 & \\
\hline \multirow[t]{2}{*}{ Moderate hunger } & 6 & 32 & 24 & 21 & 10 & 14 \\
\hline & 15.79 & 84.21 & & 67.74 & 32.26 & \\
\hline \multirow[t]{2}{*}{ Severe hunger } & 0 & 5 & 6 & 3 & 1 & 5 \\
\hline & 0.00 & 100.00 & & 75.00 & 25.00 & \\
\hline \multirow[t]{2}{*}{ Total } & 66 & 167 & 111 & 117 & 76 & 79 \\
\hline & 28.33 & 71.67 & & 60.62 & 39.38 & \\
\hline Missing information & 2 & 2 & 2 & 3 & 1 & 0 \\
\hline Cramer's V & 0.159 & & & 0.079 & & \\
\hline Pearson chi ${ }^{2}$ (statistic and p-value) & 5.91 & 0.052 & & 1.21 & 0.546 & \\
\hline Fisher's exact ( $p$-value) & & 0.066 & & & 0.560 & \\
\hline
\end{tabular}

Source: Authors' calculations. 
In Guatemala, age was significantly associated with women's empowerment in agriculture. Only 9 percent of women younger than 26 and 14 percent of those between 56 and 65 years of age were empowered, compared to more than 28 percent in other age cohorts. In contrast, among males the levels of empowerment were constant across age categories.

At standard levels of significance, there was no evidence of an association between education and empowerment in Guatemala. Most of the women in the sample had less than a primary education. Only 26 percent of women with less than a primary school education and 39 percent of women who had completed primary school were empowered in agriculture. Among men, these percentages were 59 and 65 percent, respectively.

Wealth was not strongly associated with empowerment in agriculture in the Guatemala pilot regions: 23 percent of women in the poorest quintile were empowered, compared to 33 percent in the richest 20 percent of the population. It is striking that on average, 69 percent of women in the top three wealth quintiles were not yet empowered (including 67 percent of the richest 20 percent), indicating that wealth is an imperfect proxy for women's empowerment in agriculture. Indeed, the associations with wealth were not statistically significant.

The percentage of women not yet empowered in agriculture was higher in households reporting higher hunger scores, and this association was statistically significant. On the other hand, the percentage of men not yet empowered in agriculture was lower in households reporting higher hunger scores, but this association was not statistically significant.

Table 10.4 shows that in Guatemala, there was a clear association between women's empowerment in agriculture and empowerment in other domains: greater decisionmaking and autonomy about minor household expenditures, serious health problems, protection from violence, religious faith, their own daily tasks, and use of family planning. The variable "autonomy" showed greater differences between those who were empowered in agriculture and those who were not than the variable "decisionmaking." The differences in decisionmaking were not statistically significant, but the differences in autonomy in all the areas of decision were significant at the 1 percent level. For example, 94 percent of women who were empowered in agriculture felt they could make decisions related to minor household expenditures, compared to 86 percent of women who were not empowered. Differences in autonomy results were higher: 79 percent of women who were empowered reported autonomy with minor household expenditures, but only 51 percent of disempowered women reported this type of autonomy.

Table 10.4-Tabulations between empowerment and answers to decisionmaking and autonomy questions-Guatemala pilot

\begin{tabular}{|c|c|c|c|c|c|c|c|c|c|c|}
\hline \multirow[b]{2}{*}{$\begin{array}{l}\text { Decisionmaking and } \\
\text { autonomy questions }\end{array}$} & \multicolumn{2}{|c|}{ Empowered } & \multirow[b]{2}{*}{$\begin{array}{c}\text { Phi } \\
\text { coefficient }\end{array}$} & \multicolumn{2}{|c|}{ Pearson chi ${ }^{2}$} & \multirow{2}{*}{$\begin{array}{c}\text { Fisher's } \\
\text { exact p- } \\
\text { value }\end{array}$} & \multirow[b]{2}{*}{$\begin{array}{l}\text { No. } \\
\text { obs. }\end{array}$} & \multicolumn{3}{|c|}{$\begin{array}{c}\text { Missing } \\
\text { information }\end{array}$} \\
\hline & Yes & No & & Statistic & $\begin{array}{c}\mathrm{p}- \\
\text { value }\end{array}$ & & & Emp. & $\begin{array}{l}\text { Dec.I } \\
\text { Aut. }\end{array}$ & Both \\
\hline \multicolumn{11}{|c|}{ Percent of WOMEN who feel they can make decisions regarding } \\
\hline $\begin{array}{l}\text { Minor household } \\
\text { expenditures }\end{array}$ & 93.75 & 85.80 & 0.1104 & 2.75 & 0.097 & 0.114 & 226 & 86 & 11 & 27 \\
\hline Serious health problems & 82.09 & 74.23 & 0.0842 & 1.63 & 0.202 & 0.233 & 230 & 103 & 7 & 10 \\
\hline Protection from violence & 81.54 & 78.53 & 0.0336 & 0.26 & 0.612 & 0.718 & 228 & 99 & 9 & 14 \\
\hline Religious faith & 87.88 & 83.13 & 0.0591 & 0.81 & 0.368 & 0.427 & 232 & 97 & 5 & 16 \\
\hline Daily tasks & 89.23 & 85.19 & 0.0533 & 0.64 & 0.422 & 0.524 & 227 & 100 & 10 & 13 \\
\hline Family planning & 86.00 & 77.78 & 0.0913 & 1.54 & 0.214 & 0.301 & 185 & 85 & 52 & 28 \\
\hline
\end{tabular}


Table 10.4-Continued

\begin{tabular}{|c|c|c|c|c|c|c|c|c|c|c|}
\hline \multirow[b]{2}{*}{$\begin{array}{l}\text { Decisionmaking and } \\
\text { autonomy questions }\end{array}$} & \multicolumn{2}{|c|}{ Empowered } & \multirow[b]{2}{*}{$\begin{array}{c}\text { Phi } \\
\text { coefficient }\end{array}$} & \multicolumn{2}{|c|}{ Pearson chi $^{2}$} & \multirow{2}{*}{$\begin{array}{c}\text { Fisher's } \\
\text { exact } p- \\
\text { value }\end{array}$} & \multirow[b]{2}{*}{$\begin{array}{l}\text { No. } \\
\text { obs. }\end{array}$} & \multicolumn{3}{|c|}{ Missing information } \\
\hline & Yes & No & & Statistic & $\begin{array}{c}\mathrm{p}- \\
\text { value }\end{array}$ & & & Emp. & $\begin{array}{l}\text { Dec.I } \\
\text { Aut. }\end{array}$ & Both \\
\hline \multicolumn{11}{|c|}{ Percent of WOMEN with RAI above 1 regarding } \\
\hline $\begin{array}{l}\text { Minor household } \\
\text { expenditures }\end{array}$ & 79.37 & 50.63 & 0.2636 & 15.35 & 0.000 & 0.000 & 221 & 91 & 16 & 22 \\
\hline Serious health problems & 75.76 & 50.00 & 0.2356 & 12.77 & 0.000 & 0.000 & 230 & 104 & 7 & 9 \\
\hline Protection from violence & 77.27 & 46.39 & 0.2802 & 18.22 & 0.000 & 0.000 & 232 & 98 & 5 & 15 \\
\hline Religious faith & 69.70 & 38.69 & 0.2794 & 18.27 & 0.000 & 0.000 & 234 & 102 & 3 & 11 \\
\hline Daily tasks & 79.10 & 46.34 & 0.2994 & 20.71 & 0.000 & 0.000 & 231 & 102 & 6 & 11 \\
\hline Family planning & 76.00 & 47.06 & 0.2578 & 12.36 & 0.000 & 0.000 & 186 & 88 & 51 & 25 \\
\hline \multicolumn{11}{|c|}{ Percent of MEN who feel they can make decisions regarding } \\
\hline $\begin{array}{l}\text { Minor household } \\
\text { expenditures }\end{array}$ & 84.35 & 78.87 & 0.0696 & 0.90 & 0.342 & 0.430 & 186 & 71 & 11 & 8 \\
\hline Serious health problems & 84.87 & 89.33 & 0.0637 & 0.79 & 0.375 & 0.517 & 194 & 75 & 3 & 4 \\
\hline Protection from violence & 99.17 & 93.42 & 0.1625 & 5.18 & 0.023 & 0.033 & 196 & 71 & 1 & 8 \\
\hline Religious faith & 93.22 & 94.81 & 0.0322 & 0.20 & 0.653 & 0.767 & 195 & 71 & 2 & 8 \\
\hline Daily tasks & 98.31 & 94.81 & 0.0991 & 1.91 & 0.167 & 0.215 & 195 & 72 & 2 & 7 \\
\hline Family planning & 84.26 & 94.20 & 0.1500 & 3.98 & 0.046 & 0.057 & 177 & 66 & 20 & 13 \\
\hline \multicolumn{11}{|c|}{ Percent of MEN with RAl above 1 regarding } \\
\hline $\begin{array}{l}\text { Minor household } \\
\text { expenditures }\end{array}$ & 65.52 & 39.44 & 0.2548 & 12.14 & 0.000 & 0.001 & 187 & 69 & 10 & 10 \\
\hline Serious health problems & 63.87 & 42.67 & 0.2078 & 8.38 & 0.004 & 0.005 & 194 & 72 & 3 & 7 \\
\hline Protection from violence & 63.03 & 43.42 & 0.1923 & 7.21 & 0.007 & 0.008 & 195 & 73 & 2 & 6 \\
\hline Religious faith & 63.87 & 36.36 & 0.2691 & 14.20 & 0.000 & 0.000 & 196 & 71 & 1 & 8 \\
\hline Daily tasks & 65.00 & 36.84 & 0.2753 & 14.86 & 0.000 & 0.000 & 196 & 73 & 1 & 6 \\
\hline Family planning & 64.81 & 39.06 & 0.2503 & 10.78 & 0.001 & 0.001 & 172 & 65 & 25 & 14 \\
\hline
\end{tabular}

Source: Authors' calculations.

Notes: No. obs. = number of observations; Emp. Dec./Aut. = Empowered, Decisionmaking/Autonomy; RAI = Relative Autonomy Indicator.

In the Guatemala pilot, men who were empowered reported significantly higher autonomy in all areas of decision considered. On the other hand, there was statistical evidence that men who were empowered in agriculture reported significantly lower decisionmaking about family planning.

\section{Uganda Pilot}

The tabulations between the condition of empowerment and age, education level, wealth quintile to which the household belongs, and household hunger score are displayed in Table 10.5. 
Table 10.5 - Tabulations between empowerment and individual and household characteristicsUganda pilot

\begin{tabular}{|c|c|c|c|c|c|c|}
\hline \multirow[b]{3}{*}{ Characteristics } & \multicolumn{6}{|c|}{ Empowered } \\
\hline & \multicolumn{3}{|c|}{ Women } & \multicolumn{2}{|c|}{ Men } & \multirow[b]{2}{*}{ Missing } \\
\hline & Yes & No & Missing & Yes & No & \\
\hline \multicolumn{7}{|l|}{ Age group } \\
\hline $16-25$ & $\begin{array}{c}15 \\
31.91\end{array}$ & $\begin{array}{c}32 \\
68.09\end{array}$ & 2 & $\begin{array}{c}13 \\
40.63\end{array}$ & $\begin{array}{c}19 \\
59.38\end{array}$ & 3 \\
\hline $26-45$ & $\begin{array}{c}67 \\
42.95\end{array}$ & $\begin{array}{c}89 \\
57.05\end{array}$ & 7 & $\begin{array}{c}83 \\
64.84\end{array}$ & $\begin{array}{c}45 \\
35.16\end{array}$ & 7 \\
\hline $46-55$ & $\begin{array}{c}31 \\
56.36\end{array}$ & $\begin{array}{c}24 \\
43.64\end{array}$ & 1 & $\begin{array}{c}27 \\
71.05\end{array}$ & $\begin{array}{c}11 \\
28.95\end{array}$ & 1 \\
\hline $56-65$ & $\begin{array}{c}19 \\
45.24\end{array}$ & $\begin{array}{c}23 \\
54.76\end{array}$ & 2 & $\begin{array}{c}26 \\
66.67\end{array}$ & $\begin{array}{c}13 \\
33.33\end{array}$ & 0 \\
\hline$>65$ & $\begin{array}{c}13 \\
37.14\end{array}$ & $\begin{array}{c}22 \\
62.86\end{array}$ & 3 & $\begin{array}{c}16 \\
64.00\end{array}$ & $\begin{array}{c}9 \\
36.00\end{array}$ & 2 \\
\hline Total & $\begin{array}{c}145 \\
43.28\end{array}$ & $\begin{array}{c}190 \\
56.72\end{array}$ & 15 & $\begin{array}{c}165 \\
62.98\end{array}$ & $\begin{array}{c}97 \\
37.02\end{array}$ & 13 \\
\hline Cramer's V & 0.144 & & & 0.179 & & \\
\hline $\begin{array}{l}\text { Pearson chi }{ }^{2} \text { (statistic } \\
\text { and p-value) }\end{array}$ & 6.96 & 0.138 & & 8.09 & 0.088 & \\
\hline Fisher's exact ( $p$-value) & & 0.143 & & & 0.091 & \\
\hline \multicolumn{7}{|l|}{ Education } \\
\hline Less than primary & $\begin{array}{c}97 \\
40.08\end{array}$ & $\begin{array}{c}145 \\
59.92\end{array}$ & 12 & $\begin{array}{c}70 \\
55.12\end{array}$ & $\begin{array}{c}57 \\
44.88\end{array}$ & 5 \\
\hline Primary & $\begin{array}{c}46 \\
51.69\end{array}$ & $\begin{array}{c}43 \\
48.31\end{array}$ & 3 & $\begin{array}{c}82 \\
68.91\end{array}$ & $\begin{array}{c}37 \\
31.09\end{array}$ & 6 \\
\hline Secondary & $\begin{array}{c}0 \\
0.00\end{array}$ & $\begin{array}{c}0 \\
0.00\end{array}$ & 0 & $\begin{array}{c}5 \\
71.43\end{array}$ & $\begin{array}{c}2 \\
28.57\end{array}$ & 1 \\
\hline University or above & $\begin{array}{c}1 \\
100.00\end{array}$ & $\begin{array}{c}0 \\
0.00\end{array}$ & 0 & $\begin{array}{c}5 \\
83.33\end{array}$ & $\begin{array}{c}1 \\
16.67\end{array}$ & 1 \\
\hline Technical or vocation & $\begin{array}{c}1 \\
100.00\end{array}$ & $\begin{array}{c}0 \\
0.00\end{array}$ & 0 & $\begin{array}{c}3 \\
100.0\end{array}$ & $\begin{array}{c}0 \\
0.00\end{array}$ & 0 \\
\hline Total & $\begin{array}{c}145 \\
43.54\end{array}$ & $\begin{array}{c}188 \\
56.46\end{array}$ & 15 & $\begin{array}{c}165 \\
62.98\end{array}$ & $\begin{array}{c}97 \\
37.02\end{array}$ & 13 \\
\hline Missing information & 0 & 2 & 0 & 0 & 0 & 0 \\
\hline Cramer's V & 0.136 & & & 0.177 & & \\
\hline $\begin{array}{l}\text { Pearson chi }{ }^{2} \text { (statistic } \\
\text { and p-value) }\end{array}$ & 6.172 & 0.104 & & 8.204 & 0.084 & \\
\hline Fisher's exact ( $p$-value) & & 0.045 & & & 0.089 & \\
\hline
\end{tabular}


Table 10.5-Continued

\begin{tabular}{|c|c|c|c|c|c|c|}
\hline \multirow[b]{3}{*}{ Characteristics } & \multicolumn{6}{|c|}{ Empowered } \\
\hline & \multicolumn{3}{|c|}{ Women } & \multicolumn{3}{|c|}{ Men } \\
\hline & Yes & No & Missing & Yes & No & Missing \\
\hline \multicolumn{7}{|l|}{ Wealth index } \\
\hline 1st quintile & $\begin{array}{c}22 \\
31.43\end{array}$ & $\begin{array}{c}48 \\
68.57\end{array}$ & 3 & $\begin{array}{c}32 \\
65.31\end{array}$ & $\begin{array}{c}17 \\
34.69\end{array}$ & 1 \\
\hline 2nd quintile & $\begin{array}{c}24 \\
35.82\end{array}$ & $\begin{array}{c}43 \\
64.18\end{array}$ & 3 & $\begin{array}{c}31 \\
63.27\end{array}$ & $\begin{array}{c}18 \\
36.73\end{array}$ & 4 \\
\hline 3rd quintile & $\begin{array}{c}22 \\
35.48\end{array}$ & $\begin{array}{c}40 \\
64.52\end{array}$ & 3 & $\begin{array}{c}32 \\
56.14\end{array}$ & $\begin{array}{c}25 \\
43.86\end{array}$ & 2 \\
\hline 4th quintile & $\begin{array}{c}30 \\
44.78\end{array}$ & $\begin{array}{c}37 \\
55.22\end{array}$ & 4 & $\begin{array}{c}28 \\
58.33\end{array}$ & $\begin{array}{c}20 \\
41.67\end{array}$ & 3 \\
\hline 5th quintile & $\begin{array}{c}47 \\
68.12\end{array}$ & $\begin{array}{c}22 \\
31.88\end{array}$ & 2 & $\begin{array}{c}42 \\
71.19\end{array}$ & $\begin{array}{c}17 \\
28.81\end{array}$ & 3 \\
\hline Total & $\begin{array}{c}145 \\
43.28\end{array}$ & $\begin{array}{c}190 \\
56.72\end{array}$ & 15 & $\begin{array}{c}165 \\
62.98\end{array}$ & $\begin{array}{c}97 \\
37.02\end{array}$ & 13 \\
\hline Cramer's V & 0.270 & & & 0.114 & & \\
\hline $\begin{array}{l}\text { Pearson chi }{ }^{2} \text { (statistic } \\
\text { and p-value) }\end{array}$ & 24.46 & 0.000 & & 3.41 & 0.492 & \\
\hline Fisher's exact ( $p$-value) & & 0.000 & & & 0.493 & \\
\hline \multicolumn{7}{|l|}{ Household hunger score } \\
\hline Little to no hunger & $\begin{array}{c}123 \\
48.81\end{array}$ & $\begin{array}{c}129 \\
51.19\end{array}$ & 12 & $\begin{array}{c}136 \\
65.70\end{array}$ & $\begin{array}{c}71 \\
34.30\end{array}$ & 13 \\
\hline Moderate hunger & $\begin{array}{c}17 \\
29.82\end{array}$ & $\begin{array}{c}40 \\
70.18\end{array}$ & 3 & $\begin{array}{c}20 \\
54.05\end{array}$ & $\begin{array}{c}17 \\
45.95\end{array}$ & 0 \\
\hline Severe hunger & $\begin{array}{c}5 \\
21.74\end{array}$ & $\begin{array}{c}18 \\
78.26\end{array}$ & 0 & $\begin{array}{c}6 \\
40.00\end{array}$ & $\begin{array}{c}9 \\
60.00\end{array}$ & 0 \\
\hline Total & $\begin{array}{c}145 \\
43.67\end{array}$ & $\begin{array}{c}187 \\
56.33\end{array}$ & 15 & $\begin{array}{c}162 \\
62.55\end{array}$ & $\begin{array}{c}97 \\
37.45\end{array}$ & 13 \\
\hline Missing information & 0 & 3 & 0 & 3 & 0 & 0 \\
\hline Cramer's V & 0.187 & & & 0.143 & & \\
\hline $\begin{array}{l}\text { Pearson chi }{ }^{2} \text { (statistic } \\
\text { and p-value) }\end{array}$ & 11.64 & 0.003 & & 5.27 & 0.072 & \\
\hline Fisher's exact ( $p$-value) & & 0.003 & & & 0.072 & \\
\hline
\end{tabular}

Source: Authors' calculations.

In Uganda, there was no evidence of an association between age and women's empowerment in agriculture. In contrast, the association between age and rates of empowerment among males was significant at the 10 percent level. Forty-one percent of men younger than 26 were empowered, compared to 71 percent of those between 46 and 65 years of age and 67 percent of those between 56 and 65 years of age.

There was a positive and significant association between education level and women's and men's empowerment. Forty percent of women with less than a primary school education were empowered; this increased to 52 percent among those who had completed primary school. Fifty-five percent of men with less than a primary school education were empowered, compared to 69 percent of those who had completed primary school. 
In Uganda's pilot regions, wealth was clearly associated with women's empowerment in agriculture: 31 percent of women in the poorest quintile were empowered, compared to 68 percent in the richest 20 percent of the population. In the second and third quintiles, around 35 percent of women were empowered in agriculture, rising to 45 percent in the fourth quintile and 68 percent in the fifth. In contrast, among males the levels of empowerment were constant across wealth quintiles. The percentage of men empowered in agriculture was 65 among those living in households in the poorest quintile and 71 among those living in households in the richest quintile.

The percentage of disempowered women and men was significantly higher in households reporting higher hunger scores.

Table 10.6 shows that in Uganda's pilot districts, women who were empowered in agriculture reported significantly greater decisionmaking and autonomy about almost all domains. Similar to the data from Guatemala, the variable autonomy tended to show even greater differences between those who were empowered in agriculture and those who were not than the variable decisionmaking. For example, 87 percent of women who were empowered in agriculture felt they could make decisions related to serious health problems, compared to 75 percent among women who were not empowered in agriculture. The difference in autonomy results was wider: 80 percent of women who were empowered in agriculture reported autonomy about serious health problems, but only 63 percent of disempowered women reported this type of autonomy. Men who were empowered also reported significantly greater decisionmaking and autonomy about most of the areas considered.

Table 10.6 - Tabulations between empowerment and answers to decisionmaking questionsUganda pilot

\begin{tabular}{|c|c|c|c|c|c|c|c|c|c|c|}
\hline \multirow[b]{2}{*}{$\begin{array}{l}\text { Decisionmaking and } \\
\text { autonomy questions }\end{array}$} & \multicolumn{2}{|c|}{ Empowered } & \multirow[b]{2}{*}{$\begin{array}{c}\text { Phi } \\
\text { coefficient }\end{array}$} & \multicolumn{2}{|c|}{ Pearson chi $^{2}$} & \multirow[b]{2}{*}{$\begin{array}{c}\text { Fisher's exact } \\
\text { p-value }\end{array}$} & \multirow[b]{2}{*}{$\begin{array}{l}\text { No. } \\
\text { obs. }\end{array}$} & \multicolumn{3}{|c|}{ Missing } \\
\hline & Yes & No & & Statistic & $\begin{array}{c}\mathrm{p}- \\
\text { value }\end{array}$ & & & Emp. & $\begin{array}{l}\text { Dec.l } \\
\text { Aut. }\end{array}$ & Both \\
\hline \multicolumn{11}{|c|}{ Percent of WOMEN who feel they can make decisions regarding } \\
\hline $\begin{array}{l}\text { Minor household } \\
\text { expenditures }\end{array}$ & 85.52 & 81.91 & 0.0481 & 0.77 & 0.380 & 0.457 & 333 & 11 & 2 & 4 \\
\hline Serious health problems & 86.90 & 75.40 & 0.1437 & 6.85 & 0.009 & 0.012 & 332 & 9 & 3 & 6 \\
\hline Protection from violence & 94.78 & 82.93 & 0.1784 & 8.88 & 0.003 & 0.003 & 279 & 8 & 56 & 7 \\
\hline Religious faith & 95.83 & 87.37 & 0.1466 & 7.18 & 0.007 & 0.007 & 334 & 10 & 1 & 5 \\
\hline Daily tasks & 100.00 & 94.12 & 0.1630 & 8.82 & 0.003 & 0.003 & 332 & 10 & 3 & 5 \\
\hline Family planning & 84.48 & 70.27 & 0.1664 & 3.66 & 0.056 & 0.065 & 132 & 5 & 203 & 10 \\
\hline \multicolumn{11}{|c|}{ Percent of WOMEN with RAl above 1 regarding } \\
\hline $\begin{array}{l}\text { Minor household } \\
\text { expenditures }\end{array}$ & 78.47 & 65.78 & 0.1391 & 6.41 & 0.011 & 0.014 & 331 & 11 & 4 & 4 \\
\hline Serious health problems & 80.00 & 62.96 & 0.1849 & 11.42 & 0.001 & 0.001 & 334 & 11 & 1 & 4 \\
\hline Protection from violence & 72.13 & 59.15 & 0.1344 & 5.16 & 0.023 & 0.025 & 286 & 10 & 49 & 5 \\
\hline Religious faith & 79.31 & 64.55 & 0.1612 & 8.67 & 0.003 & 0.004 & 334 & 11 & 1 & 4 \\
\hline Daily tasks & 80.69 & 70.05 & 0.1213 & 4.89 & 0.027 & 0.031 & 332 & 11 & 3 & 4 \\
\hline Family planning & 78.18 & 69.86 & 0.0932 & 1.11 & 0.291 & 0.319 & 128 & 4 & 207 & 11 \\
\hline \multicolumn{11}{|c|}{ Percent of MEN who feel they can make decisions regarding } \\
\hline $\begin{array}{l}\text { Minor household } \\
\text { expenditures }\end{array}$ & 78.18 & 71.88 & 0.0711 & 1.32 & 0.251 & 0.294 & 261 & 9 & 1 & 4 \\
\hline Serious health problems & 95.65 & 87.63 & 0.1488 & 5.71 & 0.017 & 0.025 & 258 & 12 & 4 & 1 \\
\hline Protection from violence & 98.16 & 87.50 & 0.2204 & 12.58 & 0.000 & 0.001 & 259 & 12 & 3 & 1 \\
\hline Religious faith & 96.93 & 90.72 & 0.1331 & 4.60 & 0.032 & 0.045 & 260 & 12 & 2 & 1 \\
\hline Daily tasks & 95.73 & 89.47 & 0.1218 & 3.84 & 0.050 & 0.067 & 259 & 12 & 3 & 1 \\
\hline Family planning & 81.91 & 86.67 & 0.0598 & 0.50 & 0.481 & 0.627 & 139 & 4 & 123 & 9 \\
\hline
\end{tabular}


Table 10.6-Continued

\begin{tabular}{|c|c|c|c|c|c|c|c|c|c|c|}
\hline \multirow[b]{2}{*}{$\begin{array}{l}\text { Decisionmaking and } \\
\text { autonomy questions }\end{array}$} & \multicolumn{2}{|c|}{ Empowered } & \multirow[b]{2}{*}{$\begin{array}{c}\text { Phi } \\
\text { coefficient }\end{array}$} & \multicolumn{2}{|c|}{ Pearson $\mathrm{chi}^{2}$} & \multirow[b]{2}{*}{$\begin{array}{c}\text { Fisher's exact } \\
\text { p-value }\end{array}$} & \multirow[b]{2}{*}{$\begin{array}{l}\text { No. } \\
\text { obs. }\end{array}$} & \multicolumn{3}{|c|}{ Missing } \\
\hline & Yes & No & & Statistic & $\begin{array}{c}\mathrm{p}- \\
\text { value }\end{array}$ & & & Emp. & $\begin{array}{l}\text { Dec.I } \\
\text { Aut. }\end{array}$ & Both \\
\hline \multicolumn{11}{|c|}{ Percent of MEN with RAI above 1 regarding } \\
\hline $\begin{array}{l}\text { Minor household } \\
\text { expenditures }\end{array}$ & 43.04 & 31.18 & 0.1176 & 3.47 & 0.062 & 0.081 & 251 & 9 & 11 & 4 \\
\hline Serious health problems & 41.36 & 29.47 & 0.1188 & 3.63 & 0.057 & 0.062 & 257 & 11 & 5 & 2 \\
\hline Protection from violence & 42.86 & 33.33 & 0.0943 & 2.29 & 0.130 & 0.147 & 257 & 11 & 5 & 2 \\
\hline Religious faith & 38.13 & 28.13 & 0.1019 & 2.66 & 0.103 & 0.135 & 256 & 11 & 6 & 2 \\
\hline Daily tasks & 42.86 & 27.66 & 0.1516 & 5.86 & 0.015 & 0.016 & 255 & 11 & 7 & 2 \\
\hline Family planning & 50.00 & 35.56 & 0.1368 & 2.53 & 0.112 & 0.143 & 135 & 4 & 127 & 9 \\
\hline
\end{tabular}

Source: Authors' calculations.

Notes: No. obs. = number of observations; Emp. Dec./Aut. = Empowered, Decisionmaking/Autonomy; RAI = Relative Autonomy Indicator.

In summary, there is no individual or household characteristic that is strongly associated (Cramer's V or phi coefficient greater than 0.15) with empowerment in the pilot areas of all three countries simultaneously. This exposes the weakness of some traditional proxies for women's empowerment including educational achievements and wealth in reflecting women's empowerment in agriculture. This lack of strong correlation across all three countries may arise because gender and empowerment are both culture and context-specific. For example, the low correlation between education and women's empowerment in Bangladesh may arise because agriculture is conceived of as a man's domain, and a woman, even if highly educated, may not participate much in agricultural decisions. In other cultures, she may have more scope for using her human capital to participate in agricultural decisions. These findings, of course, are based on only the three pilot countries, and further work needs to be undertaken in other countries to see whether these results can be generalized. 


\section{INTRAHOUSEHOLD PATTERNS OF EMPOWERMENT}

The richness of the intrahousehold data enables many further comparisons of women and men that were not possible previously. Recall that the 5DE values for Bangladesh, Uganda, and Guatemala pilot regions differ: In Uganda women have the highest 5DE score whereas in Guatemala it is men; among women $5 \mathrm{DE}$ is lowest in Guatemala whereas for men it is lowest in Bangladesh. In absolute terms, the lowest male 5DE of 0.77 (Bangladesh) is only marginally lower than the highest 5DE for women $(0.78$, in Uganda).

Across the pilot regions (which, recall, are not representative of the countries), gender parity is highest in the Bangladesh pilot and lowest in Guatemala. In Bangladesh, though, although the share of women enjoying parity with the primary males in their households is highest (at 59.8 percent), in the households that lack parity, the gap is 25.2 percent. In contrast, in Uganda a lower percentage of women enjoy parity (54.4 percent), but in households lacking parity, the gap is lower (22.4 percent). In Guatemala both indicators are worse, with only 35.8 percent of women enjoying parity and the remainder having the highest gap, at 29.1 percent.

Table 11.1 shows the intrahousehold patterns of 5DE. We see that the two extreme experiences are in Bangladesh and Guatemala. In Guatemala's pilot region, nearly 37 percent of households have a disempowered woman and an empowered man, and only 7 percent have the reverse. In contrast, in Bangladesh 17 percent of households have a woman who is disempowered and a man who is empowered, whereas almost 21 percent have it the other way around, with a situation more favorable to the woman than to the man. Thus, it is very useful to consider the intrahousehold patterns by gender as these evolve over time.

Table 11.1-Empowerment patterns, by household

\begin{tabular}{lccc}
\hline Household characteristic & Bangladesh Pilot & Uganda Pilot & Guatemala Pilot \\
\hline Households containing a woman and a man & 331 & 250 & 187 \\
Both woman and man are empowered & 74 & 69 & 38 \\
& $22.4 \%$ & $27.6 \%$ & $20.3 \%$ \\
Both woman and man are disempowered & 131 & 57 & 67 \\
& $39.6 \%$ & $22.8 \%$ & $35.8 \%$ \\
The woman is disempowered; the man is empowered & 57 & 90 & 69 \\
& $17.2 \%$ & $36.0 \%$ & $36.9 \%$ \\
The man is disempowered; the woman is empowered & 69 & 34 & 13 \\
& $20.8 \%$ & $13.6 \%$ & $7.0 \%$ \\
\hline
\end{tabular}

Source: Authors' computations. 


\section{NEXT STEPS}

Women's empowerment is a complex and multidimensional concept. That complexity has limited efforts to measure empowerment and incorporate it into program evaluation in a systematic manner, despite growing evidence of the important role that women's empowerment plays in poverty reduction. The few gender equity or women's empowerment measures that do exist do not address the issues most relevant for women in agriculture.

The WEAI offers a means to measure women's empowerment in a manner that is comparable across sites and relevant to agriculture. Based on intrahousehold surveys, it represents a compromise between the level of detail that might be desirable and the information that can be collected in a relatively succinct and replicable manner (that is, not based on detailed ethnographic methods or very long surveys and avoiding questions that yield too many missing values). It is not a perfect measure: as discussed above, there are limitations in several of the indicators used in the pilot survey, notably

- women who are engaged in decisionmaking on nonagricultural activities may appear disempowered if they are not involved in agricultural decisions;

- questions about control over resources and income do not capture many of the nuances behind these domains;

- the prevalence of decisionmaking questions mean that female-only households are likely to be empowered (although there may be others, such as parents, in-laws, or children with whom such women also need to negotiate);

- group membership alone is an inadequate indicator of active participation (but more detailed indicators left too many missing values);

- the relative autonomy questions in the pilot were problematic in two pilots, so training materials have been provided and an alternative form of the questions has been provided;

- 24-hour recall of time use does not capture the seasonality of agriculture unless it is administered in repeated surveys during an agricultural year; and

- the satisfaction with leisure question is subjective and may reflect adaptive preferences - that is, women may be more satisfied with their leisure than are men because their expectations have adapted to what is possible in their circumstances.

Despite these limitations, the pilot studies in Bangladesh, Guatemala, and Uganda indicate that WEAI indicators are relatively robust. The next step of testing their applicability has already begun as part of monitoring and evaluation in the Feed the Future zones of influence in 19 countries. Although the WEAI is designed to be comparable across countries, caution is in order regarding comparisons that might be made across these countries because the zones of influence are not nationally representative areas and hence women's status may be different in those zones than nationally. Tracking changes over time, particularly for the same individuals and households, to see whether there is an improvement or deterioration of women's status in agriculture is likely to be a more important use than cross-national comparison. However, it would be useful to find opportunities to build the WEAI into nationally representative datasets as well.

Other organizations, such as civil society organizations implementing interventions to empower women, as well as some multilateral organizations, have expressed interest in using the WEAI in their work, and this is welcome. A number have also asked whether the index could be modified in various ways. Although some adaptation of the questionnaire may be needed to fit local conditions, the WEAI should be computed from the same set of indicators, based on an intrahousehold survey that asks questions separately of the principal female and principal male in the household (so that the GPI can be computed). Adding questions related to other areas of empowerment (for example, healthcare and other 
decisions) would be welcome, especially for those organizations that are dealing with broader aspects of women's empowerment besides agriculture. Initially, it would be preferable to compare results of these different types of empowerment or, if they are to be added to the WEAI, to indicate this with a new name. As with other indexes, further refinement of the WEAI is possible as it is updated. Perhaps the greatest contribution of the WEAI may be to define and highlight the domains of empowerment and how multidimensional indices can be used to provide an overall analysis of women's empowerment so that agricultural development programs address all domains. Ex ante assessments of programs should, at a minimum, ensure that interventions do no harm, such as by increasing women's workloads or transferring decisionmaking or control of income from women to men. Baseline WEAI estimates can further serve as a diagnostic tool to signal key areas for interventions to increase empowerment and gender parity. As illustrated in the pilot study results, the areas of disempowerment of women (and men) differ from country to country; WEAI measures can help to identify who are the key decisionmakers in different types of production and whether the greatest needs are for resources, credit, leadership, or time. 


\section{APPENDIX-SUPPLEMENTARY TABLE}

Table A.1-Five domains of empowerment indicator definitions

\begin{tabular}{|c|c|c|c|c|c|c|c|}
\hline Dimension & $\begin{array}{l}\text { Indicator } \\
\text { name }\end{array}$ & Survey questions & Variable(s) & $\begin{array}{l}\text { Aggregation } \\
\text { method }\end{array}$ & Deprivation cut-off & $\begin{array}{c}\text { Deprivation cut-off } \\
\text { definition }\end{array}$ & Weight \\
\hline \multirow[t]{4}{*}{ Production } & $\begin{array}{l}\text { Input in } \\
\text { productive } \\
\text { decisions }\end{array}$ & $\begin{array}{l}\text { How much input did you have in making decisions } \\
\text { about food crop farming, cash crop farming, livestock } \\
\text { raising, and fish culture? To what extent do you feel you } \\
\text { can make your own personal decisions regarding these } \\
\text { aspects of household life if you want(ed) to: agriculture } \\
\text { production, which inputs to buy, which types of crops to } \\
\text { grow for agricultural production, when to take or who } \\
\text { should take crops to market, and livestock raising? }\end{array}$ & $\begin{array}{l}\text { B02 1-3,6 } \\
\text { G02 A-E }\end{array}$ & $\begin{array}{l}\text { Achievement in } \\
\text { two }\end{array}$ & $\begin{array}{l}\text { Inadequate if individual } \\
\text { participates but does } \\
\text { not/has not at least } \\
\text { some input in decisions } \\
\text { or does not make } \\
\text { decisions nor feels he or } \\
\text { she could }\end{array}$ & $\begin{array}{l}B 01==1 \& B 02==1 \\
((G 01 !=1 \& A 05==1) \\
\&(G 01 !=2 \& \\
A 05==2)) \& G 02==1\end{array}$ & 0.10 \\
\hline & $\begin{array}{l}\text { Autonomy in } \\
\text { production }\end{array}$ & $\begin{array}{l}\text { My actions in [domain] are partly because I will get in } \\
\text { trouble with someone if I act differently. Regarding } \\
\text { [domain] I do what I do so others don't think poorly of } \\
\text { me. }\end{array}$ & $\begin{array}{l}\text { G03-G05 } \\
\text { A-E }\end{array}$ & $\begin{array}{l}\text { Achievement in } \\
\text { any }\end{array}$ & $\begin{array}{l}\text { Inadequate if Relative } \\
\text { Autonomy Indicator is } \\
\text { less than } 1\end{array}$ & & 0.10 \\
\hline & & $\begin{array}{l}\text { Regarding [domain] I do what I do because I personally } \\
\text { think it is the right thing to do. }\end{array}$ & & & & & \\
\hline & & $\begin{array}{l}\text { Agricultural production, inputs to buy, crops to grow, } \\
\text { take to market, livestock. }\end{array}$ & & & & & \\
\hline \multirow[t]{3}{*}{ Resources } & $\begin{array}{l}\text { Ownership } \\
\text { of assets }\end{array}$ & $\begin{array}{l}\text { Who would you say can use the [item] most of the time? } \\
\text { Agricultural land, large livestock, small livestock, } \\
\text { chickens and so on; fishpond/equipment; farm } \\
\text { equipment (nonmechanized); farm equipment } \\
\text { (mechanized); nonfarm business equipment, house; } \\
\text { large durables; small durables; cell phone; } \\
\text { nonagricultural land (any); transport. }\end{array}$ & C03 A-N & $\begin{array}{l}\text { Achievement in } \\
\text { any if not only } \\
\text { one small asset } \\
\text { (chickens, } \\
\text { nonmechanized } \\
\text { equipment and } \\
\text { no small } \\
\text { consumer } \\
\text { durables) }\end{array}$ & $\begin{array}{l}\text { Inadequate if household } \\
\text { does not own any asset } \\
\text { or if household owns the } \\
\text { type of asset but she or } \\
\text { he does not own most } \\
\text { of it alone }\end{array}$ & $\begin{array}{l}\mathrm{C} 01 \mathrm{a}==1 \& \\
(\mathrm{C} 02 !=1,3,5,7,9)\end{array}$ & 0.07 \\
\hline & $\begin{array}{l}\text { Purchase, } \\
\text { sale, or } \\
\text { transfer of } \\
\text { assets }\end{array}$ & $\begin{array}{l}\text { Who would you say can decide whether to sell, give } \\
\text { away, rent/mortgage [item] most of the time? Who } \\
\text { contributes most to decisions regarding a new purchase } \\
\text { of [item]? Agricultural land, large livestock, small } \\
\text { livestock, chickens and so on, fishpond, farm equipment } \\
\text { (nonmechanized), farm equipment (mechanized). }\end{array}$ & $\begin{array}{l}\text { C04-C06 } \\
\text { A-G, C09 } \\
\text { A-G }\end{array}$ & $\begin{array}{l}\text { Achievement in } \\
\text { any if not only } \\
\text { chickens and } \\
\text { nonmechanized } \\
\text { farming } \\
\text { equipment }\end{array}$ & $\begin{array}{l}\text { Inadequate if household } \\
\text { does not own any asset } \\
\text { or household owns the } \\
\text { type of asset but he or } \\
\text { she does not participate } \\
\text { in decisions (exchange } \\
\text { or buy) about it }\end{array}$ & $\begin{array}{l}\mathrm{C} 01 \mathrm{a}==1 \& \\
(\mathrm{C} 04 !=1,3,5,7,9) \& \\
(\mathrm{C} 05 !=1,3,5,7,9) \& \\
(\mathrm{C} 06 !=1,3,5,7,9) \& \\
(\mathrm{C} 09 !=1,3,5,7,9)\end{array}$ & 0.07 \\
\hline & $\begin{array}{l}\text { Access to } \\
\text { and } \\
\text { decisions } \\
\text { about credit }\end{array}$ & $\begin{array}{l}\text { Who made the decision to borrow/what to do with } \\
\text { money/item borrowed from [source]? Nongovernmental } \\
\text { organization, informal lender, formal lender (bank), } \\
\text { friends or relatives, rotating savings and credit } \\
\text { associations (savings/credit group). }\end{array}$ & $\begin{array}{l}\text { C11-C12 } \\
\text { A-E }\end{array}$ & $\begin{array}{l}\text { Achievement in } \\
\text { any }\end{array}$ & $\begin{array}{l}\text { Inadequate if household } \\
\text { has no credit or used a } \\
\text { source of credit but she } \\
\text { or he did not participate } \\
\text { in any decisions about it }\end{array}$ & $\begin{array}{l}C 10<=3 \& \\
(C 11 !=1,3,5,7,9) \\
\&(C 12 !=1,3,5,7 \\
9)\end{array}$ & 0.07 \\
\hline
\end{tabular}


Table A.1-Continued

\begin{tabular}{|c|c|c|c|c|c|c|c|}
\hline Dimension & $\begin{array}{l}\text { Indicator } \\
\text { name }\end{array}$ & Survey questions & Variable(s) & $\begin{array}{l}\text { Aggregation } \\
\text { method }\end{array}$ & Deprivation cut-off & $\begin{array}{l}\text { Deprivation cut- } \\
\text { off definition }\end{array}$ & Weight \\
\hline Income & $\begin{array}{l}\text { Control over } \\
\text { use of } \\
\text { income }\end{array}$ & $\begin{array}{l}\text { How much input did you have in decisions about the } \\
\text { use of income generated from food crop, cash crop, } \\
\text { livestock, nonfarm activities, wages and salary, and fish } \\
\text { culture? To what extent do you feel you can make your } \\
\text { own personal decisions regarding these aspects of } \\
\text { household life if you want(ed) to: your own wage or } \\
\text { salary employment? Minor household expenditures? }\end{array}$ & $\begin{array}{l}\text { B03 1-6, } \\
\text { G02 G-H }\end{array}$ & $\begin{array}{l}\text { Achievement in } \\
\text { any if not only } \\
\text { minor household } \\
\text { expenditures }\end{array}$ & $\begin{array}{l}\text { Inadequate if individual } \\
\text { participates in activity } \\
\text { but has no input or little } \\
\text { input in decisions about } \\
\text { income generated }\end{array}$ & $\begin{array}{l}B 01==1 \& \\
B 03==1,((G 01 !=1 \\
\& A 05==1) \& \\
(G 01 !=2 \& \\
A 05==2)) \& \\
G 02==1\end{array}$ & 0.20 \\
\hline Leadership & $\begin{array}{l}\text { Speaking in } \\
\text { public }\end{array}$ & $\begin{array}{l}\text { Do you feel comfortable speaking up in public to help } \\
\text { decide on infrastructure (like small wells, roads) to be } \\
\text { built, to ensure proper payment of wages for public work } \\
\text { or other similar programs, to protest the misbehavior of } \\
\text { authorities or elected officials, or to intervene in a family } \\
\text { dispute? }\end{array}$ & E02 A-C & $\begin{array}{l}\text { Achievement in } \\
\text { any }\end{array}$ & $\begin{array}{l}\text { Inadequate if not } \\
\text { comfortable speaking } \\
\text { in public }\end{array}$ & & 0.10 \\
\hline \multirow[t]{2}{*}{ Time } & Workload & Worked more than 10.5 hours in the previous 24 hours. & F01 & & $\begin{array}{l}\text { Inadequate if } \\
\text { individual works more } \\
\text { than } 11 \text { hours per day }\end{array}$ & & 0.10 \\
\hline & Leisure & $\begin{array}{l}\text { How would you rate your satisfaction with your time } \\
\text { available for leisure activities such as visiting neighbors, } \\
\text { watching TV, listening to the radio, seeing movies, or } \\
\text { doing sports? }\end{array}$ & F04B & & $\begin{array}{l}\text { Inadequate if not } \\
\text { satisfied }(<5)\end{array}$ & $\mathrm{F} 01 \mathrm{~B}<5$ & 0.10 \\
\hline
\end{tabular}

Source: Authors' computations. 


\section{REFERENCES}

Agarwal, B. 2001. "Participatory Exclusions, Community Forestry, and Gender: An Analysis for South Asia and a Conceptual Framework." World Development 29 (10): 1623-1648.

Alderman, H., P. A. Chiappori, L. Haddad, J. Hoddinott, and R. Kanbur. 1995. "Unitary versus Collective Models of the Household: Is It Time to Shift the Burden of Proof?" World Bank Research Observer 10 (1): 1-19.

Alkire, S. 2005. "Quantitative Studies of Human Agency.” Social Indicators Research 74 (1): 217-260.

2007. "Measuring Agency: Issues and Possibilities." Indian Journal of Human Development 1 (1): 169178.

2008. "Concepts of Measures and Agency." In Arguments for a Better World: Essays in Honor of Amartya Sen. Vol. 1, Ethics, Welfare, and Measurement, edited by K. Basu and R. Kanbur, 455-474. Oxford, UK: Oxford University Press.

Alkire, S., and J. Foster. 2011. "Counting and Multidimensional Poverty Measurement.” Journal of Public Economics 95 (7/8): 476-487.

Alkire, S., and M. E. Santos. 2010. Acute Multidimensional Poverty: A New Index for Developing Countries. OPHI Working Paper 38. Oxford, UK: Oxford Poverty and Human Development Initiative.

Alkire, S., J. Foster, and M. E. Santos. 2011. “Where Did Identification Go?” Journal of Economic Inequality 9 (3): 501-505.

Alkire, S., K. Ura, K. Wangdi, and T. Zangmo. 2012. An Extensive Analysis of the Gross National Happiness Index. Thimphu, Bhutan: Centre for Bhutan Studies. www.grossnationalhappiness.com.

Alsop, R., and N. Heinsohn. 2005. Measuring Empowerment in Practice: Structuring Analysis and Framing Indicators. Policy Research Working Paper. Washington, DC: World Bank.

Alsop, R., M. Bertelsen, and J. Holland. 2006. Empowerment in Practice from Analysis to Implementation. Washington, DC: World Bank.

Bardasi, E., and Q. Wodon. 2006. "Measuring Time Poverty and Analyzing Its Determinants: Concepts and Applications to Guinea." In Gender, Time Use, and Poverty in Sub-Saharan Africa, edited by M. Blackden and Q. Wodon. World Bank Working Paper No. 73. Washington, DC: World Bank.

Beaman, L., and A. Dillon. 2012. "Do Household Definitions Matter in Survey Design? Results from a Randomized Survey Experiment in Mali." Journal of Development Economics, forthcoming.

Becker, E. 2012. "Themes from Feed the Future Women's Empowerment in Agriculture Index: Report from Qualitative Case Studies in Bangladesh, Guatemala, and Uganda." Unpublished report submitted to the International Food Policy Research Institute, Washington, DC.

Bomuhangi, A., C. Doss, and R. Meinzen-Dick. 2011. Who Owns the Land? Perspectives from Rural Ugandans and Implications for Land Acquisitions. IFPRI Discussion Paper 1136. Washington, DC: International Food Policy Research Institute. www.ifpri.org/sites/default/files/publications/ifpridp01136.pdf.

Branisa, B., S. Klasen, and M. Ziegler. 2009. Background Paper: The Construction of the Social Institutions and Gender Index (SIGI). Working paper. Goettingen, Germany: University of Goettingen, Department of Economics.

Budlender, D. 2003. “The Debate about Household Headship” Social Dynamics: A Journal of African Studies 9 (2) (Special issue: Households and Families in Southern Africa): 48-72.

Buvinić, M., and G. R. Gupta. 1997. "Female-headed Households and Female-maintained Families: Are They Worth Targeting to Reduce Poverty in Developing Countries?" Economic Development and Cultural Change 45 (2): 259-280.

Cain, M. T. 1984. Women's Status and Fertility in Developing Countries: Son Preference and Economic Security. World Bank Staff Working Paper No. 682. Washington, DC: World Bank. 
Chirkov, V., R. M. Ryan, and E. L. Deci. 2011. Human Autonomy in Cross-cultural Context: Perspectives on the Psychology of Agency, Freedom, and Well-being (Cross-Cultural Advancements in Positive Psychology). Dordrecht, the Netherlands: Springer.

Clinton, H. 2012. "Remarks on Evidence and Impact: Closing the Gender Data Gap.” Presentation at Gallup Organization, Washington, DC, July 19. www.state.gov/secretary/rm/2012/07/195244.htm.

Cronbach, L. 1951. "Coefficient Alpha and the Internal Structure of Tests.” Pyschometrika 16 (3): $297-334$.

Deere, C. D., G. E. Alvarado and J. Twyman. 2012. "Gender Inequality in Asset Ownership in Latin America: Female Owners vs. Household Heads.” Development and Change 43 (2): 505-530.

Deitchler, M., T. Ballard, A. Swindale, and J. Coates. 2011. Introducing a Simple Measure of Household Hunger for Cross-Cultural Use. FANTA 2 Food and Nutrition Technical Assistance Technical Note 12. Washington, DC. www.fantaproject.org/downloads/pdfs/TN12_HHS.pdf.

Doss, C., C. D. Deere, A. D. Oduro, H. Swaminathan, J. Y. Suchitra, R. Lahoti, W. Baah-Boateng, L. BoakyeYiadom, J. Contreras, J. Twyman, Z. Catanzarite, C. Grown, and M. Hillesland. 2011. The Gender Asset and Wealth Gaps: Evidence from Ecuador, Ghana, and Karnataka, India. Bangalore: Indian Institute of Management Bangalore.

Fafchamps, M., and A. R. Quisumbing. 2002. "Control and Ownership of Assets within Rural Ethiopian Households." Journal of Development Studies 38 (6): 47-82.

Food and Agriculture Organization of the United Nations. 2011. The State of Food and Agriculture: Women in Agriculture: Closing the Gender Gap for Development. Rome.

Haddad, L., J. Hoddinott, and H. Alderman, editors. 1997. Intrahousehold Resource Allocation in Developing Countries: Methods, Models, and Policy. Baltimore: Johns Hopkins University Press for the International Food Policy Research Institute.

Harvey, A. S., and M. E. Taylor. 2000. “Time Use.” In Designing Household Survey Questionnaires: Lessons from Fifteen Years of the Living Standards Measurement Study, edited by M. Grosh and P. Glewwe. Washington, DC: World Bank.

Hausmann, R., L. D. Tyson, and S. Zahidi. 2011. The Global Gender Gap Report 2011. Geneva: World Economic Forum.

Hijmans, R. 2011. GADM database of Global Administrative Areas, Version 2. University of Berkeley, CA, US, and the International Rice Research Institute, Los Baños, the Philippines. Accessed December 2011. www.gadm.org

Holland, J., and S. Brook. 2004. "Measuring Empowerment: Country Indicators.” In Power, Rights, and Poverty: Concepts and Connections, edited by R. Alsop. Washington, DC: World Bank.

Ibrahim, S., and S. Alkire. 2007. "Agency and Empowerment: A Proposal for Internationally Comparable Indicators." Oxford Development Studies 35 (4): 379-403.

Kabeer, N. 1999. "Resources, Agency, Achievements: Reflections on Measurement of Women's Empowerment." Development and Change 30 (3): 435-464.

- 2001. "Reflections on the Measurement of Women's Empowerment_-Theory and Practice." In Discussing Women's Empowerment-Theory and Practice, edited by A. Sisask, 17-54. Stockholm, Sweden: Novum Grafiska AB.

Kishor, S., and L. Subaiya. 2008. Understanding Women's Empowerment: A Comparative Analysis of Demographic and Health Surveys (DHS) Data. DHS Comparative Reports 20. Calverton, MD, US: Macro International.

Klasen, S., and F. Lamanna. 2008. The Impact of Gender Inequality in Education and Employment on Economic Growth in Developing Countries: Updates and Extensions. Ibero-America Institute for Economic Research Working Paper No. 175. Goettigen, Germany: University of Goettingen. 
Lawson, D. 2012. A Gendered Analysis of Time Poverty: The Importance of Infrastructure. Global Poverty Research Group Working Paper GPRG-WPS-078. London: Economic and Social Research Council—Global Poverty Research Group.

Lehner, B., K. Verdin, and A. Jarvis. 2006. HydroSHEDS Shuttle Radar Topography Mission Digital Elevation Model. Washington, DC: World Wildlife Fund. http://hydrosheds.cr.usgs.gov.

Lesotho, Bureau of Statistics. 2003. Household Budget Survey Report, Lesotho, 2002-2003. Maseru, Lesotho.

Mahmud, S., N. M. Shah, and S. Becker. 2012. "Measurement of Women's Empowerment in Rural Bangladesh." World Development 40 (3): 610-619.

Malhotra, A., and S. R. Schuler. 2005. "Women's Empowerment as a Variable in International Development." In Measuring Empowerment: Cross-disciplinary Perspectives, edited by D. Narayan, 219-246. Washington, DC: World Bank.

Meinzen-Dick, R., J. A. Behrman, L. Pandolfelli, A. Peterman, and A. Quisumbing. 2012. "Gender and Social Capital for Agricultural Development." In Gender in Agriculture and Food Security: Closing the Knowledge Gap, edited by A. Quisumbing, R. Meinzen-Dick, T. Raney, A. Croppenstedt, J. A. Behrman, and A. Peterman. Dordrecht, the Netherlands; Rome: Springer; Food and Agriculture Organization of the United Nations, forthcoming.

Miller, B. D. 1981. The Endangered Sex: Neglect of Female Children in Rural North India. Ithaca, NY, US: Cornell University Press.

Narayan, D. 2002. Empowerment and Poverty Reduction. Washington, DC: World Bank.

, editor. 2005. Measuring Empowerment: Cross-disciplinary Perspectives. Washington, DC: World Bank.

Narayan, D., and P. Petesch. 2007. Moving Out of Poverty: Cross-disciplinary Perspectives on Mobility. Washington, DC: World Bank.

Narayan-Parker, D. 2005. Measuring Empowerment: Cross-disciplinary Perspectives. Washington, DC: World Bank.

Peterman, A., A. Quisumbing, J. Behrman, and E. Nkonya. 2011. "Understanding the Complexities Surrounding Gender Differences in Agricultural Productivity in Nigeria and Uganda." Journal of Development Studies 47 (10): 1482-1509.

Quisumbing, A. R., editor. 2003. Household Decisions, Gender, and Development: A Synthesis of Recent Research. Washington, DC: International Food Policy Research Institute.

Quisumbing, A. R., and K. Hallman. 2005. "Marriage in Transition: Evidence on Age, Education, and Assets from Six Developing Countries." In The Changing Transitions to Adulthood in Developing Countries: Selected Studies, Panel on Transitions to Adulthood in Developing Countries, Committee on Population, Division of Behavioral and Social Sciences and Education, edited by C. B. Lloyd, J. R. Behrman, N. P. Stromquist, and B. Cohen. Washington, DC: National Academies Press.

Quisumbing, A. R., and N. Kumar. 2011. "Does Social Capital Build Women's Assets? The Long-term Impacts of Group-based and Individual Dissemination of Agricultural Technology in Bangladesh." Journal of Development Effectiveness 3 (2): 220-242.

Quisumbing, A. R., and J. A. Maluccio. 2003. "Resources at Marriage and Intrahousehold Allocation: Evidence from Bangladesh, Ethiopia, Indonesia, and South Africa. ” Oxford Bulletin of Economics and Statistics 65 (3): 283-328.

Ryan, R. M., and E. L. Deci. 2000. "Self-determination Theory and the Facilitation of Intrinsic Motivation, Social Development, and Well-being." American Psychologist 55 (1): 68-78.

. 2011. "A Self-determination Theory Perspective on Social, Institutional, Cultural, and Economic Supports for Autonomy and Their Importance for Well-being." In Human Autonomy in Cross-Cultural Context: Perspectives on the Psychology of Agency, Freedom, and Well-being, edited by V. I. Chirkov, R. M. Ryan, and K. M. Sheldon, 45-64. Dordrecht, the Netherlands: Springer. 
Sen, A. K. 1989. "Co-operation, Inequality, and the Family." In Rural Development and Population: Institutions and Policy, edited by G. McNicoll and M. Cain. New York: Oxford University Press.

Seymour, G. 2011. "Women's Empowerment in Agriculture Index: Report on the International Comparability of the Indicators in the Feed the Future Pilot Test." Unpublished report submitted to the International Food Policy Research Institute, Washington, DC.

Smith, L. C., U. Ramakrishnan, A. Ndiaye, L. Haddad, and R. Martorell. 2003. The Importance of Women's Status for Child Nutrition in Developing Countries. Research Report 131. Washington, DC: International Food Policy Research Institute.

Szekely, M., editor. 2005. Numbers That Move the World: The Measure of Poverty in Mexico. Mexico City: Secretaria de Desarrollo Social.

Udry, C. 1996. "Gender, Agricultural Production, and the Theory of the Household." Journal of Political Economy 104 (5): 1010-1046.

World Bank. 2011. World Development Report 2012: Gender Equality and Development. Washington, DC. 




\section{RECENT IFPRI DISCUSSION PAPERS}

\section{For earlier discussion papers, please go to www.ifpri.org/pubs/pubs.htm\#dp. All discussion papers can be downloaded free of charge.}

1239. Food price volatility in Africa: Has it really increased? Nicholas Minot, 2012.

1238. The comprehensive Africa agriculture program as a collective institution. Shashidhara Kolavalli, Regina Birner, and Kathleen Flaherty, 2012.

1237. Mechanization in Ghana: Searching for sustainable service supply models. Xinshen Diao, Frances Cossar, Nazaire Houssou, Shashidhara Kolavalli, Kipo Jimah, and Patrick Aboagye, 2012.

1236. Differential export taxes along the oilseeds value chain: A partial equilibrium analysis. Antoine Bouët, Carmen Estrades, and David Laborde, 2012.

1235. The role of rural producer organizations for agricultural service provision in fragile states. Catherine Ragasa and Jennifer Golan, 2012.

1234. Cash, food, or vouchers?: Evidence from a randomized experiment in Northern Ecuador. Melissa Hidrobo, John Hoddinott, Amber Peterman, Amy Margolies, and Vanessa Moreira, 2012.

1233. Public expenditures, private incentives, and technology adoption: The economics of hybrid rice in South Asia. David J. Spielman, Deepthi Kolady, Patrick Ward, Harun-Ar-Rashid, and Kajal Gulati, 2012.

1232. Malaria and Agriculture: A global review of the literature with a focus on the application of integrated pest and vector management in East Africa and Uganda. Benjamin Wielgosz, Margaret Mangheni, Daniel Tsegai, and Claudia Ringler, 2012.

1231. Did using input vouchers improve the distribution of subsidized fertilizer in Nigeria?:The case of Kano and Taraba states. Lenis Saweda O. Liverpool-Tasie, 2012.

1230. The supply of inorganic fertilizers to smallholder farmers in Tanzania: Evidence for fertilizer policy development. Todd Benson, Stephen L. Kirama, and Onesmo Selejio, 2012.

1229. The supply of inorganic fertilizers to smallholder farmers in Mozambique: Evidence for fertilizer policy development. Todd Benson, Benedito Cunguara, and Tewodaj Mogues, 2012.

1228. The supply of inorganic fertilizers to smallholder farmers in Uganda: Evidence for fertilizer policy development. Todd Benson, Patrick Lubega, Stephen Bayite-Kasule, Tewodaj Mogues, and Julian Nyachwo, 2012.

1227. Taxation policy and gender employment in the Middle East and north Africa region: A Comparative analysis of Algeria, Egypt, Morocco, and Tunisia. Ismaël Fofana, Erwin Corong, Rim Chatti, Sami Bibi, and Omar Bouazouni, 2012.

1226. Policy reform toward gender equality in Ethiopia: Little by little the egg begins to walk. Neha Kumar and Agnes R. Quisumbing, 2012.

1225. Improving the Measurement of food security. Derek Headey and Olivier Ecker, 2012.

1224. Improved performance of agriculture in Africa south of the Sahara: Taking off or bouncing back. Alejandro Nin-Pratt, Michael Johnson, and Bingxin Yu, 2012.

1223. Review of input and output policies for cereals production in Pakistan. Abdul Salam, 2012.

1222. Supply and demand for cereals in Pakistan, 2010-2030. Hina Nazli, Syed Hamza Haider, and Asjad Tariq, 2012.

1221. The road to specialization in agricultural production: Evidence from Rural China. Yu Qin and Xiaobo Zhang, 2012.

1220. Change and diversity in smallholder rice-fish systems: Recent evidence from Bangladesh. Madan M. Dey, David J. Spielman, A.B.M. Mahfuzul Haque, Md. Saidur Rahman, and Rowena A. Valmonte-Santos, 2012.

1219. Is MERCOSUR's external agenda pro-poor?: An assessment of the European Union-MERCOSUR free-trade agreement on poverty in Uruguay applying MIRAGE. Carmen Estrades, 2012.

1218. Heterogeneous pro-poor targeting in India's Mahatma Gandhi national rural employment guarantee scheme. Yanyan Liu and Christopher B. Barrett, 2012.

1217. The impacts of public investment in and for agriculture: Synthesis of the existing evidence. Tewodaj Mogues, Bingxin Yu, Shenggen Fan, and Linden McBride, 2012. 


\section{INTERNATIONAL FOOD POLICY}

RESEARCH INSTITUTE

www.ifpri.org

IFPRI HEADQUARTERS

2033 K Street, NW

Washington, DC 20006-1002 USA

Tel.: +1-202-862-5600

Fax: +1-202-467-4439

Email: ifpri@cgiar.org 